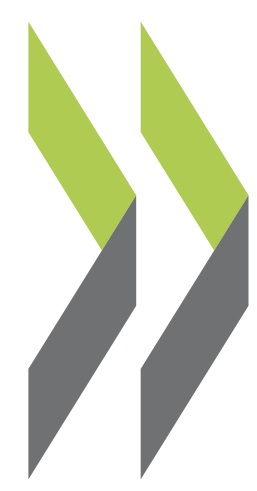

Documents de travail de I'OCDE sur la gouvernance publique No. 3

\section{Gouvernance de la} détermination décentralisée des rémunérations dans certains pays membres de I'OCDE

\section{Knut Rexed,}

Chris Moll,

Nick Manning, Jennifer Allain 


\section{Document de travail 3}

\section{Gouvernance de la \\ détermination décentralisée \\ des rémunérations dans \\ certains pays membres de l'OCDE $^{*}$}

Preparé par Knut Rexed et Chris Moll, avec Nick Manning et Jennifer Allain

avril 2007

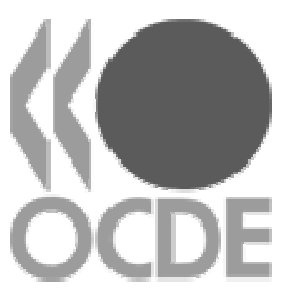

ORGANISATION DE COOPERATION ET DE DEVELOPPEMENT ECONOMIQUES

* Ce rapport a bénéficié des commentaires et de direction fournies par le groupe consultatif du projet (voir Annexe I) ainsi que par les personnes interrogées dans le cadre des études de pays (Annexe II). Le Groupe de travail de l'OCDE sur l'Emploi et la gestion publiques a également donné de precieux commentaires lors de sa réunion les 7 et 8 décembre 2006. 


\section{TABLE DES MATIÈRES}

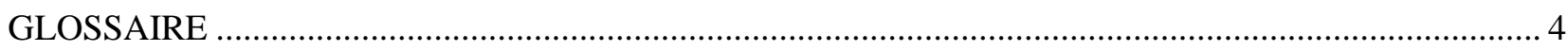

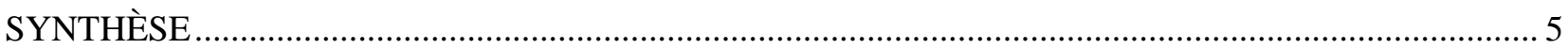

1. Principales caractéristiques des administrations publiques........................................................... 9

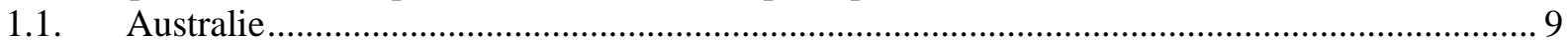

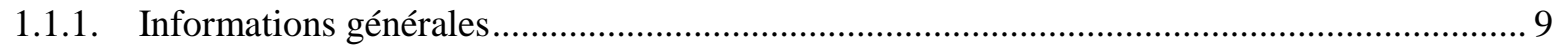

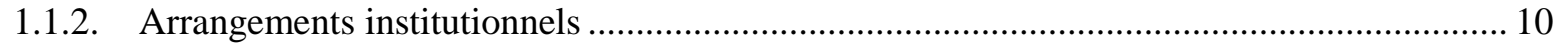

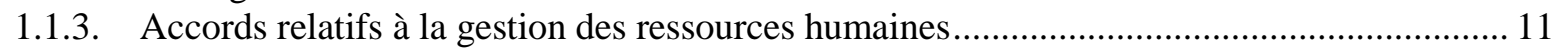

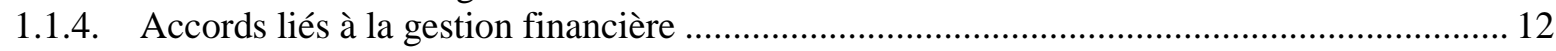

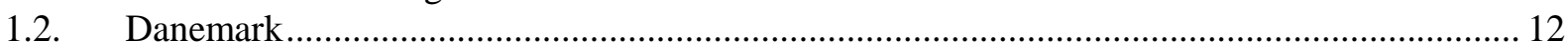

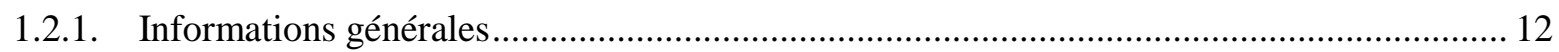

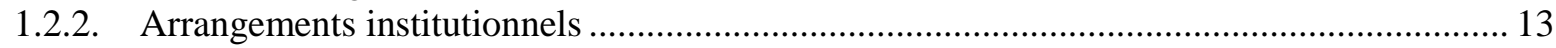

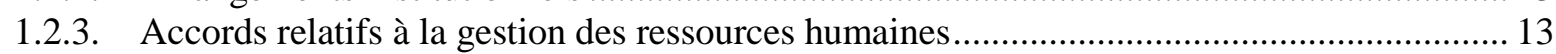

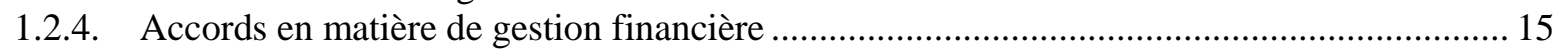

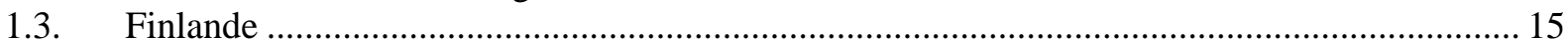

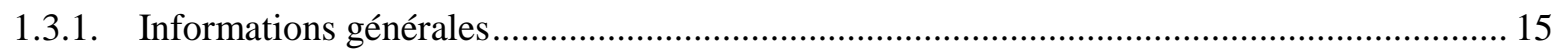

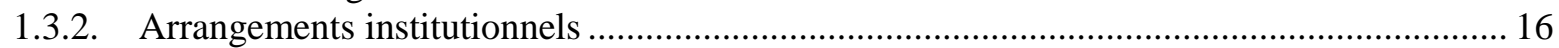

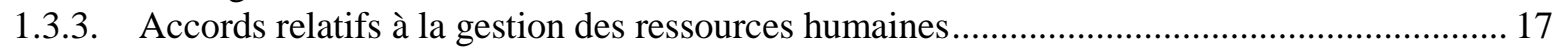

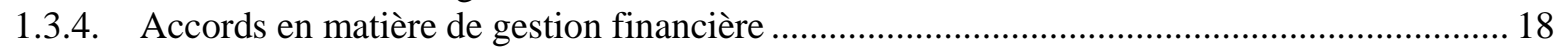

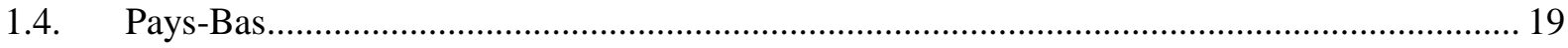

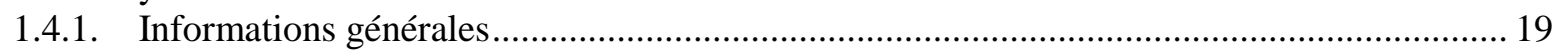

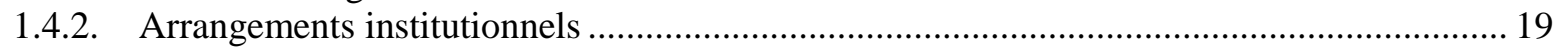

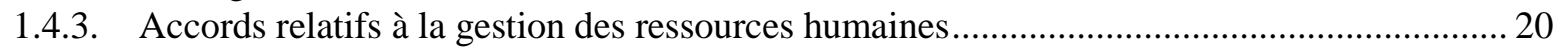

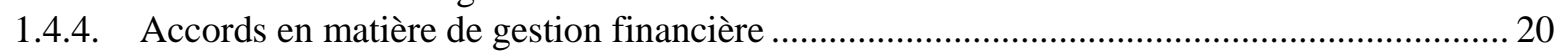

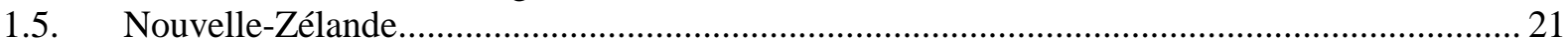

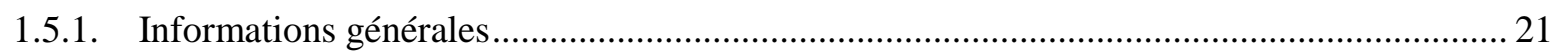

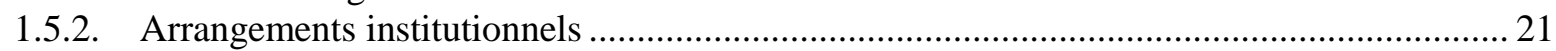

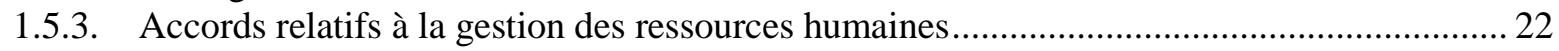

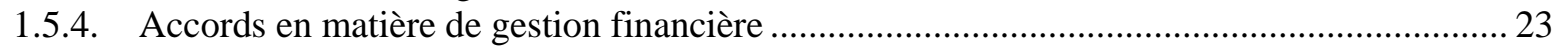

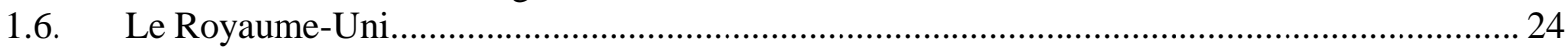

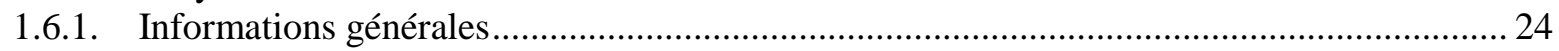

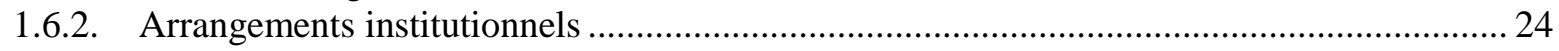

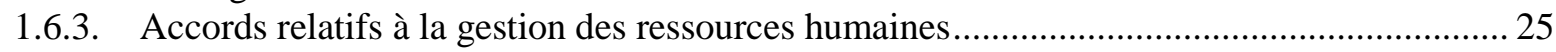

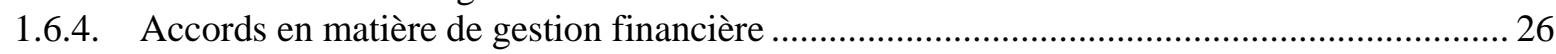

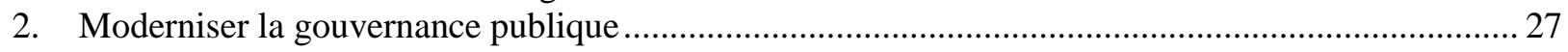

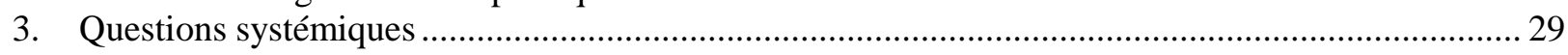

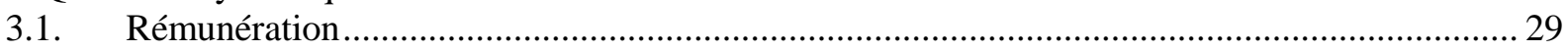

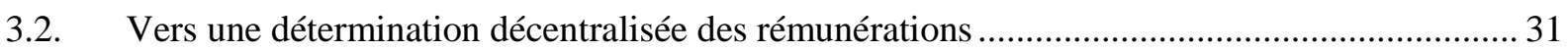

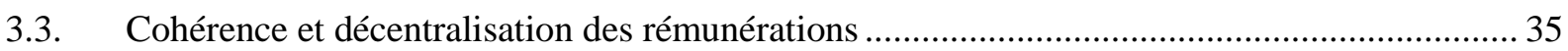

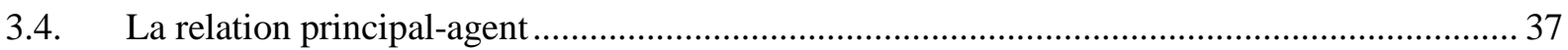

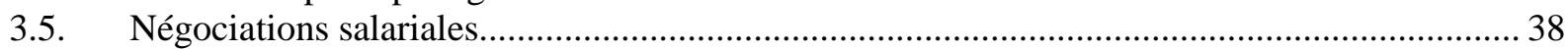




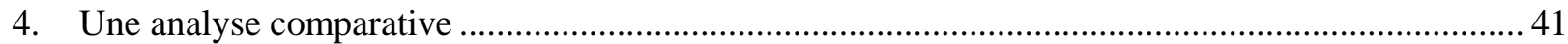

4.1. Arrangements institutionnels concernant la détermination des rémunérations.......................... 41

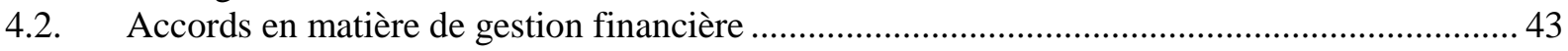

4.3. Gouvernance des salaires et autres formes de rémunération .................................................. 47

4.4. Gouvernance et autres questions relevant des ressources humaines......................................... 51

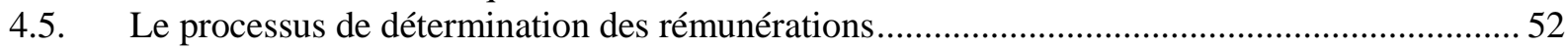

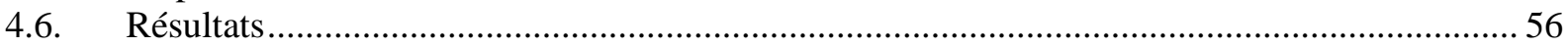

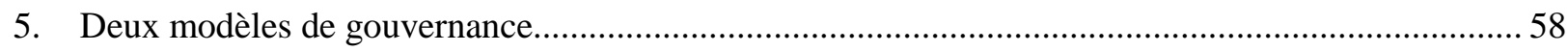

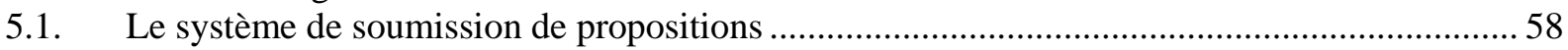

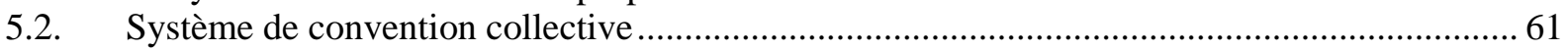

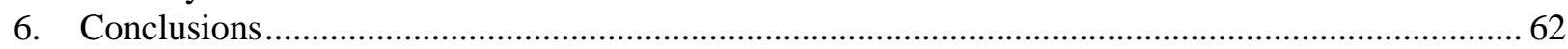

6.1. Introduction ou extension du processus décentralisé de détermination des rémunérations ....... 63

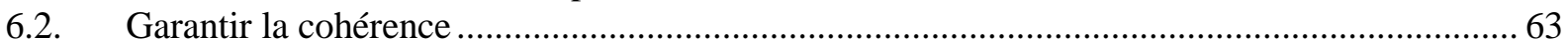

6.3. Gouvernance décentralisée de la détermination des rémunérations ........................................ 64

6.4. Mise en œuvre de la détermination décentralisée des rémunérations ........................................6 65

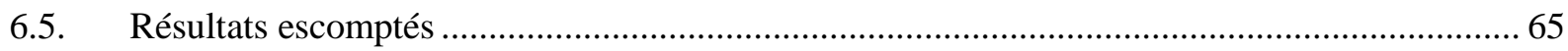

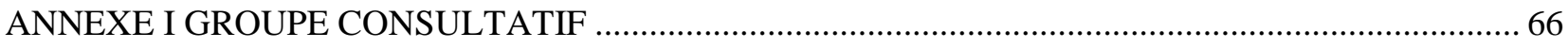

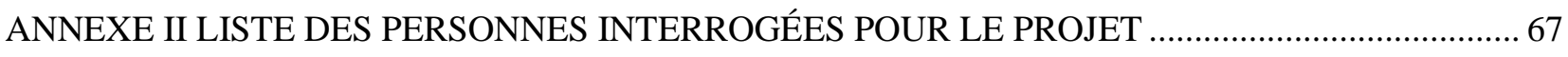

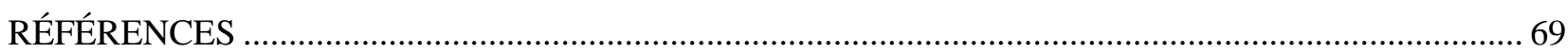

\section{Encadrés}

Étude de cas $n^{\circ} 1:$ la diversité des agences en Nouvelle-Zélande.......................................................28

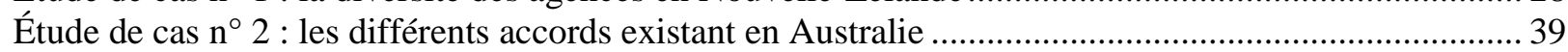

Étude de cas n ${ }^{\circ} 3:$ La Commission des services de l'État en Nouvelle-Zélande .......................................... 42

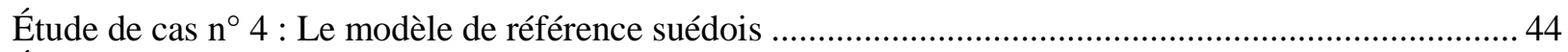

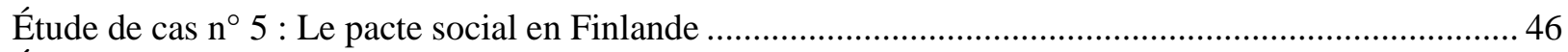

Étude de $\operatorname{cas~}^{\circ} 6$ : Les conventions collectives salariales centrales au Danemark........................................49

Étude de cas $\mathrm{n}^{\circ} 7$ : Le système britannique de soumission de propositions («remit systems ») .............. 49

Étude de cas $n^{\circ} 8:$ Gestion de la parité hommes-femmes .................................................................... 52

Étude de $\operatorname{cas}^{\circ}{ }^{\circ}$ : Garanties contre les dérives des systèmes décentralisés de détermination des

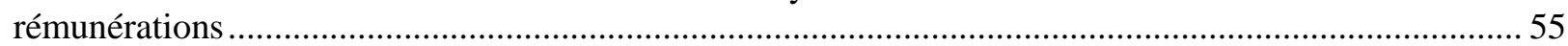

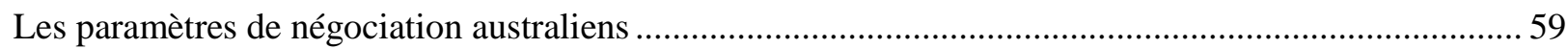

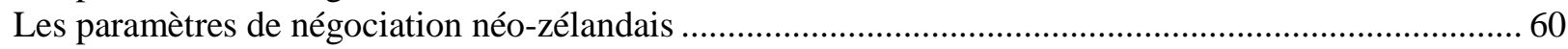

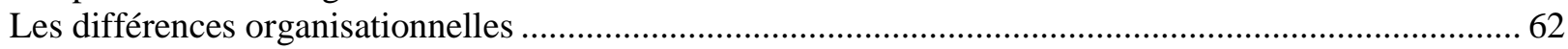

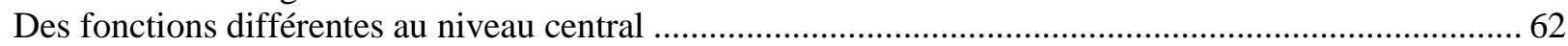




\section{GLOSSAIRE}

\begin{tabular}{|c|c|}
\hline Accol & Convention sur les conditions de travail conclue avec une seule personne. \\
\hline Accords salariaux & Somme payée par un organisme de l'État en plus du salaire. \\
\hline Budgétisation ascendante & $\begin{array}{l}\text { Processus budgétaire dont la première étape est la soumission de demandes de } \\
\text { ressources par toutes les entités concernées par le budget. Ces demandes sont } \\
\text { ensuite ajustées et agrégées au budget total. }\end{array}$ \\
\hline $\begin{array}{l}\text { Budg } \\
\text { desce }\end{array}$ & $\begin{array}{l}\text { Système budgétaire qui commence par fixer un plafond de dépenses global qui est } \\
\text { ensuite réparti entre plusieurs enveloppes correspondant à des secteurs et entités } \\
\text { distinctes. }\end{array}$ \\
\hline Convention collective & $\begin{array}{l}\text { Convention sur les conditions de travail conclue avec un syndicat ou avec une } \\
\text { autre structure de représentation des salariés. L'accord peut réglementer les } \\
\text { rémunérations individuelles. }\end{array}$ \\
\hline Décen & $\begin{array}{l}\text { Transfert d'une ou plusieurs tâches depuis l'autorité centrale vers des entités d'un } \\
\text { niveau inférieur, par l'intermédiaire de la délégation ou du transfert de } \\
\text { compétences. }\end{array}$ \\
\hline Déléga & $\begin{array}{l}\text { Forme de décentralisation où l'administration centrale continue d'assumer la } \\
\text { responsabilité des décisions prises aux niveaux inférieurs. }\end{array}$ \\
\hline $\begin{array}{l}\text { Dé } \\
\text { réı }\end{array}$ & $\begin{array}{l}\text { Le processus de détermination des rémunérations. Il englobe l'application des } \\
\text { règlements statutaires ou des clauses des conventions collectives aux employés } \\
\text { individuels. }\end{array}$ \\
\hline ilatérale & $\begin{array}{l}\text { ination des rémunérations sans aucune convention individuelle formelle } \\
\text { ve. Elle peut être, cependant, précédée par une discussion informelle. }\end{array}$ \\
\hline $\begin{array}{l}\text { Individualisation de la } \\
\text { rémunération }\end{array}$ & $\begin{array}{l}\text { Accords sur la rémunération où le traitemer } \\
\text { personnes effectuant des tâches similaires so } \\
\text { base d'une évaluation des mérites et performan }\end{array}$ \\
\hline Mod & te de l'évolution des \\
\hline $\begin{array}{l}\mathbf{N} \\
\mathbf{r e}\end{array}$ & de négociation, suivi par \\
\hline Rém & Gire de base, les primes ainsi que les bénéfices \\
\hline $\begin{array}{l}\text { Systè } \\
\text { collec }\end{array}$ & $\begin{array}{l}\text { Une convention collective est signée par les partenaires sociaux. Elle fixe un } \\
\text { cadre au sein duquel des négociations secondaires seront menées au niveau local } \\
\text { concernant, entre autres, les traitements. Les conditions de travail peuvent être } \\
\text { normalisées en étant incluses aux conventions centrales. }\end{array}$ \\
\hline $\begin{array}{l}\text { Système de conventions } \\
\text { collectives à un seul }\end{array}$ & $\begin{array}{l}\text { Tous les éléments pertinents sont contenus dans la convention à un seul niveau } \\
\text { (central ou local). Il peut s'agir d'une convention unique, signée au niveau central } \\
\text { pour l'ensemble de l'administration publique, mais, le plus souvent, il s'agit de } \\
\text { conventions multiples signées au niveau local. }\end{array}$ \\
\hline $\begin{array}{l}\text { Système de soumission de } \\
\text { propositions }\end{array}$ & $\begin{array}{l}\text { Système où les entités habilitées à déterminer les rémunérations (ci-après } \\
\text { «entités habilitées ») soumettent au niveau supérieur une proposition de } \\
\text { rémunération ou des paramètres de négociation afin qu'ils soient examinés, } \\
\text { acceptés ou approuvés. }\end{array}$ \\
\hline Transf & $\begin{array}{l}\text { Forme de décentralisation où l'ensemble des responsabilités a été transféré au } \\
\text { niveau local. }\end{array}$ \\
\hline
\end{tabular}




\section{SYNTHÈSE}

Ce rapport étudie la gouvernance de la détermination décentralisée des rémunérations dans les administrations centrales pour les pays suivants : Australie, Danemark, Finlande, Pays-Bas, NouvelleZélande et Royaume-Uni. Il porte sur la décentralisation de l'autorité centrale vers des entités d'un niveau inférieur; Les délégations secondaires ne font pas l'objet du présent rapport. La négociation des rémunérations et des relations du travail ne sont pas non plus couverts par le présent rapport. Celui-ci ne traite ces sujets que quand il est nécessaire comme référence du thème principal.

Le rapport se fonde sur des entretiens (voir annexe II) réalisés au cours de déplacements (pour les pays européens) et par téléphone (pour les deux autres pays). Il s'appuie également sur des informations tirées de divers documents, pages Internet et autres sources (voir annexe III). Il a profité d'une discussion avec la Commission syndicale consultative auprès de l'OCDE. Ce rapport a été examiné à la réunion du Groupe de travail sur l'emploi et la gestion publics de l'OCDE à sa réunion annuelle en décembre 2006.

Les six pays examinés ne constituent nullement un échantillon aléatoire. Ils ont été choisis en raison de leur expérience de la détermination décentralisée des rémunérations et de l'intérêt qu'ils portent à cette question. Ils ont mis en place une vaste palette de mesures, de pratiques et d'expériences et constituent donc une base solide pour effectuer des comparaisons et en tirer des conclusions provisoires. Il convient de souligner que celles-ci sont émises sous réserve. Cette étude ne vise nullement à l'exhaustivité ; les observations qu'elle contient se fondent sur un ensemble limité de données sujettes à interprétation.

Le besoin d'une plus grande différenciation dans la politique de rémunération du secteur public est sans doute le principal moteur de la décentralisation. Le marché du travail - comme les activités publiques - ont perdu de leur homogénéité et les administrations publiques doivent, comme tout employeur, élaborer des accords de rémunération qui soient suffisamment flexibles pour permettre d'adapter les systèmes et structures de rémunération :

- à la situation et aux exigences spécifiques de chaque unité organisationnelle ;

- aux compétences, mérites et performances particulières de chaque employé ; et/ou

- au fait que ces compétences soient recherchées sur le marché du travail.

Alors que les systèmes de rémunération évoluent vers une plus grande flexibilité, il semble de moins en moins rationnel et efficace de procéder à une détermination centralisée de la rémunération. En effet, afin de tenir compte des compétences, performances et besoins professionnels individuels, cette différenciation doit se baser sur des informations communiquées, et détenues, au niveau local. Dans le même temps, la décentralisation grève les coûts de transaction, des négociations multiples venant remplacer un processus unique. Elle ne sera donc justifiée que si, en adaptant les systèmes et structures de rémunération aux besoins de chaque entité opérationnelle, son utilisation apporte une valeur ajoutée suffisamment importante. 
L'organisation constitutionnelle et administrative de l'Australie et de la Nouvelle-Zélande témoigne de ses origines britanniques. Il existe dans ces pays des négociations collectives menées à un niveau unique, mais également des contrats de travail individualisés pour les lieux de travail couverts par des conventions collectives. La détermination des rémunérations est extrêmement décentralisée, mais elle est dans le même temps régie par des paramètres de négociation auxquels les entités habilitées de l'administration centrale sont censées adhérer. Le budget et les processus de négociation sont effectivement distincts alors que les ministères des Finances ne sont pas directement tenus de veiller à ce que les paramètres de négociation soient respectés. Ces pays disposent également d'organisations professionnelles distinctes qui œuvrent en faveur d'une saine gestion des ressources humaines (la Commission australienne de la fonction publique et la Commission néo-zélandaise des services de l’État).

Les accords en vigueur au Royaume-Uni sont similaires à ceux qui existent en Australie et en Nouvelle-Zélande mais leur élaboration ne répond pas à des critères aussi systématiques. Le Trésor est chargé d'assurer la conformité de ceux-ci avec les paramètres de négociation alors que les processus d'élaboration du budget et de négociation ne sont pas totalement séparés. Le Bureau du Conseil des ministres est chargé de promouvoir la bonne gestion des ressources humaines; le Commissaire à la fonction publique joue davantage un rôle de second plan.

L'organisation constitutionnelle et administrative du Danemark et de la Finlande sont le reflet de la culture sociale et administrative nordique qui se distingue, entre autres, par l'existence de puissants mouvements syndicaux réformistes. La négociation collective s'exerce à deux niveaux: certaines conditions de travail sont réglementées par des conventions collectives négociées au niveau central, et d'autres relèvent de conventions locales. La détermination de la rémunération est décentralisée mais s'inscrit dans un cadre explicite défini dans les conventions collectives centrales. Les processus budgétaires doivent tenir compte des résultats des négociations menées au niveau central, mais sont séparés de manière effective des processus de négociation locaux. Dans la négociation centrale, l'employeur est représenté par des services autonomes des ministères des Finances (l'Autorité de l'État employeur au Danemark et le Bureau de l'État employeur en Finlande). Ces services agissent également en qualité d'organisations professionnelles. À ce titre, ils œuvrent en faveur d'une saine gestion des ressources humaines et aident les instances gouvernementales à élaborer les politiques et les lois.

Aux Pays-Bas, la négociation salariale est moins décentralisée et les arrangements sont en constante évolution. Dans 13 secteurs, les négociations sont menées à un seul niveau. Parmi ceux-ci, cinq sont des secteurs dits «ministériels », où l'employeur est représenté par un ministre, cinq appartiennent au secteur de l'éducation et trois sont des collectivités territoriales (provinces, municipalités et commissions d'eau). Les processus d'élaboration budgétaire et de négociation dialoguent avec les secteurs « ministériels » mais sont séparés pour les sous-secteurs et les collectivités locales. C'est le ministère de l'Intérieur et des relations au sein du Royaume qui coordonne au sein de l'administration centrale la négociation salariale et les autres questions relevant de la gestion des ressources humaines. Il n'existe à ce niveau aucune organisation professionnelle dont l'objectif est de promouvoir une saine gestion des ressources humaines, contrairement à ce qui est le cas dans les autres pays examinés.

Une des conclusions du rapport souligne l'existence de deux alternatives principales en matière de négociation des rémunérations (voir le Tableau 5 à la Section 6 pour plus de détails). Ces alternatives ont en commun l'existence d'une agence centrale indépendante et compétente capable de gouverner et de surveiller la conduite des entités habilitées, et le financement aux entités décentralisés d'une enveloppe pour la masse salariale dont le montant peut être prévu. Chaque système fonctionne bien dans le contexte du pays qui l'utilise. 
- Système de soumission de propositions : Modèle avec une entité centrale qui utilise un système de soumission de propositions, permettant la surveillance du respect des paramètres de négociation du gouvernement. Ce système peut promouvoir des valeurs et des pratiques communes en matière de la gestion des ressources humaines. Ce système existe en Australie et en Nouvelle-Zélande.

- Système de convention collective: Modèle avec un employeur central et un système de conventions collectives à deux niveaux. Dans ce modèle, ce sont les conventions collectives centrales qui définissent la structure de la détermination des rémunérations. Ce modèle est utilisé au Danemark et en Finlande.

Les principaux aspects qui les distinguent sont les suivants :

- Au Danemark et en Finlande, la négociation collective s'exerce à deux niveaux, alors qu'elle relève d'un seul niveau en Australie et en Nouvelle-Zélande.

- Le Danemark et la Finlande «cloisonnent » au sein du ministère des Finances les responsabilités de négociation salariale et budgétaire, qui sont assumées par des unités distinctes ; l'Australie et la Nouvelle-Zélande disposent d'organismes séparés pour chacune de ces fonctions.

- Le Danemark et la Finlande associent au niveau central la responsabilité de négociation salariale à la responsabilité générale de règlement du personnel du secteur public; l'Australie et la Nouvelle-Zélande disposent d'organes distincts pour ces fonctions.

Ces deux modèles semblent bien fonctionner dans les pays qui les utilisent, probablement car ils sont conformes aux spécificités de leurs cultures politique et administrative. Ils représentent deux voies de développement différentes : la voie anglo-saxonne, qui, notamment, privilégie les relations contractuelles individuelles et la voie nordique, qui met davantage l'accent sur la cohésion et l'action collective. Il est donc impossible de proposer des recommandations générales : chaque pays doit trouver sa propre voie en se fondant sur sa situation actuelle.

On peut toutefois tirer de cet examen des conclusions générales que l'on peut résumer ainsi :

1. Introduire une détermination décentralisée des rémunérations, ou étendre son application, implique un processus d'apprentissage. Des règles formelles ne suffisent pas, tous les tiers doivent être à l'aise avec le processus et compétent en la matière. Une préparation adaptée augmentera substantiellement les chances que ces pratiques soient introduites ou étendues avec succès. Inversement, des compétences, un soutien et un contrôle inappropriés, ou encore une absence de confiance quant au sérieux de l'opération, feront entrave à des résultats positifs.

2. Les pouvoirs publics doivent définir clairement si tel aspect de la gestion des ressources humaines doit être identique dans l'ensemble de l'administration centrale, s'il peut varier selon les services administratifs, mais ce uniquement dans des limites prédéfinies, ou s'il peut être défini librement; ils devront adapter en conséquence la portée de leurs opérations de décentralisation.

3. Pour une décentralisation efficace de la rémunération, il apparaît essentiel de disposer d'accords de gestion financière appropriés. Il est fondamental que ceux-ci séparent effectivement les affectations budgétaires et la négociation salariale, afin que la détermination décentralisée des rémunérations s'inscrive dans des limites d'accessibilité qui soient à la fois fixes et crédibles ${ }^{1}$. 
4. Un contrôle et une évaluation effectifs de l'adéquation des décisions des responsables opérationnels des entités habilitées sont également essentiels au bon déroulement de la décentralisation, en particulier à long terme. Les pays disposant d'un système de détermination des rémunérations décentralisé doivent également investir en vue de constituer un corps de cadres publics disposant des compétences adaptées aux spécificités de l'administration.

5. La détermination décentralisée des rémunérations joue un rôle positif sur les performances des administrations, pour autant que le pays ait institué des accords adéquats en matière de gestion financière et de gouvernance notés ci-dessus. L'introduction de ces pratiques ne devrait toutefois pas produire des résultats immédiats.

Aménager de manière uniforme les budgets des organisations chargées de la détermination des rémunérations présente des avantages spécifiques. En effet, ceci réduit les coûts de transaction, améliore leur capacité à planifier leurs opérations sur plusieurs années et permet aux administrations publiques de concentrer leurs délibérations politiques sur les organisations pour lesquelles des ajustements supplémentaires semblent nécessaires d'un point de vue politique ou opérationnel.

On s'est souvent demandé si la négociation salariale décentralisée était compatible avec le maintien dans l'administration publique d'une cohérence suffisante de la rémunération et des autres conditions de travail. De nombreux pays ont noté que les différences entre structures et niveaux de rémunération sont venues compliquer les fusions des différentes entités habilitées à déterminer les rémunérations. Mais il semble que ces problèmes aient correctement pu être traités dans la plupart des pays. Le Royaume-Uni est le seul où des différences de rémunération plus préoccupantes semblent exister entre des personnes occupant de mêmes postes ou possédant de mêmes compétences.

Les notions de différenciation et d'individualisation ne se recouvrent pas nécessairement (l'individualisation désigne des situations où la rémunération et les conditions de travail de personnes effectuant des tâches similaires présentent d'importantes différences découlant d'une évaluation de leurs mérites et performances). Il semble que l'on a souvent surestimé les possibilités d'individualisation. Cette méthode sous-tend des coûts de transaction supérieurs aux normes et conventions collectives. On peut donc penser qu'un responsable opérationnel rationnel utilisera des contrats et des conditions de travail normalisés et des structures de rémunération collectives, à moins qu'une valeur ajoutée notable ne découle de l'individualisation.

Rappelons que ce rapport porte principalement sur la gouvernance de la détermination des rémunérations et d'autres aspects de la gestion des ressources humaines dans les administrations centrales. Sans compter des défis liés à la détermination des rémunérations, il en existe d'autres que nous avons choisi de ne pas évoquer ici. Ceux-ci peuvent se poser pour les collectivités territoriales et d'autres types d'entités semi-autonomes. Il s'agit notamment d'entités de droit privé en charge d'une mission de service public, financées totalement ou dans une large mesure par l'administration centrale, par le biais de transferts économiques ou d'affectations budgétaires de nature contractuelle. Il existe également des entités de droit privé détenues par l'État.

Deux raisons politiques majeures expliquent pourquoi l'administration centrale cherche à influencer ou à contrôler les pratiques de gestion des ressources humaines dans les administrations de niveau intermédiaire. La première est que l'évolution des rémunérations au niveau de l'administration intermédiaire peut stimuler les exigences salariales au niveau central, en particulier lorsque le marché du travail est étroitement intégré. La deuxième est que ceci permettrait à l'administration centrale de poursuivre d'autres objectifs en matière d'équité, en particulier afin de favoriser l'emploi des femmes ou des minorités, objectifs qu'il est difficile d'atteindre par des moyens législatifs ou par des mesures incitatives de transferts budgétaires entre administrations. 
Sans tenir compte de leur faisabilité pratique et politique, on peut constater que l'administration centrale dispose de ces options si elle souhaite coordonner les problèmes de rémunération dans le secteur public élargi. Les options varient suivant la relation avec l'administration centrale :

- L'action des entités placées sous le contrôle direct des pouvoirs publics (c'est-à-dire pour lesquelles les instances gouvernementales peuvent émettre des directives contraignantes) peut être régie et coordonnée par l'intermédiaire des systèmes décrits dans ce rapport. Il peut être nécessaire à ce titre de disposer d'une autorité de surveillance, de paramètres de négociation appropriés et d'un système de contrôle fondé sur un processus de soumission de propositions.

- Les entités de droit privé détenues par l'État peuvent être régies par les directives de leur propriétaire. Elles peuvent, s'il y a lieu, être soumises au même type de gouvernance que celles de droit public placées sous le contrôle direct de l'État.

- Les opérations des entités de droit privé opérant en vertu d'un contrat public peuvent être régies par des clauses contractuelles. Elles peuvent également, s'il y a lieu, être soumises au même type de gouvernance que les entités de droit public placées sous le contrôle direct de l'État.

- Toute entité bénéficiant de subventions publiques peut être contrôlée en subordonnant ces aides, entièrement ou en partie, au respect d'un ensemble approprié de paramètres de négociation. Elles peuvent dès lors être soumises au même type de gouvernance qu'une entité de droit public placée sous le contrôle direct de l'État.

- Les pouvoirs publics peuvent, lorsque nécessaire, proposer des lois et d'autres dispositions législatives applicables de manière générale afin d'établir des conditions de rémunération cohérentes dans l'ensemble des entités de droit privé et de droit public.

Les relations entre l'administration centrale et les organes directement élus de l'administration intermédiaire peuvent se révéler particulièrement délicates et ne pas être adaptées à des instructions directes de l'autorité centrale. Dans de tels cas, l'administration devra peut-être se fonder, au moins au départ, sur des consultations visant à parvenir à une meilleure convergence des politiques de rémunération et des positions de négociation.

\section{Principales caractéristiques des administrations publiques}

\section{1. $\quad$ Australie}

\subsubsection{Informations générales}

L'Australie ${ }^{2}$ compte 20264082 habitants (estimation de juillet 2006), pour une superficie de 7.6 millions de km2. Membre du Commonwealth, elle est une fédération de six états et deux territoires. Les données utilisées dans cette étude font référence au gouvernement fédéral, sauf indication contraire.

La Constitution australienne attribue au gouvernement fédéral certains domaines du pouvoir législatif, notamment la fiscalité, la défense, les affaires étrangères et les services postaux et de télécommunications. Les services fournis au niveau fédéral comprennent ceux liés au secteur privé (y compris l'agriculture et le tourisme), aux échanges, à l'environnement, à l'emploi, à la famille ainsi qu'aux affaires indigènes. Le gouvernement fédéral coordonne et soutient certaines activités du secteur public. La fonction publique australienne est organisée en plusieurs départements ministériels et plusieurs agences autonomes ${ }^{3}$. 
Pour toutes les autres questions qui se posent à l'intérieur de leurs frontières, y compris pour ce qui est de la police ${ }^{4}$, des hôpitaux, de l'éducation et des transports publics, le pouvoir législatif revient aux états.

Bien que l'existence de collectivités locales remonte à plus de 160 ans, la Constitution australienne ne les reconnaît pas et elles sont placées sous l'autorité des états et territoires. Par conséquent, leurs rôles et responsabilités sont différents d'un état à l'autre.

\subsubsection{Arrangements institutionnels}

Le ministère des Finances et de l'Administration assiste le gouvernement fédéral pour la préparation et l'administration du budget fédéral. En outre, il élabore et tient à jour la réglementation financière qui s'applique au secteur public. À ce titre, il met l'accent sur l'efficacité de la gouvernance financière, la gestion financière et l'obligation de rendre des comptes. Il contribue à une meilleure efficience des opérations menées par les administrations, en particulier celles qui concernent l'acquisition, la gestion et le désinvestissement en matière d'actifs publics. Enfin, il concourt à l'action des ministres, sénateurs et membres du Parlement ainsi qu'à celle de leurs équipes et encourage les entités publiques à utiliser efficacement les technologies de l'information et de la communication.

Le ministère de l'Emploi et des Relations professionnelles fournit au gouvernement fédéral des conseils, programmes et services de grande qualité en vue d'apporter une aide efficace au marché du travail, de contribuer à une plus grande productivité et à une meilleure rémunération ainsi qu'à une plus grande participation des salariés. Il transmet des conseils politiques et des lignes directrices sur les relations professionnelles dans le secteur public.

La Commission de la fonction publique est une agence de niveau central dépendant de la Fonction publique australienne. Elle joue un rôle moteur pour améliorer les capacités futures de la fonction publique et assurer sa pérennité. La Commission œuvre en faveur de bonnes pratiques de gestion de ressources humaines en renforçant au sein de la Fonction publique australienne l'exercice des responsabilités, l'apprentissage et le développement des compétences et en favorisant un comportement éthique et une plus grande diversité sur le lieu de travail. Elle remplit également un rôle important en matière d'évaluation en travaillant avec les institutions pour s'assurer que la Fonction publique australienne respecte de manière constante les valeurs dont elle se prévaut.

La Commission pour l'équité des rémunérations est un organisme national chargé de la négociation et de l'ajustement des salaires et conditions de travail prévus par les accords salariaux. La Commission protège ainsi les travailleurs durant le processus de négociation en garantissant le salaire minimal ainsi que les salaires fixés par arbitrage, conformément aux normes australiennes d'équité des rémunérations et des conditions de travail. Ces normes définissent les salaires minimaux et les conditions de travail qui s'appliquent aux salariés en vertu de la Loi sur les relations du travail de 1996. Complétant ainsi le travail de la Commission pour l'équité des rémunérations, la Commission australienne de relations du travail est une instance nationale chargée notamment de la résolution des différends et du traitement des plaintes pour licenciement abusif.

Le Conseil de l'emploi apporte aux employeurs et salariés assistance et informations en ce qui concerne la conclusion des accords. Les conventions collectives et accords individuels sont déposés auprès du Conseil qui vérifie qu'elles satisfont à la législation sur les relations professionnelles, et notamment aux normes australiennes d'équité des rémunérations et des conditions de travail. 


\subsubsection{Accords relatifs à la gestion des ressources humaines}

La dernière réforme majeure de la gestion des ressources humaines dans la fonction publique fédérale remonte à 1999 avec le vote de la nouvelle Loi sur le service public. Si elle continuait de se fonder sur une fonction publique de carrière et de privilégier la sélection au mérite, elle a également introduit la notion de gestion fondée sur les valeurs.

L'ensemble des responsabilités de gestion des ressources humaines a été délégué aux différentes agences. Au sein de celles-ci, un directeur dispose eu égard aux employés de la fonction publique australienne qui y travaillent de tous les droits, responsabilités et pouvoirs relevant de l'employeur, y compris quant à leur recrutement et leur licenciement. Le Commissaire à la fonction publique peut rédiger à l'intention des directeurs d'agence des lignes directrices s'appliquant à la gestion et à l'encadrement des fonctionnaires australiens. Des lois fédérales spécifiques couvrent des questions telles que les retraites, les indemnités, les congés de longue durée et les congés maternité.

L'Australie dispose d'un système de conventions collectives à un seul niveau. La Loi fédérale sur les relations de travail de 1996 prévoit six types d'accords professionnels. On trouve parmi ceux-ci les Accords professionnels australiens (ou AWA), ou accords de type individuel, les conventions collectives syndicales et les conventions collectives salariales. Une même agence peut utiliser simultanément ces trois types d'accords professionnels pour différents groupes de salariés. Environ $70 \%$ des agences disposent de conventions collectives syndicales, $25 \%$ de conventions collectives salariales et $5 \%$ recourent exclusivement à des accords individuels. La part des fonctionnaires dont la rémunération est fixée par l'intermédiaire de conventions collectives est passée de $86.6 \%$ en 2002 à $89.3 \%$ en 2004. La part des fonctionnaires dont la rémunération est déterminée par un accord individuel a aussi augmentée, passant de $7.4 \%$ en 2002 à $9.9 \%$ en $2004{ }^{5}$. La part des fonctionnaires dont la rémunération est déterminée par des primes a diminuée proportionnellement ${ }^{\dagger}$.

Le gouvernement australien a publié en avril 2006 ses Paramètres stratégiques à appliquer dans le cadre de la conclusion d'accords professionnels dans les services publics australiens. Il cherche ainsi à fournir aux institutions publiques un cadre pour l'élaboration des accords. Avant qu'une convention collective ne puisse être approuvée et déposée auprès du Conseil de l'emploi, le ministère de l'Emploi et des Relations professionnelles doit d'abord évaluer si elle satisfait à ces Paramètres. Le ministère n'est toutefois pas habilité à approuver les accords professionnels. Il revient au directeur d'agence et au ministre concerné de décider s'il convient ou non de proposer un accord aux salariés. Selon les Paramètres stratégiques, les accords professionnels mis en œuvre dans l'agence doivent être des instruments «simples et fondés sur des principes » et les augmentations de salaire doivent être liées à une amélioration de la productivité au sein de l'organisation.

La fonction publique australienne dispose d'un système de classification des employés qui comprend six catégories non cadre et deux catégories de cadres. Il existe en outre trois catégories de cadres supérieurs. Il revient toutefois à chaque institution de déterminer en fonction de ses propres besoins l'échelle de rémunération afférente à ces différentes catégories. Les agences sont encouragées à inclure dans leurs systèmes de rémunération une part liée à la performance. L'enquête annuelle sur les rémunérations, menée par le ministère de l'Emploi et des Relations professionnelles, a permis de rédiger un rapport sur les variations de salaires et les salaires médians à l'échelle de la fonction publique australienne. Il existe également des réseaux informels qui aident les agences à comparer leurs politiques ; elles peuvent en outre bénéficier des services de consultants privés. 


\subsubsection{Accords liés à la gestion financière}

L'Australie utilise une budgétisation ascendante. L'élaboration du budget commence chaque année en novembre par la soumission des propositions budgétaires des différents ministres. Ces propositions sont examinées par un groupe restreint composé des ministres les plus importants (y compris le Premier ministre). Des propositions détaillées sont ensuite remises en mars à un comité du Cabinet, en vue de leur inclusion possible dans le budget. Le gouvernement convient des dernières modifications et les documents budgétaires sont déposés au Parlement au mois de mai.

Les agences du gouvernement australien disposent pour leurs dépenses administratives d'une seule enveloppe budgétaire, qui inclut les rémunérations. Pour calculer le montant de ces dépenses, elles utilisent une méthode normalisée qui consiste à ajuster le budget par le biais d'un indice mesurant l'augmentation globale des prix et celle des salaires sur le marché du travail dans son ensemble. La plupart des agences retranchent chaque année de leurs dépenses un dividende d'efficience de 1.25\%.

La seule restriction économique dont l'agence doit tenir compte lorsqu'elle convient des rémunérations est que les augmentations de salaire doivent être financées dans les limites de son budget. Elles doivent être justifiées par une amélioration de la productivité de l'organisation et être financées par l'enveloppe qui lui est allouée. Les agences doivent également tenir compte des rémunérations de marché des différentes compétences. Une organisation qui éprouve des difficultés à honorer ses dépenses sans dépasser le budget total peut examiner en conjonction avec le ministère des Finances sa situation financière. Ceci peut permettre d'identifier où des gains d'efficience peuvent être réalisés ou bien de revoir le financement de l'organisation dans le prochain budget.

\subsection{Danemark}

\subsubsection{Informations générales}

Le Danemark compte 5450661 habitants (estimation de juillet 2006) pour une superficie de $42300 \mathrm{~km}^{2}$ (hors Îles Féroé et Groenland). C'est un État unitaire et un membre de l'Union européenne. Les données utilisées dans cette étude font référence à l'administration centrale, sauf indication contraire.

L'administration centrale est divisée en un certain nombre de ministères qui comprennent eux-mêmes un département et une ou plusieurs agences autonomes (styrelser) ${ }^{6}$. Chaque département est dirigé par un ministre et un secrétaire permanent (relevant de la fonction publique) et les agences par des directeurs généraux (qui appartiennent également à la fonction publique).

L'administration territoriale de l'État est constituée par les bureaux locaux d'institutions présentes sur l'ensemble du territoire, telles que la police, l'administration pénitentiaire et encore les autorités responsables de l'environnement de travail, ainsi que d'autres types d'institutions ou d'organismes, comme les universités, les archives régionales et les services de sauvetage en mer.

Au Danemark, l'État est fortement décentralisé. Les communes (kommune) et les comtés (amt) sont les premières entités chargées de mettre en œuvre la politique de l'État. La grande majorité des services sociaux, l'enseignement primaire et secondaire ainsi que les services de santé relèvent de leur responsabilité. Les communes et comtés sont financés en partie par les impôts locaux et en partie par une dotation générale nationale. Suite à l'importante réforme des administrations locales votée en 2005, les 275 communes ont été réorganisées et il n'en demeure que 99 depuis le $1^{\mathrm{er}}$ janvier 2007. Quant à eux, les 14 comtés ont laissé la place à cinq régions. 
Un grand nombre d'institutions publiques/semi-publiques occupent des fonctions identiques ou comparables à celles des administrations d'État ou municipales : institutions autonomes dans les secteurs du social ou de l'éducation, garderies et écoles privées, instituts universitaires professionnels, usines d'incinération utilisées par plusieurs collectivités et entreprises publiques.

\subsubsection{Arrangements institutionnels}

Le ministère des Finances est en charge de la gouvernance publique, de la gestion réglementaire, de l'organisation et de l'encadrement de l'administration publique. Il est également responsable de la préparation des négociations annuelles entre le gouvernement et les collectivités locales ainsi que du contrôle des résultats de ces accords.

Le ministère coordonne les tâches administratives et de gouvernance qui lui incombent par l'intermédiaire de son Centre de politique administrative (Administrationspolitisk center). Les objectifs principaux du Centre sont de parvenir à une bonne gouvernance et une administration publique efficace. Le ministère participe également au Forum pour la gestion publique (Forum for Offentlig Topledelse), où les cadres de l'administration centrale, des régions et des collectivités locales œuvrent ensemble en faveur du programme de modernisation de l'État.

L'Autorité de l'État employeur (Personalestyrelsen) est une agence autonome du ministère des Finances. Elle assume les responsabilités générales de l'État employeur dans les domaines des salaires, des retraites ainsi que de la politique du personnel et des cadres. Elle conclut des conventions collectives centrales et d'autres accords avec les syndicats représentant les salariés du secteur public et fournit des conseils et une assistance aux ministères et aux agences. L'Autorité dispose de divisions distinctes pour les conventions collectives et la politique salariale, pour les questions juridiques ou concernant les retraites ainsi que pour la politique du personnel et des cadres.

L'Agence de la gestion publique (Økonomistyrelsen) est un service autonome au sein du ministère des Finances qui œuvre en faveur d'un système de contrôle financier convenable et d'une meilleure efficience au sein du secteur public.

\subsubsection{Accords relatifs à la gestion des ressources humaines}

En matière de relations professionnelles, le Danemark suit le modèle nordique traditionnel qui comprend un système de conventions collectives à deux niveaux. La législation du travail et les autres réglementations ne jouent qu'un rôle secondaire sur le marché du travail. Les conditions de travail sont principalement réglementées par des conventions collectives nationales, généralement complétées et/ou modifiées par des conventions collectives locales. Les accords de niveau central constituent le cadre de la détermination des rémunérations alors que les salaires individuels sont définis par le biais d'accords locaux.

Trente-cinq pour cent des employés de l'État sont des fonctionnaires ou assimilés fonctionnaires. Ils ne sont pas autorisés à participer à des mouvements revendicatifs mais bénéficient de régimes de retraite plus avantageux. Leur rémunération est déterminée par système de grades et de salaires très formel, ainsi qu'une convention collective centrale qui définit les salaires de chaque grade et échelon. Leur part de l'emploi public de l'administration centrale est progressivement réduite et l'objectif du gouvernement est que seuls le personnel en uniforme et les hauts fonctionnaires puissent bénéficier de ce statut.

Le système danois de détermination des rémunérations au sein de l'administration est plus centralisé que dans les autres pays nordiques. Dans les années 1970, le droit pour chaque ministère de négocier les conditions de travail et la rémunération des agents relevant de sa compétence a été transféré au ministère des Finances, qui a par la suite représenté l’État employeur pour les différents ministères et institutions. 
Dans les années 1980 et 1990, la modification de la structure et du contenu des conventions collectives a réintroduit les négociations locales sur les rémunérations et les conditions de travail. Ces négociations doivent toutefois s'inscrire dans un cadre de référence adopté au niveau central ${ }^{7}$.

Les autorités politiques et le bureau du budget du ministère des Finance participent à l'élaboration des paramètres utilisés par l'Autorité de l'État employeur pour négocier la convention collective cadre. Le ministre est officiellement désigné pour diriger les négociations menées au niveau central sur les augmentations de salaires et autres questions importantes. La conduite des négociations relatives aux accords ou autres points spécifiques est déléguée par le ministre à l'Autorité de l'État employeur. En pratique, l'Autorité négocie l'ensemble des accords cadres, mais le ministre et le Secrétaire permanent sont informés en continu du déroulement de la procédure.

La principale convention collective est liée à l'évolution des rémunérations dans le secteur privé. Quatre-vingts pour cent de la différence constatée l'année précédente entre les augmentations du secteur marchand et du secteur public sont ajoutés au (ou soustraits du) relèvement déjà convenu. Au cours de l'année précédente, les rémunérations du secteur privé ont peu progressé, réduisant en retour les augmentations convenues dans le secteur de l'État.

La rémunération de plus de $60 \%$ des employés de l'État relève aujourd'hui d'un nouveau système qui fait la transition entre un dispositif fondé sur l'ancienneté et des mécanismes de niveau local qui privilégient les données opérationnelles. Le traitement global d'un agent peut ainsi comprendre les éléments suivants :

- un salaire de base ;

- des indemnités de fonction (liées par exemple aux domaines d'activité ou aux responsabilités spécifiques) ;

- des indemnités de qualification (liées par exemple aux diplômes, à la formation complémentaire ou à l'expérience); et

- une part liée aux résultats ou à la performance (c'est-à-dire à l'efficacité), versée à titre individuel ou collectif.

Les conventions collectives centrales prévoient des augmentations générales pour l'ensemble des employés de l'État. Les différents départements et agences peuvent convenir d'augmentations supplémentaires pour leurs employés si leur budget le leur permet. Sept pour cent de la masse salariale relevant de ces nouveaux systèmes consistent en des primes locales. Les augmentations locales pour les employés autres que les hauts responsables doivent être convenues avec un représentant syndical local.

Les salaires des hauts responsables (catégorie de cadres d'un certain niveau hiérarchique) sont définis au niveau central. En outre, l'Autorité de l'État employeur confère à chaque ministère le pouvoir de leur attribuer un montant spécifique de primes personnelles. Il est également possible de prévoir le versement d'une prime unique ou d'une part liée à la performance qui ne soit pas restreinte par le montant total attribué.

L'Autorité de l'État employeur doit contrôler la mise en œuvre et les résultats de cette délégation de la détermination des rémunérations. L'institution a publié des rapports sur les indicateurs qui peuvent être utilisés pour identifier une utilisation inappropriée de ce système. 
L'Autorité de l'État employeur conseille les départements et agences en matière de rémunération. Elle place également à leur disposition un certain nombre d'outils statistiques, tels que des bases de données sur les conventions collectives et une base de données en ligne sur les rémunérations et les conditions de travail (ISOLA), qui peuvent permettre d'analyser les évolutions en la matière au sein d'une organisation, d'un secteur ministériel ou de l'administration publique dans son ensemble.

\subsubsection{Accords en matière de gestion financière}

Le Danemark pratique une budgétisation descendante. Des prévisions sur plusieurs années sont présentées avec chaque budget. Le ministère des Finances propose des objectifs budgétaires globaux qui comprennent pour chaque ministère des plafonds de dépenses et de transferts de revenus. Les ministères concernés soumettent des propositions de budgets pour leur secteur, projets qui seront ensuite négociés au niveau gouvernemental.

Après le début de l'année fiscale, les modifications éventuelles des affectations budgétaires ne pourront être mises en œuvre que par l'intermédiaire de décisions du Comité des Finances du Parlement. Toutes les demandes devront être approuvées par le ministère des Finances avant de pouvoir être communiquées au Comité.

Les départements et agences bénéficient normalement de l'enveloppe qui leur était attribuée l'année précédente, sur laquelle sont pratiquées une déduction de productivité de $2 \%$ ainsi qu'une augmentation fondée sur le résultat estimé des négociations salariales menées au niveau central. Les affectations peuvent être majorées si des moyens plus importants que prévu sont nécessaires à l'application de la convention centrale. L'évolution des rémunérations dans le secteur privé n'influe sur ces enveloppes que par l'intermédiaire de la convention collective centrale. Il n'existe donc aucun modèle de référence.

Les dépenses de rémunération sont plafonnées pour environ la moitié des départements et agences, tels les départements ministériels et les agences traditionnelles. Les agences dont le fonctionnement se rapproche davantage de celui des entreprises privées bénéficient de plus de liberté. Elles peuvent ainsi utiliser les revenus supplémentaires ou les économies réalisées sur les autres dépenses afin de recruter ou d'augmenter les salaires. Elles peuvent également reporter les excédents et déficits sur le prochain exercice budgétaire.

\subsection{Finlande}

\subsubsection{Informations générales}

La Finlande compte 5231372 habitants (estimation de juillet 2006) pour une superficie de $304000 \mathrm{~km}^{2}$. C'est un État unitaire et un membre de l'Union européenne. Une de ses provinces (les Îles Åland) bénéficie d'une autonomie garantie par la Constitution. La Finlande est un pays bilingue : on y parle le finnois, langue dominante, et le suédois ${ }^{8}$. Les données utilisées dans cette étude font référence à l'administration centrale, sauf indication contraire.

L'administration centrale est composée de 13 ministères, dont certains possèdent des départements disposant d'un pouvoir exécutif, ainsi que d'agences autonomes (ämbetsverk). Lors de la formation d'un nouveau gouvernement, il est convenu du partage des responsabilités entre les différents ministres.

Les Centres pour l'emploi et le développement économique œuvrent en faveur des entreprises, de l'industrie et du développement des régions. Les Centres régionaux pour l'environnement traitent de problèmes liés à la protection de l'environnement et l'aménagement du territoire. Les Autorités de province occupent au niveau régional des responsabilités relevant de l'administration générale, de la 
supervision et de la sécurité. En outre, un grand nombre d'autorités de district opèrent dans différents secteurs de l'administration.

En Finlande, les communes jouissent depuis longtemps d'une grande autonomie. Chargées d'organiser la majorité des services sociaux, elles jouent un rôle central dans la société. La Finlande compte actuellement 432 communes. Les groupements de communes organisent en particulier les services impliquant des coûts importants; les conseils régionaux sont chargés du développement régional et de l'aménagement du territoire. Le gouvernement a récemment lancé un programme de réformes structurelles après avoir conclu un accord avec l'Association des autorités locales et régionales de Finlande. L'objectif est de fusionner les communes afin de créer des entités plus efficaces et de dimension plus importante ainsi que des Districts de services locaux chargés d'administrer des soins aux malades, aux personnes âgées et aux enfants.

\subsubsection{Arrangements institutionnels}

Le ministère des Finances est chargé de l'élaboration de la politique économique et fiscale. Il est également responsable des politiques d'emploi et de ressources humaines de l'État ainsi que du développement général de l'administration publique. Son principal objectif est de favoriser de par sa gestion des finances nationales la meilleure évolution possible de l'économie finnoise. Dans le gouvernement actuel, le ministère des Finances compte un ministre délégué chargé de l'administration publique et la politique du personnel. Le plus haut fonctionnaire du ministère est le secrétaire d'État permanent. Il est assisté de deux sous-secrétaires d'État permanents chargés des affaires économiques, de l'administration publique et de la politique mise en œuvre par l'État employeur.

Le Département de la gestion publique (Avdelningen för utvecklandet av förvaltningen) du ministère est en charge de la politique de gestion de l'administration centrale et apporte au gouvernement son expertise en matière d'évolutions administratives. Il concourt aux réformes administratives engagées dans les différentes agences et soutient les mesures visant à améliorer les prestations de service et la qualité au sein de l'administration centrale.

Le Département du personnel (Personalavdelningen) du ministère est chargé de la politique d'emploi et de gestion du personnel de l'administration centrale ; il agit également en qualité d'agence. Le Bureau de l'État employeur (Statens arbetsmarknadsverk), qui dirige les négociations au niveau central, œuvre en faveur de la compétitivité des politiques d'emploi de l'administration centrale accompagne les administrations dans leur rôle d'employeur.

Le Bureau dispose d'une Unité chargée des conventions collectives (Förhandlingsenheten). Elle représente l'administration centrale lors des négociations collectives menées au niveau national et protège les intérêts de l'État employeur quant à la politique de rémunération et les conditions de travail, ainsi que pour les décisions relatives à la période d'activité. Elle aide également les agences à mieux remplir leur rôle d'employeurs. L'Unité de politique du personnel (Enheten för personalpolitik) est chargée de rédiger les dispositions législatives concernant les fonctionnaires, les retraites et les autres conditions d'emploi au sein de l'administration centrale. L'Unité de recherche (Utredningsenheten) est responsable des statistiques de rémunération, des informations sur les ressources humaines et des bases de données de l'État employeur, au niveau central. Elle concourt également aux activités des différentes administrations en leur fournissant des informations comparatives. 
Le Trésor (Statskontoret) est une agence chargée de fournir des conseils de saine gestion, de produire des informations économiques et enfin de gérer les actifs et les dettes ainsi que les questions d'assurance.

Le ministère de l'Intérieur est en charge de l'administration régionale, de l'administration locale, des registres de population, des services de police et de la protection des frontières. Un ministre délégué est chargé du développement régional et local, y compris en matière de prérequis juridiques et financiers pour les communes autonomes.

\subsubsection{Accords relatifs à la gestion des ressources humaines}

En matière de relations professionnelles, la Finlande suit le modèle nordique traditionnel qui comprend un système de conventions collectives à deux niveaux. Les conditions de travail sont réglementées par des conventions collectives nationales, complétées et/ou modifiées par des conventions collectives locales. Les accords de niveau central constituent le cadre de la négociation des rémunérations et les traitements individuels sont définis par le biais d'accords avec les syndicats locaux.

Un accord tripartite ${ }^{9}$ complet sur les revenus a été signé en décembre 2005 et couvre la période allant jusqu'à septembre 2007. Cet accord concerne environ 90\% des employés en Finlande et exerce une forte influence sur l'évolution des secteurs non couverts. L'accord prévoit des augmentations de salaire et des baisses d'impôt et garantit aux employés une augmentation annuelle de leur pouvoir d'achat comprise entre 1.5 et $2 \%$. Cet accord comporte également d'autres progrès pour les salariés.

Le statut juridique des fonctionnaires d'État (qui représentent 83\% des employés de l'administration centrale) est défini dans la Loi sur la fonction publique nationale, celui des agents contractuels par la Loi sur les contrats de travail, qui porte sur l'ensemble du marché du travail. Il existe également une Loi sur les conventions collectives des fonctionnaires, qui couvre les conditions de travail de cette catégorie, ainsi qu'une Loi sur les conventions collectives, qui porte sur les conditions de travail du personnel sous contrat de travail ordinaire.

La convention collective actuelle englobe les fonctionnaires d'État et les employés sous contrat au niveau national, et est fondée sur l'Accord général sur les revenus. Il est également possible de négocier au niveau local des conventions collectives distinctes pour les fonctionnaires d'État et les agents contractuels. Toutefois, les conventions collectives spécifiques sur les systèmes de salaires des agences sont généralement des accords uniques.

Une réforme majeure des systèmes de rémunération a été mise en œuvre par l'intermédiaire des accords locaux précédemment mentionnés. Elle est aujourd'hui presque achevée. Ces nouveaux mécanismes couvraient $100 \%$ des employés à la fin 2006. Bien qu'ils soient spécifiques aux différentes agences, ils se fondent sur des principes généraux similaires compris dans l'accord central. La rémunération est constituée du salaire de base, qui est fonction des spécificités de l'emploi occupé, auquel vient s'ajouter une composante personnelle fondée sur les performances et compétences individuelles. Les exigences liées à la fonction ainsi que les performances feront l'objet d'une revue annuelle au cours d'entretiens individuels centrés sur la performance et le développement professionnel. Ces nouveaux systèmes tiennent également compte de l'expérience par l'intermédiaire d'une composante basée sur les années de service ou la spécificité des conditions de travail. L'accord central actuel comprend une augmentation générale pour tous les employés et une réserve pour des augmentations supplémentaires allouées par les accords locaux ${ }^{10}$. L'accord comprend également une réserve pour les femmes avec un bas salaire ${ }^{11}$. 
La convention collective centrale doit être approuvée par le ministre responsable. Le pouvoir politique ne participe en principe pas à la négociation salariale, bien qu'il existe un exemple d'intervention d'un ministre (en 25 ans) dans le processus de négociation. Récemment, un conflit impliquant les gardesfrontières a failli se transformer en problème politique.

Le Bureau de l'État employeur rassemble et publie des statistiques sur le personnel de l'administration centrale et notamment sur sa structure et sur ses conditions de travail. Des études sont régulièrement menées sur le coût de la main d'œuvre, les conditions d'emploi et la rotation du personnel ainsi que sur l'évolution des traitements et la conduite des réformes des systèmes de salaire ou encore sur la compétitivité de l'administration centrale en tant qu'employeur. Ces informations statistiques servent de base à la négociation collective et à la prise de décision en matière de ressources humaines, au niveau central comme au niveau local.

\subsubsection{Accords en matière de gestion financière}

La Finlande pratique une budgétisation descendante. Au début de la période électorale, le gouvernement décide du montant des dépenses qui pourront être engagées sur l'ensemble de celle-ci. Le plafond des dépenses autorisées pour les différents secteurs administratifs fait ensuite l'objet d'une révision annuelle. Lorsqu'ils préparent leurs propositions pour le prochain budget, les ministres sont tenus de respecter les limites générales définies par le gouvernement.

En fonction de ces plafonds et des directives émises par le ministère des Finances, les ministères transmettent leurs propres instructions aux agences et aux départements sous leur tutelle. Ils peuvent ensuite proposer de modifier ces plafonds de dépense. Ces propositions sont examinées par le gouvernement lorsqu'il décide de sa proposition de budget final, proposition qui sera soumise au Président pour approbation et présentée devant le Parlement.

Des propositions budgétaires supplémentaires peuvent être présentées au Parlement au cours de l'année fiscale. Des procédures identiques s'appliquent généralement à la formulation de nouvelles propositions et à l'élaboration du budget.

Les autorités locales bénéficient d'une autonomie étendue, garantie par la Loi constitutionnelle. Les principales dispositions de cette loi confèrent aux autorités locales le pouvoir de prélever des impôts et de décider de la gestion de leurs fonds. Les autorités locales conviennent en toute indépendance du taux de l'impôt sur le revenu qui s'applique au niveau local ainsi que du barème de l'impôt foncier, dans des limites définies par le gouvernement. En outre, il reçoivent une part des recettes provenant de l'impôt sur les sociétés, part dont le montant est, ici encore, décidé par le gouvernement. Les différences économiques entre les communes sont compensées par un système de transferts budgétaires de l'administration centrale.

L'accord sur les revenus est un facteur important pour calculer l'enveloppe économique dont disposent les agences et autres entités habilitées durant la période couverte par ledit accord. Lorsque aucun accord sur les revenus n'est en vigueur, il n'existe aucun modèle de référence permettant de tenir compte de l'évolution des rémunérations des autres secteurs. Le département du Budget ne participe pas directement au calcul des rémunérations car il pourrait alors se trouver en porte-à-faux avec son principal rôle, qui est de contenir les coûts. C'est le ministre concerné qui doit prendre l'initiative d'un compromis économique s'il s'avère nécessaire de procéder à des augmentations de salaires supérieures à la moyenne. 


\subsection{Pays-Bas}

\subsubsection{Informations générales}

Les Pays-Bas comptent 16491461 habitants (estimation de juillet 2006) pour une superficie de $41500 \mathrm{~km}^{2}$. C'est un État unitaire et fait partie de l'Union européenne. Les données utilisées dans cette étude font référence à l'administration centrale, sauf indication contraire.

Celle-ci est composée de 14 ministères, tous dirigés, à une exception près ${ }^{12}$, par un ministre. Jusqu'à une date récente, les départements étaient la seule composante de l'administration centrale et ils étaient donc chargés de l'élaboration et de la mise en œuvre des politiques. Depuis 1994, un nombre croissant d'agences (agentschappen) ont été créées par les ministères clés, résultant en une division de plus en plus importante des fonctions de formulation et d'application des politiques. Les Pays-Bas comptent aujourd'hui 27 agences, mais on estime que 25 autres organismes de ce type devraient être créés dans un proche avenir.

Une agence est une institution relevant d'un ministère mais gérée de façon autonome, disposant de son propre budget et de sa propre administration financière. Toutefois c'est en dernière instance le ministre concerné qui est responsable de ses activités. Il existe en outre un certain nombre d'organes administratifs indépendants (zelfstandige bestuursorganen). Ces organisations sont chargées de l'exécution de tâches confiées par le gouvernement mais ne relèvent toutefois pas de la responsabilité directe du ministère.

Il existe 12 provinces (Provincie), 458 communes (Gemeente) et 27 Commissions des eaux (Waterschap). Les Waterschap sont des organismes publics chargés de la gestion des eaux dans une région donnée. Ils exercent leurs responsabilités sur des espaces correspondant non pas à des provinces ou à des communes, mais aux bassins des rivières d'une zone donnée.

Il existe de nombreux fournisseurs de service de caractère hybride public/privé, financés par l'État ou par les cotisations de sécurité sociale. Ces fournisseurs ont une mission de service public, mais ne constituent pas à proprement parler des entités publiques. Cet ensemble d'organisations est désigné par le terme «secteur bénéficiant de financements et subventions » (Gepremieerde en Gesubsidieerde, G\&G) et comprend une large gamme d'organismes, allant d'entités relevant du domaine de la santé aux orchestres.

\subsubsection{Arrangements institutionnels}

Les trois domaines clés du ministère des Finances sont la politique budgétaire, la politique économique et financière et la fiscalité. Généralement, la politique budgétaire traite des recettes et des dépenses des instances gouvernementales; la politique financière et économique relève des marchés financiers et de la situation financière de l'administration, du secteur marchand et de la population; et la politique fiscale concerne tous les aspects liés à la fiscalité. Après que le Conseil des ministres ait convenu du niveau futur des recettes et dépenses, le ministre des Finances élabore le budget national en consultation avec ses collègues.

Le ministère de l'Intérieur et des relations au sein du Royaume (Ministerie van Binnenlandse Zaken en Koninkrijksrelaties - " $M B Z K »$; ci-après, le « ministère de l'Intérieur ») assume à titre principal la charge de l'administration publique et coordonne la négociation des conditions de travail dans la fonction publique. Il est responsable de la politique gouvernementale concernant les fonctionnaires, du système de classification des emplois, des systèmes de retraite et de sécurité sociale et des conditions de travail générales. En outre, il est chargé d'œuvrer pour la représentation des diversités au sein de la fonction publique, en ce qui concerne les femmes, les minorités ethniques et les handicapés. 


\subsubsection{Accords relatifs à la gestion des ressources humaines}

Les Pays-Bas n'utilisent pas de conventions collectives stricto sensu dans le secteur public. Les négociations résultent en des conclusions communes ${ }^{13}$, mises en œuvre par le biais de décisions du gouvernement. La portée de ces conclusions est renforcée par une ordonnance du gouvernement exigeant que toute modification de la rémunération et des conditions de travail soit acceptée par un syndicat.

Les négociations se déroulent à un seul niveau, certaines questions étant négociées par le ministère de l'Intérieur pour l'ensemble du gouvernement et d'autres, y compris les rémunérations, étant négociées au niveau sectoriel. Il existe actuellement 13 secteurs de négociation des rémunérations ${ }^{14}$.

Ce modèle (Sectorenmodel) a été introduit en 1993. Les négociations centrales se déroulent au Conseil des relations professionnelles du secteur public (Raad voor het Overheids Personeelsbeleid), un organe assurant des fonctions de conseil à l'intention des ministères, du Parlement et des différents secteurs. Au niveau des collectivités locales ${ }^{15}$, les partenaires sociaux se rencontrent par l'intermédiaire de comités sectoriels. Le ministre responsable représente l'employeur au sein des secteurs dits «ministériels », alors que la Ligue des employeurs des provinces (Interprovinciale Werkgeversoverleg), l'Union des communes (Vereniging van Nederlandse Gemeenten) et l'Union des Commissions des eaux (Unie van Waterschappen) représentent collectivement l'employeur au niveau des collectivités locales.

Le secteur de l'éducation est constitué de plusieurs composantes. Les organes qui représentent l'employeur au sein de ces sous-secteurs négocient directement avec les syndicats. L'enseignement primaire et l'enseignement secondaire sont sans doute aussi appelés à devenir indépendants et le nombre de secteurs de négociation des rémunérations devrait donc passer à 15. Dans l'intervalle, le ministère de l'Éducation continuera d'agir pour ces domaines en qualité d'employeur.

À l'origine, la quasi-totalité des conditions de travail était négociée au niveau central ; le ministère de l'Intérieur jouait un rôle de coordinateur et seules les décisions sur des points d'importance mineure étaient prises au niveau sectoriel. Le centre de gravité s'est toutefois déplacé vers les différents secteurs. Les retraites sont désormais le seul point traité au niveau central, mais un transfert décisionnel est également envisagé en la matière.

Le ministre de l'Intérieur publie les paramètres de négociation (Speerpuntenbrief) dont il a été convenu en Conseil des ministres. Ces paramètres incluent notamment les conventions qu'il convient de respecter lors des négociations avec les syndicats. Ils recouvrent un certain nombre de points sur lesquels le gouvernement souhaite parvenir à un accord, depuis les rémunérations et retraites jusqu'aux prestations d'invalidité, en passant par la garde des enfants. Ils spécifient également des plafonds pour les enveloppes budgétaires attribuées à chaque secteur. Ces paramètres lient les employeurs des secteurs " ministériels », mais n'ont qu'une valeur indicative pour les autres secteurs et sous-secteurs. Les négociations se déroulent généralement au cours du printemps suivant.

\subsubsection{Accords en matière de gestion financière}

Les Pays-Bas pratiquent une budgétisation descendante. Lors de la formation d'un gouvernement ${ }^{16}$, un cadre de référence est publié en matière de dépenses, sous la forme d'un Accord gouvernemental (Regeerakkoord). Celui-ci devra servir de guide à la politique financière du gouvernement jusqu'aux prochaines élections.

Chaque année, en janvier, le ministre des Finances actualise les prévisions de dépenses établies sur plusieurs années et, en mars, les ministères concernés soumettent des documents d'orientation où sont notamment présentées de nouvelles propositions de dépenses. Sur la base de ces données, de perspectives économiques récentes et d'autres paramètres micro-économiques, le ministre des Finances transmet aux 
ministères dépensiers des enveloppes budgétaires (Kaderbrief) qui précisent les plafonds pour l'année à venir. Le budget est présenté devant le Parlement en septembre, suite à des négociations internes entre le ministre des Finances et ses homologues.

Dans le même temps, le ministre de l'Intérieur adopte un indice qui permet de calculer l'enveloppe consacrée aux rémunérations. Cet indice est basé sur un modèle de référence (Referentiemodel) qui tient compte de l'évolution des salaires dans le secteur privé ainsi que de l'évolution des contributions sociales payées par les employeurs. Le gouvernement peut décider unilatéralement de le modifier. Au printemps, le ministre de l'Intérieur transmet aux secteurs ministériels et aux sous-secteurs placés sous leur tutelle un communiqué concernant l'enveloppe salariale (Ruimtebrief). Il présente le niveau estimé des dépenses salariales de l'année en cours. Si les augmentations de traitement dont a convenu l'employeur sont supérieures à l'indice de rémunération, il devra alors les financer en réduisant d'autres postes de ce budget.

\subsection{Nouvelle-Zélande}

\subsubsection{Informations générales}

La Nouvelle-Zélande compte 4076140 habitants (estimation de juillet 2006) pour une superficie de $270000 \mathrm{~km}^{2}$. C'est un État unitaire et un membre du Commonwealth. Sa constitution est similaire à celle du Royaume-Uni. La Nouvelle-Zélande est un État bilingue (anglais et maori). Les données utilisées dans cette étude font référence à l'administration centrale, sauf indication contraire.

Le secteur public est composé du secteur de l'État et des collectivités territoriales. Le secteur de l'État (également désigné par le terme «secteur de l'État au sens large ») recouvre les organisations dont la situation financière et les performances sont présentées dans les états financiers annuels du gouvernement. Il comprend les services de l'État, certains autres départements, les institutions d'enseignement supérieur, les organes du Parlement et les entreprises publiques. Les services de l'État se composent de départements de service public, qui tous (à l'exception des institutions d'enseignement supérieur) constituent des entités de la Couronne, de divers autres organismes ainsi que de la Banque de réserve de la Nouvelle-Zélande. La plupart des employés des services de l'État travaillent pour les entités de la Couronne, principalement dans les secteurs de la santé et de l'éducation.

Les collectivités territoriales sont autonomes. Elles sont composées de 12 conseils régionaux, 15 conseils municipaux et 57 conseils de district. Les conseils régionaux sont responsables de la gestion de l'eau, de l'utilisation des sols et de l'air, de la gestion des rivières et du contrôle des inondations, de la sécurité et de la navigation portuaire, des contrôles de biosécurité, de la pollution marine et du rejet d'hydrocarbures, de la planification du trafic terrestre et de la passation de marchés dans le secteur du transport. Les conseils municipaux et de district doivent veiller au bien-être et au développement de la population, y compris en matière d'aménagement du territoire et de contrôle du développement, d'hygiène et de sécurité environnementales (et notamment de contrôle des bâtiments et de protection civile), d'infrastructures (routes et transports, assainissement, eaux/eaux pluviales), de loisirs et de culture.

\subsubsection{Arrangements institutionnels}

Le Trésor assiste et conseille le gouvernement en matière de politique économique et financière, y compris en matière fiscale, pour la gestion budgétaire et l'élaboration des états financiers. Le Trésor est l'une des trois agences centrales chargées d'encadrer, de coordonner et de contrôler l'ensemble du secteur public. La deuxième est le Département du Premier ministre et du Cabinet, qui assiste et conseille le pouvoir exécutif (détenu par le Gouverneur général, le Premier ministre et le Cabinet). En outre, le département contribue à coordonner les travaux des services publics et ministères clés. 
La troisième agence de ce type est la Commission des services de l'État. Celle-ci joue un rôle central pour promouvoir en Nouvelle-Zélande un service public impartial, professionnel et durable. Le Commissaire est à la fois directeur général de la Commission et titulaire de charges publiques. En qualité de titulaire de charges publiques, il travaille de manière indépendante sur un large éventail de questions ayant trait au fonctionnement du service public, des services de l'État et du secteur de l'État au sens large.

Les responsabilités du Commissaire recouvrent les domaines suivants : promouvoir et développer au sein de la fonction publique des politiques et normes en matière d'administration du personnel et d'égalité des chances, ainsi que le leadership et les compétences d'encadrement; fournir des conseils sur les systèmes de gestion ainsi que sur les structures et l'organisation du service public et des entités de la Couronne; mettre en œuvre des normes d'intégrité et de conduite pour le service public, la plupart des entités de la Couronne ainsi que certaines autres agences; conseiller le gouvernement quant à la structure du secteur de l'État, et notamment pour l'attribution des fonctions entre les agences.

La flexibilité est l'une des caractéristiques principales des arrangements institutionnels en NouvelleZélande. Il existe une grande diversité d'accords dans le secteur de l'État. Le modèle de gestion publique national offre un grand choix en termes opérationnels et en matière de conception et les gouvernements peuvent ainsi modifier leur approche au fil du temps. Par exemple, la Commission des services de l'État peut choisir entre de nombreuses modalités pratiques pour exercer son autorité et la Commission joue un rôle moins actif aujourd'hui dans la détermination des rémunérations qu'il y a 20 ans..

Ce changement global est compatible avec le principe du secteur public, à savoir que la comptabilité doit être alignée au lieu de responsabilité. Par exemple, dans le secteur public, ce principe est manifesté par l'intermédiaire d'un instrument statutaire de délégation et des paramètres de négociation ${ }^{17}$. L'utilisation de tels paramètres de délégation et de négociation est un choix politique que l'on peut changer si nécessaire. De plus, les conditions qui s'appliquent à la délégation, la mise en œuvre et le contenu des paramètres de négociation eux-mêmes impliquent des choix dans la conception. Ces questions sont actuellement à l'étude par le gouvernement. Il est probable que les ministres attendront de la Commission des service de l'État de prendre un rôle plus proactif, au sein du secteur public mais aussi au sein du secteur de l'État au sens large. Ceci est compatible avec le principe de la comptabilité du directeur pour la négociation.

\subsubsection{Accords relatifs à la gestion des ressources humaines}

La responsabilité en matière des ressources humaines est exercée aux niveau des agences. En générale, les directeurs des entités de l'État ont tous les droits, responsabilités et pouvoirs d'un employeur, y compris l'embauche et le licenciement des employés ${ }^{18}$.

En Nouvelle-Zélande, les conventions collectives sont régies par un système à un seul niveau. La rémunération des employés de l'État est ainsi réglementée soit par des contrats individuels, soit par des conventions collectives. Même si l'on considère en Nouvelle-Zélande que les négociations collectives participent largement au développement de relations professionnelles fructueuses, la part de la maind'œuvre couverte par des conventions collectives dans le secteur public n'est aujourd'hui plus que de $49 \%$.

Comme on l'a vu plus haut, la classification des entités publiques est plus complexe en NouvelleZélande que dans la plupart des pays étudiés. En outre, il existe d'importantes différences quant aux marges de manœuvre pour les questions opérationnelles et salariales. Il convient également de souligner que les conventions collectives ne couvrent pas obligatoirement les rémunérations actuelles, qui sont parfois négociées par l'intermédiaire d'un processus de consultation moins formel. 
En 2000, le gouvernement a signé un accord de «Partenariat pour la qualité » avec le plus important syndicat du service public (l'Association du service public). Il porte principalement sur la mise en place d'une relation ouverte et fondée sur la coopération. Des modifications y ont été apportées en 2003. La nouvelle version vise à élargir l'application de ces principes à plus de départements et agences et à renforcer son impact.

Comme on l'a noté ci-dessus, la Commission des services de l'État rédige des paramètres de négociation qui reflètent les politiques et les attentes du gouvernement en matière de négociations collectives et de relations d'emploi. La Commission cherche également à encourager la coordination et à promouvoir une approche des relations professionnelles et des conditions de travail qui puisse être appliquée à l'ensemble de l'administration. Dans leur définition étroite, les paramètres de négociation s'appliquent uniquement à la négociation collective au sein de la fonction publique. Cependant, dans la mesure où ils définissent des politiques générales concernant les questions d'emploi dans l'administration, les départements du service public doivent aussi les appliquer lors de toute négociation professionnelle. Les entités de la Couronne doivent aussi tenir compte des paramètres.

Le Commissaire aux services de l'État a le pouvoir statutaire de négocier et de conclure des négociations collectives au sein du secteur public (bien que le directeur concerné continue d'agir en qualité d'employeur). Il a la capacité, dont il a déjà fait usage, de déléguer ce pouvoir aux directeurs, à condition que ces derniers consultent la Commission des services de l'État et qu'ils se conforment avec les paramètres de négociation définis par les instances gouvernementales.

Les agences du secteur de l'État au sens large ne seront pas tenues de consulter la Commission sur les questions de négociation collective, à moins que ceci ne leur soit explicitement demandé. La Commission peut toutefois les conseiller et leur apporter son soutien, en se fondant sur ces paramètres.

\subsubsection{Accords en matière de gestion financière}

La processus budgétaire en Nouvelle-Zélande est toujours en train d'évoluer et d'importants éléments relevant de mécanismes descendants («top-down») ont été introduits par l'utilisation de déclarations préliminaires de politique budgétaire et attribution par certains ministres de ressources selon des modalités intersectorielles. Comme la loi l'exige, les gouvernements doivent publier, chaque année leurs objectifs fiscaux à long terme. Le processus budgétaire annuel opère dans une enveloppe global, afin d'assurer que les objectifs fiscaux sont atteints. L'étape dite «stratégie»du processus budgétaire fixe le niveau de financement global, les priorités de dépenses générales, et les allocations budgétaires des zones prioritaires. Des déclarations préliminaires de politique budgétaire sont obligatoires et informent les citoyens des plafonds et des priorités.

L'étape dite « initiatives » voit la soumission de propositions ascendantes («bottom-up ») par tous les ministres pour toute nouvelle dépense, propositions qui sont ensuite priorisées dans l'enveloppe budgétaire prévue pour chaque domaine prioritaire avant d'être approuvées par le Cabinet.. Les principaux ministres se rencontrent également afin d'examiner les priorités, avant que le gouvernement ne décide des enveloppes budgétaires.

Les agences soumises aux contrôles budgétaires du gouvernement reçoivent une enveloppe budgétaire pour les divers catégories de services qu'ils fournissent, et doivent gérer tous les coûts intrants, y compris les rémunérations, sans dépasser cette enveloppe. La plupart des entités habilitées ne bénéficient d'aucun aménagement automatique de leurs budgets. Le budget de l'année précédente, auquel s'ajoutent des ajustements structurels, sert généralement de base de travail. Les agences doivent chercher à réduire les coûts et à améliorer leur productivité afin de pouvoir financer les augmentations de salaire. Si elles estiment qu'une rallonge budgétaire leur est nécessaire, elles devront soumettre une demande argumentée. 
Aucun modèle prédéfini n'est utilisé pour prendre en compte les évolutions du secteur privé, mais nul n'empêche les directeurs d'en faire. L'habileté dont les entités habilitées débattent de la situation du marché du travail dans leur secteur ainsi que les conséquences du budget en matière de recrutement et de maintien du personnel ont un rôle à jouer dans le processus budgétaire.

Tous les entités du secteur public peuvent être en déficit, mais l'autorisation explicite du gouvernement est obligatoire. Un grand nombre d'entités de la Couronne doit avoir l'accord d'emprunter, ce qui impose un certain degré de discipline concernant les décisions de dépenses sensibles de créer des déficits. Il existe actuellement un certain nombre d'agences qui ont effectué des dépenses excessives ; d'autres encore éprouvent des difficultés à contenir leurs coûts.

\subsection{Le Royaume-Uni}

\subsubsection{Informations générales}

Le Royaume-Uni compte 60609153 habitants (estimation du mois de juillet 2006), pour une superficie de $245000 \mathrm{~km}^{2}$. Il constitue une union politique composée de quatre pays (Angleterre, Écosse, Pays de Galles et Irlande du Nord), qui est membre du Commonwealth ainsi que de l'Union européenne. Les données utilisées dans cette étude font référence à l'administration centrale, sauf indication contraire.

Le secteur public est composé de l'administration centrale, des collectivités locales et d'entreprises publiques. L'administration centrale comprend les différents départements et leurs agences; les administrations décentralisées d'Écosse, du Pays de Galles et d'Irlande du Nord (lorsque rétablies), les organismes publics non ministériels, et d'autres organismes publics gérés et principalement financés par l'administration centrale. Les collectivités locales comprennent tout type d'administration publique dont les pouvoirs s'étendent exclusivement à une localité particulière, ainsi que tout type d'organisme non marchand géré et principalement financé par lesdites administrations. Les entreprises publiques sont des organisations marchandes contrôlées soit par l'administration centrale soit par une collectivité locale. Elles comprennent des sociétés d'État ainsi que des trading funds (fonds à caractère commercial).

Le degré de contrôle permet de déterminer si un organisme relève du secteur public. Il sera considéré comme appartenant au secteur public si l'administration centrale ou une collectivité locale exerce un contrôle important sur sa politique générale et ses opérations au jour le jour.

Au cours des dernières décennies, le Royaume-Uni a entrepris une série de réformes de la gestion publique visant à améliorer les résultats de l'administration centrale. L'une d'entre-elles consistait en la création d'agences aux responsabilités et à la structure hiérarchique clairement définies, supervisées par un directeur. Une distinction a en outre été établie entre les activités clés, entreprises par les départements chargés de l'élaboration des politiques, et l'exécution de ces politiques par les agences.

\subsubsection{Arrangements institutionnels}

Le Bureau du Conseil des ministres (ou «Cabinet Office») constitue le centre du pouvoir politique ; il est le «siège » du gouvernement (avec le Trésor). Son objectif premier est d'améliorer le fonctionnement de l'administration ; il exerce à ce titre trois fonctions principales :

- $\quad$ assister le Premier ministre : définir et mettre en œuvre les objectifs du gouvernement ;

- $\quad$ assister le Bureau du Conseil des ministres : assurer la qualité, la mise en œuvre et la cohérence de la politique et des opérations au sein des départements, et enfin ; 
- renforcer la position de la fonction publique : s'assurer qu'elle soit organisée de façon efficace et qu'elle dispose des compétences, des valeurs et de l'autorité nécessaires pour remplir les objectifs du gouvernement.

Le Bureau du Conseil des ministres est également responsable de la gestion globale des ressources humaines au sein de la fonction publique. Le Commissaire à la fonction publique veille à ce que l'État demeure efficace et impartial en établissant des règles de recrutement et en procédant à l'audition des recours conformément au Code de la fonction publique.

Le Trésor constitue le ministère de l'Économie et des Finances du Royaume-Uni et est dirigé par le Chancelier de l'Échiquier. Il est chargé de l'élaboration et de l'application de la politique financière et économique du gouvernement. Son objectif est d'augmenter le taux de croissance durable et de parvenir à une plus grande prospérité, à un meilleur niveau de vie ainsi qu'à des opportunités économiques et d'emploi pour tous. Lors de son examen des dépenses, le Trésor fixe pour trois ans et pour chaque département des plafonds fixes et définitifs de dépenses. Les contrats de service public conclus avec les différents départements permettent de définir leurs objectifs propres. Par le biais du processus de soumission de propositions, le Trésor souhaite s'assurer que, pour l'ensemble du secteur public, le niveau des salaires et leur augmentation n'entraînent pas de pressions inflationnistes et qu'ils s'inscrivent dans l'environnement fiscal plus large.

Le rôle principal du Comité de rémunération du secteur public (Public Sector Pay Committee), créé récemment, est de superviser toutes les augmentations significatives des rémunérations du secteur public et de définir pour l'ensemble des administrations des objectifs communs en la matière. Il doit également s'assurer que les primes et les systèmes de rémunération reposent sur des observations factuelles, qu'ils soient utilisés de façon optimale et soient financièrement viables à long terme. Il permet d'évaluer les stratégies de rémunération et de ressources humaines des différents départements. Le Comité est présidé par le Bureau du Conseil des ministres. Il est membre permanent du Trésor.

Huit organes d'examen des rémunérations indépendants conseillent le Premier ministre et plusieurs secrétaires d'État sur des problématiques qui leur a été demandé d'examiner. Leur rôle consiste principalement à fournir des recommandations annuelles sur les niveaux de rémunération pour les 1.8 million d'employés du secteur public entrant dans le champ de leurs responsabilités respectives ${ }^{19}$. Le Bureau économique de la main d'œuvre leur apporte son concours.

\subsubsection{Accords relatifs à la gestion des ressources humaines}

Le Royaume-Uni possède un système de conventions collectives à un seul niveau. Toutefois, la rémunération de certains groupes de fonctionnaires est directement décidée par le gouvernement, après avoir pris connaissance des propositions des organes indépendants.

Les employés du gouvernement au Royaume-Uni appartiennent soit à la catégorie des fonctionnaires, soit à celle des autres personnels. Ils peuvent soit bénéficier des conditions d'emploi habituelles des fonctionnaires, soit être employés sous contrat. Environ 550000 des 2.6 million d'employés de l'administration centrale sont fonctionnaires.

Au cours des dernières décennies, les réformes de la gestion publique sont allées de pair avec une réforme du processus de négociation salariale dans la fonction publique. L'ancienne structure, fondée sur un petit nombre de conventions extrêmement centralisées, a été supprimée. La détermination des rémunérations a été déléguée aux départements et aux agences, qui peuvent définir leurs propres barèmes de rémunération et structures de grades. Tous les ministères possédant des agences exécutives (à l'exception du ministère du Travail et des Retraites) leur ont délégué le pouvoir de convenir de leurs 
propres conditions d'emploi.. Tous les ministères ont leur propre système de rémunération qui permet de satisfaire à leurs exigences spécifiques, même s'il existe, pour les échelons et grades, des similitudes avec l'ancien mécanisme.

En 2000, le Bureau du Conseil des ministres, les syndicats intersectoriels de la fonction publique et le Conseil des syndicats de la fonction publique ont signé un accord de partenariat national visant à promouvoir une relation franche et efficace entre les ministères, les agences et leurs représentants syndicaux. Par cet accord, le Bureau du Conseil des ministres accepte que les syndicats soient les représentants légitimes des agents et reconnaît qu'une représentation effective doit passer par l'implication et la participation sincère des parties. Les syndicats, quant à eux, acceptent que le Bureau du Conseil des ministres opère conformément au cadre et aux directives généraux définis par le gouvernement.

Le Bureau du Conseil des ministres est chargé de gérer la politique du gouvernement quant à la rémunération et aux résultats des fonctionnaires. Le Trésor, en collaboration avec le Bureau du Conseil des ministres, applique pour les rémunérations un système de «soumission de propositions » (« remit system ») afin de garantir que les entités négociatrices utilisent des principes économiques et cohérents et que les systèmes de rémunération soient modernisés (par exemple pour favoriser de meilleures prestations et promouvoir l'égalité et l'équité).

Ce processus de soumission est utilisé pour déterminer les rémunérations d'une grande partie de la fonction publique ainsi que pour les salariés du secteur public travaillant dans les organismes publics non ministériels. Chaque entité négociatrice doit s'assurer tous les ans que le Trésor accepte ses propositions salariales. Le Trésor définit les paramètres de négociation qui serviront de cadre à ce processus. Il convient également de points de référence en matière d'accessibilité économique ainsi que de critères approuvés applicables aux propositions. En règle générale, les ministères devront démontrer que leur offre est économiquement viable et qu'elle ne devrait pas entraîner de pression inflationniste. Ils doivent également comparer leur rémunération à celles qui existent sur ce segment du marché du travail .

Les principales agences et les principaux organismes publics non ministériels doivent obtenir l'accord de leur ministre avant de soumettre leur proposition au Trésor. De plus, le nouveau Comité des rémunérations du service public aura le pouvoir d'examiner les offres particulièrement litigieuses.

Les organes d'examen des rémunérations se servent de données disponibles et de leurs propres recherches pour émettre des recommandations sur la rémunération des employés de leur secteur. Elles sont présentées au Premier ministre et aux secrétaires d'État en début d'année.

\subsubsection{Accords en matière de gestion financière}

Le budget présenté par le Chancelier (le ministre en charge du Trésor) détermine la somme totale allouée à l'ensemble des activités du gouvernement (relevant de son mandat ou discrétionnaires). Le pouvoir et la responsabilité de déterminer le plafond des dépenses ou les restrictions fiscales qui s'appliquent au gouvernement reviennent également au Chancelier. Le budget n'est donc pas le résultat de négociations politiques entre les ministres.

Le Trésor est juridiquement tenu de présenter deux prévisions économiques par an. À l'automne, le Chancelier présente un avant-projet de budget ainsi qu'un rapport d'étape et un point sur l'état de l'économie et des finances publiques. Le budget, présenté au printemps devant le Parlement, inclut la législation relative aux recettes ainsi que quelques plans de dépenses reflétant les priorités du gouvernement. Les examens de dépenses («Spending reviews») permettent de répartir les dépenses discrétionnaires entre les différents ministères. Ces examens étaient auparavant effectués une fois par an. Mais, lors de la prise de ses fonctions, l'actuel Chancelier a institué des examens pluriannuels. 
Ces études définissent les budgets administratifs de la plupart des ministères. Le processus de soumission de propositions permet également au Trésor de s'assurer que les rémunérations ne créent pas de pressions inflationnistes, soient cohérentes au vu de l'environnement fiscal global et qu'elles soient utilisées de manière optimale.

\section{Moderniser la gouvernance publique}

Le modèle classique d'organisation et de gouvernance des administrations publiques est né en Europe au $17^{\mathrm{e}}$ siècle. Son émergence coïncide avec la transition de structures de gouvernance archaïques vers des mécanismes mieux adaptés à l'importance croissante des activités commerciales privées et à l'introduction de systèmes parlementaires démocratiques. De nombreux responsables politiques ont contribué dans différents pays au développement de ce système, qui est toutefois le plus souvent associé au chercheur Max Weber $^{20}$. Ses fondements sont les suivants :

- l'autorité publique doit se fonder sur le droit et être exercée conformément aux lois ;

- les citoyens doivent, en des circonstances similaires, bénéficier d'une égalité de traitement, sans que leur position sociale ou leurs idées politiques n'entrent en ligne de compte ;

- $\quad$ il doit exister une administration publique professionnelle et politiquement neutre, qui serait ainsi à même de servir avec la même compétence tous les gouvernements et ;

- afin de garantir ces principes, la gestion des ressources humaines doit reposer sur un statut particulier, qui prévoit un emploi à vie au sein de l'administration publique.

La «nouvelle gestion publique » («New Public Management») désignait à l'origine un ensemble de mesures spécifiques introduites par le Royaume-Uni dans son administration publique. Cette méthode est rapidement devenue un véritable paradigme managérial de modernisation des services publics. Grand nombre de gouvernements l'utilisent depuis les années 1980.

Le terme «nouvelle gestion publique » revêt une acception très large ainsi qu'une grande complexité. Il recouvre une vague de réformes du secteur public qui s'est étendue au monde entier. La méthode se fonde, entre autres, sur les théories du «choix public » principal-agent et, tirée de la gestion d'entreprise de la «gestion des services ». Sa principale hypothèse est qu'accorder à la logique de marché une plus grande importance au sein la gouvernance publique permettra aux pouvoirs publics d'améliorer le rapport coût-efficacité de leur action, sans que ceci n'ait d'effet négatif sur les autres objectifs et considérations. On pourrait dire, en le comparant au modèle «weberien » classique, qu'il représente un mouvement des dispositions législatives et statutaires vers des objectifs,et des procédures établies vers des résultats et des gains d'efficience.

La nouvelle gestion publique se compose de trois groupes de politiques distincts. Le premier vise à réduire l'intervention du gouvernement dans l'économie par l'intermédiaire de la déréglementation et de la réduction des effectifs. Le deuxième relève d'accroître la concurrence : la sous-traitance et l'introduction de solutions axées sur les choix de consommation. Ces groupes ne rentrent pas dans le cadre de cette étude.

Le troisième ensemble, toutefois, sous-tend une nouvelle forme de gouvernance et de gestion des administrations publiques. Son hypothèse de base est que, pour être efficaces, l'organisation et la gestion de la production des services publics doivent être différentes du modèle weberien traditionnel. Ces politiques se fondent principalement sur les principes suivants :

- l'agent qui rencontre le « client » doit répondre à ses besoins et demandes ; 
- le «principe du service identique » doit faire place au «principe du service adapté », fondé sur une évaluation de la situation particulière du «client »;

- à des réglementations prescrivant des procédures correctes, il faut préférer des relations de nature contractuelle privilégiant les résultats ;

- le contrôle des ressources et les autres formes de contrôle ex ante doivent autant que possible laisser place à l'obligation de rendre compte, et enfin ;

- il faut permettre aux gestionnaires de promouvoir l'efficience et l'efficacité en leur accordant une plus grande marge de manœuvre quant à la structure et à la gestion de leur organisation.

Durant les 100 dernières années, les fonctions des administrations publiques se sont diversifiées pour englober diverses infrastructures physiques et immatérielles ainsi que des services sociaux et d'enseignement. Dans un rapport consacré à la réorganisation de l'administration centrale, le gouvernement finlandais ${ }^{21}$ a souligné l'hétérogénéité de l'administration publique moderne et fait valoir que ses différentes missions possèdent chacune leur propre logique et leur propre rationalité. La forme appropriée de gouvernance et de gestion publique dépend ainsi des tâches qui doivent être administrées et gérées.

\section{Étude de cas $\mathrm{n}^{\circ} 1$ : la diversité des agences en Nouvelle-Zélande}

Le Département de la jeunesse, de l'enfance et de la famille ${ }^{22}$ était un organisme public habilité à intervenir pour protéger et aider les enfants souffrant de mauvais traitements ou d'actes de négligence ou qui présentent des troubles du comportement. Le département était chargé de fournir logement et aide aux enfants en situation difficile ainsi qu'aux jeunes délinquants. II devait également évaluer les candidats à l'adoption et transmettait les demandes y afférentes au Tribunal de la famille. Enfin, il finançait les associations qui travaillaient avec les enfants et les jeunes ainsi que leurs familles.

Le Département était le principal employeur de travailleurs sociaux en Nouvelle-Zélande. La présence d'un fort esprit de corps, associé à un taux élevé de syndicalisation, explique le caractère traditionnel de la convention collective de ces employés: rémunération principalement fixée en fonction du poste occupé, existence d'une part liée aux performances mais progression relativement normalisée de la rémunération au sein de chaque catégorie.

L'Agence de développement économique de la Nouvelle-Zélande est une entité de la Couronne qui œuvre en faveur du développement économique du pays. Son Conseil est principalement composé de représentants du secteur privé. Elle propose une vaste palette de services et programmes qui recouvrent l'ensemble du cycle de vie des entreprises, des jeune pousses aux groupes d'exportateurs les plus établis : programmes de formation, informations de marché, financements, aide à la constitution de réseaux ou de partenariats.

L'agence dispose d'employés en Nouvelle-Zélande et à l'étranger. Elle recrute principalement dans le secteur privé. Le taux de syndicalisation est faible et il n'existe aucune convention collective. À chaque poste correspondent des échelons de rémunération; le traitement est fonction des salaires du marché, à compétences et expérience comparables, ainsi que des performances individuelles.

L'exemple finnois est convaincant. La gestion publique traditionnelle promulguée par Weber est sans doute, comme le font valoir certains spécialistes en droit administratif, la plus adaptée à la gestion et à l'exercice de l'autorité publique alors que la nouvelle gestion publique convient sans doute mieux à la production de services. Il s'agit d'un argument fort en faveur de modèles asymétriques de détermination des rémunérations où les modalités de traitement dépendent des caractéristiques et besoins professionnels de chaque organisation. 


\section{Questions systémiques}

\subsection{Rémunération}

Le coût de la main d'œuvre ainsi que les niveaux de rémunération sont des éléments fondamentaux de la structure de coûts des administrations publiques. Celles-ci doivent constamment chercher à rationaliser l'organisation et la mise en œuvre de leurs activités et introduire à cet effet des mesures visant à une meilleure productivité avec un même nombre d'employés, ou à des résultats similaires avec une maind'œuvre réduite. C'est pourquoi elles doivent éviter de verser des salaires supérieurs à ceux qui s'appliqueraient dans le secteur privé ${ }^{23}$.

Dans sa plus simple définition, la rémunération constitue une rétribution pour des services fournis ; elle fait à ce titre partie intégrante du contrat qui lie l'employeur et le salarié. Dans cette perspective, un traitement adapté correspond à celui qui est nécessaire pour recruter et fidéliser un nombre suffisant d'employés disposant des savoir-faire et compétences adéquats. Toutefois, l'emploi public est traditionnellement considéré comme une relation fiduciaire, et non comme une relation contractuelle. Les rémunérations étaient donc fixées de manière à permettre aux agents de bénéficier d'un niveau de vie approprié ${ }^{24}$. Un problème récurrent qui se pose dans l'administration publique est toutefois que l'évolution de la rémunération des gestionnaires n'a pas suivi celle du marché.

Le marché du travail est constitué d'un certain nombre de marchés secondaires correspondant à divers savoir-faire et compétences et à différentes zones géographiques. Le niveau et l'évolution de la rémunération varient entre ces différents marchés. Les critères individuels ont également gagné en importance là où il est difficile de trouver une main-d'œuvre qualifiée.

Les augmentations de salaire relativement élevées qui, en raison du manque de personnel compétent, peuvent exister sur un marché spécifique constituent normalement un aspect positif. La rémunération effective étant ajustée afin de refléter les conditions de marché, les compétences les plus rares seront progressivement allouées aux emplois où elles apportent la plus forte valeur ajoutée. Au fil du temps, des augmentations de salaire relativement conséquentes devraient également attirer davantage de maind'œuvre vers ces marchés spécifiques.

L'administration publique a longtemps été considérée comme un "marché secondaire distinct », ce qui est sans doute aujourd'hui encore partiellement vrai. Les rémunérations moins importantes qui y sont pratiquées ne devraient pas poser dans l'immédiat de problèmes de conservation du personnel. Mais elles pourraient toutefois provoquer un certain mécontentement des agents et des difficultés d'attirer de la maind'œuvre vers ces métiers.

Aujourd'hui, toutefois, la plus grande partie de l'administration publique est en concurrence avec les entreprises privées dans sa recherche de main-d'œuvre qualifiée. La gamme de ses activités s'est élargie, les emplois contractuels sont plus nombreux et la mobilité s'est accrue du fait que les employés recherchent une meilleure rémunération. Les salaires plus bas pratiqués dans cette partie du secteur public peuvent pénaliser le recrutement et la conservation du personnel. Dans le même temps, toutefois, les demandeurs d'emplois qui possèdent des compétences intéressantes ne tiennent pas seulement compte de la rémunération, mais également du caractère attractif de l'activité et des conditions de travail. La concurrence interne au sein de ces institutions ne devrait pas accroître les pressions qui existent déjà sur le marché.

Ces organisations doivent également relever d'autres défis. La rémunération relativement élevée proposée aux nouveaux entrants est un phénomène récurrent au sein des administrations publiques des pays membres de l'OCDE. On peut en parallèle constater une évolution moins rapide du traitement, et 
donc des niveaux de rémunération inférieurs à la moyenne pour la main-d'œuvre la plus qualifiée et expérimentée. La différenciation accrue des augmentations, nécessaire pour rectifier de tels déséquilibres, pèse lourdement sur les relations professionnelles.

Autre problème courant, les rémunérations en vigueur dans l'administration de certains pays membres de l'OCDE augmentent plus lentement que celles du secteur privé. La nécessité de réduire le déficit budgétaire est sans doute une des raisons cette situation. Le traitement des agents constitue une part importante des dépenses publiques et on pourrait donc estimer que limiter les augmentations serait plus efficace et moins dommageable que réduire plus radicalement les engagements publics. Cette situation pourrait aussi découler du fait que l'augmentation des dépenses non discrétionnaires limite les possibilités de dépenses discrétionnaires, notamment en ce qui concerne la revalorisation du traitement des agents. Ceci pourrait enfin s'expliquer par les différences de gains de productivité entre les secteurs public et privé, le secteur marchand disposant ainsi d'une plus grande marge de manœuvre en matière d'augmentations.

Deux autres problèmes récurrents plaident en outre en faveur d'une différenciation géographique de la rémunération. Tout d'abord, les bureaux de l'administration centrale sont pour la plupart situés dans les capitales ou dans les grandes villes, où le coût de la vie - et en particulier du logement - est supérieur à celui qui existe au sein d'autres régions. Dans le même temps, les organismes publics qui fournissent des services dans des régions isolées doivent parfois proposer des primes spécifiques ou un salaire plus élevé pour attirer et fidéliser un personnel qualifié.

La rémunération est un outil de gestion important. Le principal argument en faveur d'une détermination décentralisée des rémunérations est que les cadres publics doivent pouvoir y recourir pour réaliser leurs objectifs de performance et de résultats. Les différences relatives de traitement et les ajustements salariaux permettent de souligner quelles sont les attentes et de récompenser un comportement ou des performances satisfaisants. On peut également les utiliser à des fins de sanction. Des augmentations constamment supérieures à l'inflation renforcent les liens entre l'employeur et les salariés et fidélisent les agents. Au contraire, des augmentations systématiquement inférieures vont inciter les agents à se tourner vers d'autres emplois.

Les coûts de transaction sont un élément essentiel pour comprendre la manière dont l'employeur (privé ou public) gère les rémunérations. Lorsque les employés sont nombreux, procéder à des décisions personnalisées exigerait des ressources importantes. Les employeurs rationnels chercheront dès lors à normaliser les rémunérations, à moins que des avantages spécifiques et concrets ne découlent de la différenciation ${ }^{25}$.

Dans l'administration publique, cette normalisation consiste normalement à établir un système de grades, commun à l'ensemble des postes, chaque grade étant associé à un niveau de rémunération ou à une échelle de rémunération, elle-même subdivisée en échelons distincts. La progression au sein d'une échelle de rémunération est dès lors fondée sur l'ancienneté et le mérite; les compétences individuelles ne sont prises en compte que pour les promotions à un grade supérieur ${ }^{26}$.

Pour tendre vers une différenciation fondée sur les besoins opérationnels, on pourrait tout d'abord introduire des augmentations spécifiques fixes, définies de façon centralisé, en fonction du secteur ou de l'organisme, pour les employés possédant des compétences spécifiques ou travaillant dans des conditions particulières. Pour tendre vers une différenciation fondée sur les performances individuelles, il conviendrait par exemple de mettre en place une prime de performance, ou de subordonner toute progression au sein de l'échelle de rémunération à une évaluation discrétionnaire des compétences et performances de l'agent. 
La dernière étape de cette évolution consiste à transférer aux unités opérationnelles les pouvoirs décisionnels en matière de rémunérations. Cependant, celles-ci constateront que, prendre des décisions individuelles pour un nombre important de personnel, tout en recherchant un équilibre entre normalisation et individualisation de leurs systèmes de rémunération et des conditions de travail, exigerait de nombreuses ressources.

L'administration centrale n'a cependant pas la capacité de déléguer le financement de la masse salariale. Toutes les formes de détermination décentralisée des rémunérations doivent s'inscrire dans une structure économique qui assure un contrôle central des coûts totaux.

Enfin, il faut considérer les conséquences négatives que pourrait avoir une détermination arbitraire ou subjective des rémunérations. L'emploi n'est pas seulement une relation de nature économique mais également, dans la plupart des cas (et certainement dans le service public), une relation fiduciaire. Si les raisons qui sous-tendent les différences de traitement et d'augmentation ne sont pas comprises et acceptées par les agents, la politique de rémunération pourra conduire à une plus grande insatisfaction et à une plus grande aliénation professionnelles. Les liens entre l'employeur et l'agent et le taux de conservation du personnel s'en trouveraient affaiblis, ce qui aurait un impact négatif sur le moral des agents et leur efficacité.

Dans cette perspective, notons que la plupart des caractéristiques individuelles varient entre les individus en fonction de la loi de distribution normale (courbe en cloche). Il serait donc plus facile de pratiquer une différenciation individuelle de la rémunération à mesure que l'on rapproche de l'une ou l'autre extrémité de cette courbe. Il serait plus difficile de le faire pour la partie centrale de la distribution.

\subsection{Vers une détermination décentralisée des rémunérations}

Le mot « décentralisation » est ici une notion générale, impliquant un transfert de compétences depuis une autorité compétente unique vers plusieurs autres organes. La décentralisation peut prendre deux formes : transfert de compétences ou délégation. Le terme «transfert de compétences » désigne un transfert parallèle des pouvoirs et responsabilités. On parle au contraire de «délégation » lorsque les responsabilités continuent d'être assumées par l'autorité centrale qui a donc à ce titre le «dernier mot ». La décentralisation peut également parfois désigner la répartition géographique des activités. Dans de telles circonstances, nous utiliserons généralement dans ce rapport le terme « déconcentration ».

On peut raisonnablement affirmer qu'il y a de cela un siècle, la détermination des traitements était centralisée pour l'ensemble des administrations publiques centrales. Depuis, tous les pays membres de l'OCDE ont à tous le moins introduit des éléments de décentralisation. À ce jour, les facteurs favorisant cette tendance dans le secteur non marchand des pays membres de l'OCDE n'ont cependant fait l'objet que de peu de débats. Il apparaît que les tendances qui sont apparues en la matière dans le secteur privé, et notamment la décentralisation de la négociation salariale, ont eu impact significatif sur les accords conclus dans le service public ${ }^{27}$.

L'hétérogénéité croissante de la main-d'œuvre a également joué un rôle important au cours des 50 dernières années. Par conséquent, les sociétés privées ont élaboré des structures par grades et de rémunération qui sont mieux adaptées aux compétences spécifiques recherchées et qui encouragent un recrutement et une réorganisation appropriés des salariés ${ }^{28}$. Durant cette période, les administrations publiques des pays membres de l'OCDE ont diversifié leurs activités et, partant, leurs besoins en ressources humaines. 
Il existe une corrélation entre la décentralisation et le passage de systèmes d'emploi fondés sur l'ancienneté à des modèles dépendant davantage des exigences du poste de travail. Le fonctionnement d'un service public traditionnel (début de carrière à un jeune âge, emploi à vie, mobilité à l'intérieur de l'administration et système de promotion normalisé) nécessite un système de gestion centralisé, y compris pour les rémunérations. Cependant, les possibilités de décentralisation, et les incitations en la matière, évolue de manière croissante. En effet, on privilégie désormais les exigences du poste par rapport à l'ancienneté et de procédural orientation à une basée sur la performance.

La nécessité que la politique de rémunération du secteur public soit davantage différenciée semble de toute évidence être un des principaux moteurs de la décentralisation des rémunérations. S'il est possible de recourir à la différenciation dans un système centralisé, il semble rationnel de décentraliser cette pratique lorsqu'elle dépend d'informations fournies et détenues au niveau local. Cette «différenciation décentralisée » des rémunérations peut se baser sur les facteurs suivants :

- $\quad$ situation et exigences spécifiques de chaque unité organisationnelle ;

- compétences, mérite et performances particulières de chaque salarié et/ou ;

- rareté des compétences sur le marché du travail en question.

La décentralisation en matière de rémunération interagit avec les changements concernant la façon dont on détermine les rémunérations. Les lois concernant la rémunération conduisent à des contrats de rémunération individuels et collectifs. La détermination des rémunérations unilatérale conduit à la négociation salariale. Le niveau politique qui définit les statuts concernant les rémunérations décide souvent de se concentrer sur la structure, les principes et le mécanisme de comptabilité, et de donner la responsabilité de la négociation salariale et la détermination même des rémunérations à des fonctionnaires aux niveaux central et local. Les syndicats ont donc souvent, parfois sans le savoir, fait un premier pas vers la décentralisation et la différenciation en réclamant le droit de négocier les rémunérations et d'édicter des règles concernant les traitements par le biais de conventions collectives.

Les avantages d'accords de rémunération décentralisés seraient donc les suivants ${ }^{29}$ :

- Reconnaissance de l'hétérogénéité des services publics. La décentralisation permet de bénéficier de structures de rémunération et de grades plus diversifiées, adaptées aux objectifs organisationnels et aux divers services fournis par les organisations. Les départements et agences peuvent introduire, en vertu d'accords décentralisés, les structures de rémunération et de grades les plus adaptés à leur organisation.

- Clarification des objectifs organisationnels. Le fait d'être responsables de la rémunération et des systèmes de grades encourage les cadres du secteur public à réfléchir davantage aux objectifs de l'organisation qu'ils dirigent et à la manière dont le système de salaires et de primes peut contribuer à la réalisation de ses objectifs stratégiques.

- Encouragement de l'innovation. La décentralisation encourage les départements et agences à innover, tant pour ce qui est de l'organisation du travail que pour les différents systèmes de rémunération (primes d'équipe et primes individuelles liées à la performance).

- Augmentation des investissements dans la formation. La décentralisation permet aux organisations de concevoir des structures et des systèmes de récompenses qui incitent leurs agents à demeurer suffisamment longtemps pour que l'administration et l'individu tirent parti de l'investissement que représentait cette formation. 
- Réajustement des rémunérations. La décentralisation permet aux organisations d'aménager la rémunération de leurs agents en fonction de la situation spécifique du marché et d'aligner celle de leurs cadres sur les risques et responsabilités associés à leurs fonctions.

La détermination des rémunérations doit être décentralisée à des directeurs d'organisations opérationnelles relativement homogènes pour que ces avantages se manifestent. Cela ne sera pas possible tant que l'influence de la détermination des rémunérations reste au niveau politique dans les ministères. La décentralisation lui-même ne garantit aucun de ces avantages. Son résultat sera fonction de si, et de comment, les cadres des organisations opérationnelles responsables des accords en matière de rémunération et de grades exploiteront ces nouvelles opportunités. La détermination décentralisée des rémunérations présente également un certain nombre d'inconvénients ${ }^{30}$ :

- Coûts de transaction plus élevés. Des coûts de transaction sont associés à la détermination des rémunérations et à la communication des grilles de rémunération. La décentralisation a pour effet de remplacer la négociation salariale unique qui existait au sein du système centralisé par plusieurs négociations distinctes, ce qui accroît les coûts administratifs et de négociation.

- Opacité des signaux salariaux. Les personnes en recherche d'emploi, qui changent d'activité professionnelle ou qui suivent simplement l'évolution du marché, devront acquérir et traiter une plus grande quantité d'informations qu'avec un système centralisé. Les systèmes décentralisés sont également associés à une plus grande incertitude quant à la structure réelle des récompenses relatives, un grand nombre de structures de rémunération étant sujettes à de fréquents changements.

- Le comportement monopolistique ou monopsonistique se voit favorisé. La décentralisation peut exposer l'employeur à un comportement monopolistique lorsque le syndicat est le seul « vendeur » de main-d'œuvre au sein d'un marché local. Le syndicat pourra alors chercher à fixer une rémunération supérieure au taux d'équilibre du marché. D'autre part, le fait qu'une organisation soit le seul acquéreur d'une compétence particulière sur un marché local favorise les comportements monopsonistiques et les rémunérations peuvent alors être tirées vers le bas.

Il existe un large éventail d'accords portant sur la décentralisation de la rémunération dans la fonction publique, allant de conventions très restrictives à une décentralisation quasi-totale. L'accord de décentralisation est le plus souvent vertical, conclu entre une autorité négociatrice centrale et un nombre important d'entités habilitées relevant de niveaux organisationnels inférieurs. Il existe toutefois des exemples d'accords horizontaux, conclus entre un décisionnaire central et des entités distinctes situés dans chaque secteur ministériel. Les systèmes mixtes sont également une possibilité. Il existe donc quatre type d'accords : centralisés, horizontaux, décentralisés horizontalement et décentralisés verticalement. Le Tableau 1 présente les principales caractéristiques des systèmes des six pays sous examen par la présente étude. 
Tableau 1. Accords relatifs à la décentralisation de la rémunération

\begin{tabular}{|l|l|l|}
\hline Pays & Type de décentralisation & Contraintes \\
\hline Australie & $\begin{array}{l}\text { Transfert de compétences vertical } \\
\text { complet }\end{array}$ & $\begin{array}{l}\text { Paramètres de négociation } \\
\text { Accessibilité économique }\end{array}$ \\
\hline Danemark & Délégation verticale limitée & $\begin{array}{l}\text { Convention collective centrale } \\
\text { Accessibilité }\end{array}$ \\
\hline Finlande & Délégation verticale complète & $\begin{array}{l}\text { Accord sur les revenus } \\
\text { Convention collective centrale } \\
\text { Accessibilité }\end{array}$ \\
\hline Nouvelle-Zélande & $\begin{array}{l}\text { Transfert de compétences vertical } \\
\text { complet }\end{array}$ & $\begin{array}{l}\text { Paramètres de négociation } \\
\text { Accessibilité }\end{array}$ \\
\hline Pays-Bas & $\begin{array}{l}\text { Transfert de compétences } \\
\text { horizontale avec certains éléments } \\
\text { relevant d'une délégation vertical }\end{array}$ & $\begin{array}{l}\text { Paramètres de négociation } \\
\text { Accessibilité }\end{array}$ \\
\hline Royaume-Uni & $\begin{array}{l}\text { Formes diverses de délégation } \\
\text { verticale }\end{array}$ & $\begin{array}{l}\text { Paramètres de négociation } \\
\text { Approbation de l'autorité centrale } \\
\text { Accessibilité }\end{array}$ \\
\hline
\end{tabular}

Au Danemark et en Finlande, les accords relèvent de la délégation. L'existence d'une convention collective centralisée signifie que la compétence sera transférée aux parties centrales dans l'éventualité où les parties locales ne parviennent pas à un accord. Ce n'est qu'au Royaume-Uni que l'accord central est présenté comme un système de modération des salaires du fait que son système de soumission de propositions ( «remit system ») s'applique également au salaire proposé tandis que, dans les autres pays, les éléments correspondants concernent uniquement les autres aspects des accords conclus au niveau local.

Aux Pays-Bas, les accords diffèrent de ceux conclus dans les cinq autres pays en ceci que le «modèle du secteur» ne s'agit pas de la décentralisation mais d'une fragmentation de l'autorité politique centrale par un transfert de compétences auprès d'un certain nombre de ministères. La détermination des rémunérations demeure normalement centralisée et sous contrôle politique au sein de chaque secteur. Toutefois, ils comprennent également des éléments relevant d'une délégation dans le secteur de l'enseignement.

En Australie, les accords ne s'agissent pas formellement d'un transfert de compétences complet, puisque les conventions collectives doivent être approuvées par le ministre responsable. Cependant, on peut le classifier comme un transfert de compétences. On peut dire la même chose pour les arrangements en Nouvelle-Zélande, où la compétence en matière de la détermination des rémunérations a été transférée de l'administration au Commissaire aux services de l'État, et puis seulement formellement déléguée aux départements et aux agences.

Le risque d'une dispersion des rémunérations constitue un problème récurrent dans les pays n'ayant pas encore décentralisé la détermination de la rémunération. Comme noté au début de cette partie, les pouvoirs publics doivent, pour s'engager dans une opération de décentralisation, être favorables à une certaine différenciation salariale. Ceci implique un risque non couvert de dispersion des rémunérations entre salariés chargés de mêmes tâches et possédant des qualifications similaires, mais il semble de toute évidence possible de l'atténuer (voir les cas de l'Autriche, du Danemark, de la Finlande et de la NouvelleZélande) et d'éviter ainsi toute conséquence préjudiciable. Ces points sont abordés plus en détails dans la section 3.3.

Les administrations publiques craignent souvent que la mise en place d'une gestion décentralisée et différenciée de la rémunération ne fasse entrave à la mobilité interne au sein du secteur public. Il semble qu'il existe un problème de nature transitoire lié à l'assouplissement des systèmes statutaires uniformes, en particulier s'il ne concerne que certains secteurs de l'administration publique. Dans le même temps, il semble peu probable que les structures de rémunération fassent obstacle à la mobilité une fois que 
l'administration aura achevé sa transition vers un emploi axé sur les exigences du poste et vers un système de rémunération différenciée, et alors que les responsables opérationnels seront en mesure de négocier les salaires d'entrée avec les chercheurs d'emploi. Les systèmes de retraite ${ }^{31}$ aux droits non transférables peuvent cependant continuer de faire obstacle à la mobilité.

Les administrateurs du secteur public craignent également souvent qu'une délégation de la détermination des rémunérations ne vienne affaiblir le contrôle centralisé de l'évolution des coûts salariaux, risquant ainsi de provoquer une augmentation des coûts du fait de la demande interne pour des compétences rares. Cette question relève principalement de l'adéquation des accords de gestion financière, qui sont abordés plus en détails à la section 4.2.

La plupart des pays étudiés possèdent également des arrangements institutionnels qui prévoient le transfert de compétences de la détermination des rémunérations vers les entités infranationales (états en Australie, communes dans d'autres pays). Sous-traiter des travaux à financement public à des fournisseurs de service externes constitue aussi un tel transfert. Ces questions n'entrent toutefois pas dans le champ de cette étude.

\subsection{Cohérence et décentralisation des rémunérations}

Bien qu'ils ne soient habituellement pas explicités, les termes cohérent et cohérence ${ }^{32}$ sont des propriétés générales d'une politique de rémunération efficace dans les administrations publiques. Ils ne sont cependant nullement synonymes d'uniformité, et ne sont pas incompatibles avec une différenciation des rémunérations et des autres conditions de travail. Ils impliquent toutefois que toute pratique de différenciation doive résulter en une structure de rémunération logique et systématique.

Les pays membres de l'OCDE s'entendent largement sur le fait que, les administrations publiques étant devenues plus hétérogènes, il faudra, pour assurer la qualité et l'efficience des services, adapter davantage la détermination des rémunérations et les autres pratiques de gestion des ressources humaines aux compétences et performances individuelles ainsi qu'aux besoins opérationnels.

Le cadre général dans lequel s'inscrit la gestion centralisée des rémunérations peut inclure une part de différenciation dépendant de facteurs objectifs : nature du poste, niveau d'études, ancienneté et situation géographique. Cependant, l'existence d'évaluations et, partant, une meilleure connaissance de la personne et des activités ainsi qu'une participation plus directe à l'évolution et au bon fonctionnement de l'organisation, sont nécessaires à toute adaptation aux compétences et performances individuelles ou aux besoins opérationnels. Ces modes de différenciation exigeraient donc de décentraliser les politiques de rémunération (par délégation ou transfert de compétences). Une telle décentralisation est donc intrinsèquement liée à la volonté de s'adapter aux compétences et performances individuelles et/ou aux besoins opérationnels.

La cohérence désigne ici une condition ceteribus paribus : la rémunération et les conditions de travail doivent être identiques si tous les autres facteurs pertinents sont égaux par ailleurs. Un des corollaires de cette affirmation est qu'une différenciation non uniforme peut être cohérente, pour autant qu'elle résulte d'un ajustement convenable aux compétences et performances individuelles et aux besoins opérationnels.

La non uniformité est inévitablement associée à un certain degré d'incertitude ; une différenciation injustifiée de la rémunération et des autres conditions de travail pourrait engendrer des coûts importants pour l'administration publique concernée ${ }^{33}$. La mise en ouvre ou le renforcement de politiques managériales visant une cohérence suffisante de l'évaluation des compétences et des performances individuelles doit accompagner toute décentralisation des politiques de rémunération. En outre, les 
compétences de gestion opérationnelle des directeurs des organismes d'État devront être plus solides que celles dont disposent généralement les cadres de la fonction publique des systèmes centralisés.

Les mesures pris par le centre favorisant une plus grande cohérence des politiques de rémunération décentralisées comprennent notamment :

- l'élaboration et la diffusion de normes de référence ou de méthodes d'évaluation normalisées ;

- la mise en place, pour les différents postes, d'une norme de classification qui permettrait d'établir des statistiques complètes sur les rémunérations et, partant, d'évaluer la structure de rémunération ;

- l'élaboration et la mise en œuvre de mécanismes assurant une plus grande responsabilisation, d'une part concernant l'usage des pouvoirs décentralisés et, d'autre part, en matière de résultats , avec le développement des métriques appropriées et indicateurs; et ;

- des formations et autres formes d'appui de capacité pour les personnes dont l'activité est liée aux politiques de rémunération décentralisées.

La décentralisation des politiques de rémunération peut être partielle ou totale. Selon le contexte dans lequel ils évoluent, mais également selon leurs objectifs et leurs valeurs clés, les gouvernements pourront conserver une politique d'uniformité ou d'autres formes de contrôle centralisé sur certains aspects de la rémunération ou des conditions de travail. L'examen des pratiques existantes dans les pays membres de l'OCDE montre que ces notions sont, en pratique, utilisées de nombreuses manières: depuis une acceptation apparemment totale des modalités de différenciation locale, jusqu'au strict respect d'un cadre défini au niveau central selon lequel seules quelques rares décisions sont décentralisées.

Le fait de s'adapter aux niveaux de rémunération du marché constitue en soi un ajustement approprié aux compétences et performances individuelles. La main invisible du marché crée une structure de rémunération appropriée pour les administrations publiques qui poursuivent une telle politique. Cette démarche implique également qu'il existe une concurrence dans la recherche de compétences rares, que ce soit entre employeurs publics ou entre employeurs privés. ${ }^{34}$

On affirme souvent qu'une structure de rémunération et des conditions de travail homogènes sont nécessaires pour que la mobilité interne puisse exister dans l'administration publique. Toutefois, une décentralisation globale des politiques de rémunération permettrait aux organismes d'État de concevoir des politiques de rémunération adaptées à leurs besoins en termes de recrutement. Rien ne permet donc d'affirmer que des politiques de rémunération décentralisées, pour autant qu'elles soient suffisamment cohérentes, fassent entrave à la mobilité interne.

Les instances gouvernementales peuvent maintenir un contrôle centralisé sur l'age de la retraite et sur le montant des retraites ${ }^{35}$. Ceci est encore plus valable pour les systèmes de retraite fondés sur des prestations précises, où les coûts totaux n'apparaissent seulement après un grand nombre d'années, et pour les systèmes par répartition, où les coûts d'aujourd'hui n'ont rien à voir avec les activités d'aujourd'hui. Toutefois, l'administration peut maintenir un contrôle centralisé également sur les systèmes en fonction des contributions, pour des raisons d'équité.

Il convient de noter qu'une individualisation totale de l'ensemble des conditions de rémunération engendre d'importants coûts de transaction. L'employeur peut donc réaliser d'importantes économies en mettant en place des conditions d'emploi normalisées qui seront utilisées à moins qu'il existe des raisons 
suffisantes de s'en écarter. Les instances gouvernementales peuvent en outre décider de contrôler au niveau central la rémunération des directeurs généraux (cadres de la fonction publique).

\subsection{La relation principal-agent ${ }^{36}$}

En économie, la question de la «relation principal-agent» désigne le problème que pose le fait d'inciter une partie à agir au nom de l'autre. On le retrouve lorsqu'un «principal » propose de rétribuer un «agent » pour qu'il effectue certaines actions qui sont utiles au «principal » et coûteuses pour l'agent, ou dont la réalisation même pourrait s'avérer onéreuse.

Le contrat existant entre un «principal » et un «agent» est habituellement incomplet; il s'inscrit dans un univers incertain et risqué, caractérisé par une asymétrie d'informations. La capacité pour le «principal » de parvenir à un résultat optimal dépend de sa capacité à permettre à l' «agent » d'utiliser de manière appropriée l'autorité qui lui a été déléguée. Toutefois, l' "agent » possède ses propres valeurs et intérêts, et ce qui semble optimal de son point de vue peut ne pas l'être de celui du «principal ». En outre, le «principal » ne sait généralement pas si (ou dans quelle mesure) le contrat est ou a été rempli.

La délégation de la détermination des rémunérations depuis une autorité centrale unique vers plusieurs autres organisations résulte en une relation «principal-agent». La responsabilité finale des systèmes et structures de rémunération incombe à l'administration centrale, mais les résultats dépendront du comportement des entités habilitées. L'autorité centrale doit donc élaborer et mettre en œuvre des stratégies et des méthodes qui lui permettent de s'assurer que les objectifs opérationnels des entités habilitées (les «agents ») correspondent à ses propres objectifs stratégiques (en tant que «principal»).

Il convient de noter que la portée et la gravité de ce problème dépendront des ambitions de l'autorité centrale, notamment en ce qui concerne les systèmes de rémunération et leur cohérence. Il serait largement atténué si celle-ci acceptait l'existence de systèmes et structures de rémunération diversifiés et souhaitait seulement conserver un contrôle limité sur le niveau des traitements et leur évolution. Il disparaîtrait même si elle acceptait de transférer l'ensemble de ses responsabilités selon des modalités prédéfinies ${ }^{37}$.

La solution du problème «principal-agent» consiste à mettre en place des mesures incitatives appropriées pour que les choix rationnels opérés par les agents en vertu de leur intérêt personnel coïncident avec les choix désirés par le «principal ». Le «principal» devra donc porter son attention sur les aspects suivants :

- le caractère approprié et efficient de l'environnement dans lequel le contrat est conclu ;

- le caractère approprié et efficient de la conception du contrat ;

- l'efficience des mesures incitatives mises en œuvre pour l' «agent»;

- l'efficience des mécanismes de contrôle des activités de l'«agent » et des résultats, et enfin ;

- la capacité du «principal » à contraindre l'«agent » à rendre compte de résultats médiocres ou d'actions inappropriées. 
On pe
contrats $^{38}$ :

1. Le principe de la qualité informationnelle pose pour l'essentiel qu'il convient d'intégrer au contrat de rémunération toute évaluation de la performance qui (de façon marginale) révèle des informations quant au niveau d'effort consenti par l'«agent ».

2. Le fait de définir des mesures incitatives les plus «intenses» possibles n'est pas nécessairement optimal du point de vue du «principal». Le principe de l'intensité des incitations pose que l'intensité optimale des mesures incitatives dépend de quatre facteurs : l'augmentation des profits générée par l'effort supplémentaire, la précision de l'évaluation des activités souhaitées, la tolérance au risque de l'«agent» et son degré de réceptivité par rapport aux mesures incitatives.

3. Le principe de l'intensité du contrôle vient compléter la précédente démonstration : selon celui-ci, les situations où l'intensité optimale des mesures incitatives est élevée correspondent à des situations où le niveau optimal de contrôle est lui aussi important. Ceci s'explique du fait que le contrôle est un moyen coûteux de réduire la variance de la performance de l'agent, ce qui influe sur les profits dégagés lorsqu'il est également optimal d'«intensifier» les mesures incitatives.

4. Le principe de la compensation équivalente pose pour l'essentiel que l' «agent» doit évaluer de la même manière les activités qui, selon le "principal», ont une même valeur. Les «agents » peuvent prendre part à différentes activités. Celles qui ne sont pas contrôlées, ou qui sont moins contrôlées, seront délaissées, alors que celles dont le rendement marginal est supérieur pour l'agent seront favorisées. Privilégier certaines variables mesurables peut avoir des conséquences défavorables pour les autres.

\subsection{Négociations salariales}

À l'origine, les relations entre l'État et les fonctionnaires se fondaient sur un ensemble de droits et responsabilités mutuels. Les fonctionnaires devaient être fidèles et loyaux, en l'échange de quoi ils bénéficiaient de ce statut et jouissaient d'une rémunération garantie à vie, bien que le plus souvent modeste. Négocier une rémunération supérieure, que ce soit au niveau individuel ou collectif, «ne faisait pas partie du contrat ».

L'attitude de l'État employeur envers ses agents a connu depuis une évolution remarquable dans les pays membres de l'OCDE. Les relations fiduciaires laissent de plus en plus souvent place à des relations contractuelles qui privent les employés de l'État de leurs droits statutaires. L'État a abandonné l'authoritarianisme unilatéral et a reconnu que les agents ont donc légitimement le droit de faire connaître leurs intérêts et préoccupations.

Cette transition largement répandue vers le dialogue et la consultation peut prendre différentes formes. L'information, la consultation et la négociation constituent ainsi des modalités distinctes d'échange. La consultation et la négociation peuvent être des mécanismes exclusifs, mais aussi complémentaires. La nature de ces systèmes peut également différer, allant de la simple expression d'opinions à des négociations visant à établir des contrats formels. Bien que tous les pays étudiés dans ce rapport disposent désormais d'une forme de négociation salariale au sein de leur administration publique, ils ont institutionnalisé différemment le dialogue social et la détermination des rémunérations et conditions de travail. 
Toute négociation collective des rémunérations nécessite la présence de partenaires mandataires clairement identifiables. Ceci signifie généralement que le gouvernement doit désigner une ou plusieurs organisation(s) compétente(s) et lui/leur conférer le pouvoir de négocier et de signer des conventions collectives. En outre, il doit exister une ou plusieurs organisations suffisamment représentatives agissant au nom des employés de l'État. Les critères de représentativité et les procédures de négociation peuvent être prévus par la loi ou convenus entre les parties.

Les négociations salariales peuvent aussi bien être menées dans un contexte de détermination centralisée que de détermination décentralisée des rémunérations. La négociation salariale décentralisée introduit toutefois une nouvelle dimension à la détermination déléguée des rémunérations car elle instaure une relation «principal-agent». L' «agent », c'est-à-dire l'entité habilitée, est engagé dans deux relations contractuelles différentes: la première avec le «principal» et la deuxième avec les syndicats qui représentent ses salariés. Souvent, le «principal» souhaite que l'«agent» respecte son intention et le contrat qu'ils ont conclu mais, dans le même temps (le «principal » étant ici un gouvernement élu), il ne souhaite pas être tenu responsable de conflits inutiles entre l'«agent» et les syndicats. L' «agent» peut profiter de cette situation pour renégocier son contrat avec le «principal» de telle manière qu'il soit conforme à celui conclu avec les syndicats.

La mise en place d'un accord-cadre, conclu au niveau central entre un organe représentant l'État employeur et les syndicats nationaux (voir l'exemple du Danemark et de la Finlande) permet au gouvernement de mieux contrôler cette double relation contractuelle. Comme on l'a vu en Australie et en Nouvelle-Zélande, on peut cependant parvenir à un même cadre général par l'intermédiaire de paramètres de négociation élaborés au niveau central et d'un processus de soumission de propositions qui permet à l'autorité centrale de superviser leur mise en application.

\section{Étude de cas $\mathrm{n}^{\circ} 2$ : les différents accords existant en Australie}

La Loi sur les relations de travail prévoit six types d'accords professionnels. Le choix entre ces contrats dépend d'un certain nombre de facteurs de nature individuelle ou collective, qui ont également trait aux employeurs et employés, à la structure de représentation des salariés et au fait que le projet, l'entité ou l'activité constitue ou non une nouveauté. Tous les accords professionnels doivent être déposés auprès du Bureau du Conseil de l'emploi.

Un Accord professionnel australien («Australian Workplace Agreement») est un accord écrit individuel conclu entre un employeur et un employé. La salarié peut lui-même négocier son contrat ou choisir un intermédiaire.

Une Convention collective salariale («Employee Collective Agreement») est un accord écrit conclu entre un employeur et un groupe d'employés qui seront couverts par la convention. Les salariés peuvent faire appel à un médiateur. Les employés concernés votent pour approuver ces conventions.

Une Convention collective syndicale ("Union Collective Agreement») est un accord écrit conclu entre un employeur et un ou plusieurs syndicats. Le syndicat négocie au nom des employés. Les employés concernés votent pour approuver ces conventions.

Une Convention salariale pour sites nouveaux ( Employer Greenfields Agreement») et une Convention syndicale pour sites nouveaux («Union Greenfields Agreement») sont signées avant tout recrutement correspondant à de nouveaux projets ou de nouvelles entreprises.

Un Accord applicable à plusieurs entreprises («Multiple Business Agreement») est une convention collective qui permet à plusieurs employeurs de convenir d'une convention unique qui s'applique à l'ensemble de leurs activités. Un tel accord est généralement utilisé pour les franchises, structures où un certain nombre d'entreprises ont des activités similaires et souhaitent proposer des conditions de travail identiques.

Lorsqu'il n'existe aucun accord, des conditions générales d'emploi peuvent être décidés par le biais d'une sentence arbitrale (« award»). 
Les accords professionnels australiens fixent les conditions générales de travail, qui viennent remplacer les conditions générales prévues par la sentence qui s'appliquerait à défaut, à l'exception de certaines garanties. Les conventions collectives ne peuvent remplacer un accord professionnel australien, ou une autre forme de convention collective, qui n'ait pas atteint sa date d'échéance. L'accord professionnel australien remplace par contre toute convention collective ou précédent accord de travail qui s'appliquerait au salarié. II peut prévaloir sur toute condition prévue par la législation de l'État ou du territoire, pour autant qu'il spécifie lesdites conditions. II ne pourra toutefois prévaloir sur les lois de l'État ou du territoire en ce qui concerne l'hygiène et la sécurité du travail, l'assurance professionnelle ou les accords de formation.

Les conventions collectives sont généralement conclues avec un syndicat, mais également, comme en Australie, par le biais d'une autre forme de représentation salariale. Leur contenu peut varier. Leur principal objectif est de réglementer le contenu du contrat normalisé utilisé par l'employeur, y compris les systèmes de grades et les échelles de rémunération, lorsque de tels systèmes sont utilisés. Ils peuvent également couvrir d'autres questions relatives à la gestion des ressources humaines, en instituant par exemple des exigences minimales en matière de formation continue, ou encore, dans certains pays, être utilisés pour réglementer les processus de travail et autres questions managériales et opérationnelles.

Les modalités pratiques de la détermination des rémunérations varient également entre les pays. Le montant des salaires individuels par rapport aux grilles de rémunération générales peut être déterminé par des dispositions législatives ou par des conventions collectives. Lorsqu'ils sont individualisés et différenciés, les traitements sont déterminés soit par le biais de décisions unilatérales de l'employeur, d'accords individuels ou de conventions collectives. Des formes «mixtes» peuvent également être utilisées. Une convention collective peut par exemple comporter des clauses a minima et réglementer les procédures relatives à la détermination des rémunérations et aux griefs, mais ne pas aborder la fixation des salaires, qui revient à l'employeur ou est fixée par l'intermédiaire d'un contrat.

Le degré d'implication des syndicats dans ce processus varie donc entre les pays. Ceci témoigne des différences existantes en ce qui concerne leurs règles juridiques, le poids des syndicats et leurs caractéristiques ainsi que l'histoire et la culture des relations professionnelles et de politique publique. Cette étude abordera ces questions d'un point de vue factuel et ne s'intéressera pas aux causes ou effets de ces différences.

L'article 2 de la Convention $n^{\circ} 87$ de l'OIT sur la liberté syndicale et la protection du droit syndical (1948) prévoit que «les travailleurs et les employeurs, sans distinction d'aucune sorte, ont le droit, sans autorisation préalable, de constituer des organisations de leur choix, ainsi que celui de s'affilier à ces organisations, à la seule condition de se conformer aux statuts de ces dernières. ». Les dispositions de cet instrument s'appliquent à tous les travailleurs, sans distinction d'aucune sorte, et couvrent donc les employés de l'État. Les fonctionnaires doivent pouvoir créer et rejoindre les organisations de leur choix, sans autorisation préalable, afin de promouvoir et protéger leurs intérêts.

Dans les pays étudiés, la densité syndicale est plus élevée dans le secteur public que dans le secteur privé. Ceci s'explique sans doute principalement par la sécurité de l'emploi dont jouissent les fonctionnaires et par l'attitude tolérante ou favorable des autorités envers les organisations qui les représentent.

Les syndicats ont adopté des positions différentes quant à la décentralisation de la détermination des rémunérations. Les recherches menées dans le domaine indiquent que les syndicats traditionnels peuvent éprouver des difficultés à gérer une détermination « déléguée » des rémunérations, et que la mise en place de ces pratiques peut les inciter à modifier leurs organisations et leurs processus opérationnels et à remplacer ou former à cet effet leurs représentants syndicaux. Pourtant, il existe également des exemples où les syndicats ont modernisé leurs organisations et leurs méthodes de travail et sont à même d'utiliser la décentralisation à l'avantage de leurs membres. Il y a aussi des signes que la négociation des rémunérations décentralisée porte à plus de participation des membres dans la négociation des rémunérations et d'autres 
aspects de travail syndicalisé. Cependant, il semble généralement réticents, voir même franchement hostiles, à une différenciation individuelle des rémunérations, bien qu'il existe des exceptions ${ }^{39}$.

\section{Une analyse comparative}

\section{1. $\quad$ Arrangements institutionnels concernant la détermination des rémunérations}

Cette section traite de la manière dont les administrations centrales sont organisées pour gérer la détermination décentralisée des rémunérations. Comme nous le verrons ci-dessous, chaque pays dispose d'arrangements institutionnels spécifiques qui sous-tendent différents systèmes d'attribution des pouvoirs et de législation administrative.

Deux pays ont des accords peu conventionnels et manque de séparation entre les niveaux politiques et administratif. Les ministres sont toujours responsables pour la détermination des rémunérations au sein de l'administration centrale aux Pays-Bas (sauf dans le secteur l 'enseignement). Par ailleurs, les conventions collectives centrales, ne sont pas de même type que celles des autres pays. On pourrait plutôt les considérer comme des «conclusions communes », ultérieurement confirmées par des décisions du gouvernement. $\mathrm{Au}$ sein des « secteurs ministériels », le processus budgétaire et les négociations salariales ne semblent pas être nettement séparés. Le Royaume-Uni dispose d'un système à un seul niveau avec délégation formelle aux ministères sectoriels et entités sous-ministérielles. Cependant, le vrai contrôle semble être partagé entre le Trésor et les commissions d'examen indépendantes.

La convention collective centrale au Danemark et en Finlande joue le même rôle que les paramètres de négociation en Australie et en Nouvelle-Zélande, mais présente l'avantage d'avoir été décidée d'un commun accord avec la confédération nationale des syndicats et de lier les syndicats locaux. Un autre de ses avantages est qu'elle permet de conclure des accords portant sur des conditions normalisées s'appliquant à l'ensemble de l'administration centrale.

Trois de ces pays, le Danemark, la Finlande et la Nouvelle-Zélande, disposent d'organisations professionnelles centrales distinctes responsables de définir les paramètres du processus de négociation ; elles sont soit juridiquement indépendantes du pouvoir politique, soit gérées de façon séparée par un service du ministère chargé des questions organisationnelles. Dans ces pays, cette étude n'a relevé aucune indication d'un quelconque précédent ou interférence politique directs en ce qui concerne la détermination des rémunérations, à l'exception de l'Accord général sur les revenus en vigueur en Finlande. Il semble que ces organisations professionnelles aient joué un rôle essentiel dans la réalisation de réformes des rémunérations relativement efficaces. L'Australie semble être parvenue au même résultat suite à un transfert de compétences plus compréhensif. Au sein de son administration centrale, les questions de rémunération sont gérées par un ministère exerçant une responsabilité d'ordre général sur le marché du travail.

La comparaison entre le Danemark et les Pays-Bas est particulièrement intéressante. Au cours des années 1970, le Danemark a transféré toute autorité du domaine de la négociation collective des rémunérations depuis les ministères sectoriels vers une autorité centrale unique. Depuis, le pays a poursuivi sa politique de décentralisation et est actuellement en train d'introduire un nouveau système de rémunération conçu pour faciliter son adaptation aux besoins opérationnels locaux. En 1993, les Pays-Bas ont pour leur part choisi une autre orientation, transférant l'autorité d'une entité unique aux ministères sectoriel ${ }^{40}$. Depuis, cette évolution n'a plus concerné que le seul secteur de l'enseignement, au sein duquel des sous-secteurs ont pris en charge la négociation des rémunérations. 
Ce processus de centralisation danois semble trouver sa justification en tant que premier pas et condition préalable pour une ultérieure décentralisation. Ce type de centralisation était considéré comme nécessaire afin d'assurer la bonne gouvernance d'un réseau constitué d'un nombre important d'organismes habilités. Si tel est effectivement le cas, on peut donc émettre l'hypothèse que, aux Pays-Bas, l'évolution a été contrariée par l'absence d'une autorité centrale unique semblable à celle existant en Australie, au Danemark, en Finlande et en Nouvelle-Zélande.

Au Danemark comme en Finlande, le même service du ministère des Finances est responsable à la fois des négociations centrales et des relations professionnelles, ainsi que des politiques s'appliquant aux fonctionnaires et des réglementations statutaires. Quoi qu'il en soit, cette solution semble avoir bien fonctionné pour ces deux pays et est probablement l'expression d'un consensus bien établi entre les partenaires sociaux quant à la nécessité de ne pas entremêler ces deux dimensions. Les pays qui ont décentralisé la détermination des rémunérations et d'autres fonctions des ressources humaines ont trouver, néanmoins, nécessaires de garder la responsabilité des politiques et statuts au niveau ministériel.

L'Australie nous donne un exemple probant d'une séparation effective entre les processus budgétaires internes de l'État et ceux de négociation collective. Ainsi ce pays est-il en mesure d'éviter les situations où les affectations budgétaires deviennent un élément de la négociation des rémunérations. Il a également ainsi pu maîtriser le conflit implicite entre accords de détermination des rémunérations relevant d'une logique de marché et accords statutaires traditionnels. Cette séparation semble avoir été motivée par le désir de permettre aux diverses agences de fonctionner selon les mêmes conditions que tout autre employeur présent sur le marché du travail australien. En même temps, l'Australie n'est pas parvenue à mettre en œuvre un transfert de compétences total, du fait que, dans ce pays, les conventions collectives sont toujours censées respecter les paramètres de négociation édictés par l'autorité centrale.

La Nouvelle-Zélande se distingue par l'existence d'une Commission des services de l'État disposant de pouvoirs statutaires et de vastes responsabilités. Certains éléments semblent cependant indiquer qu'un tel ensemble de pouvoirs statutaires - comprenant la nomination de directeurs pour des durées limitées et l'évaluation de leurs performances - peut avoir des effets néfastes quant à son rôle de conseil et de consultation par rapport aux organismes qu'elle chapeaute.

\section{Étude de cas $\mathrm{n}^{\circ} 3$ : La Commission des services de l’État en Nouvelle-Zélande}

En Nouvelle-Zélande, le Bureau du Commissaire aux services de l'État joue un rôle central dans la promotion d'un service public impartial, professionnel et durable. Le Commissaire est à la fois directeur général de la Commission et titulaire de charges publiques. En cette dernière qualité, il travaille de manière indépendante sur un large éventail de questions ayant trait au fonctionnement du service public, des services de l'État et du secteur de l'État au sens large.

II nomme et emploie des directeurs de service public au nom de la Couronne, passe en revue leurs résultats au nom de leurs ministres de tutelle, enquête et établit des rapports sur la performance des différents ministères.

En vertu de la Loi sur le secteur de l'État, il dispose du pouvoir de négocier et de conclure des conventions collectives au sein du secteur public (bien que les directeurs concernés continuent d'agir en qualité d'employeurs). II a la capacité, dont il a déjà fait usage, de déléguer ce pouvoir aux directeurs, à condition que ces derniers consultent la Commission des services de l'État lors des négociations et qu'ils se conforment aux paramètres de négociation définis par les instances gouvernementales.

Les responsabilités du Commissaire recouvrent également les domaines suivants : promouvoir et développer au sein de la fonction publique des politiques et normes en matière d'administration du personnel et d'égalité des chances, ainsi que le leadership et les compétences d'encadrement ; fournir des conseils sur les systèmes de gestion ainsi que sur les structures et l'organisation du service public et des entités de la Couronne ; mettre en œuvre des normes d'intégrité et de conduite pour le service public, la 
plupart des entités de la Couronne ainsi que certaines autres agences; conseiller le gouvernement quant à la structure du secteur de l'État, et notamment pour la répartition des fonctions entre les agences.

Au Royaume-Uni, les arrangements institutionnels paraissent extrêmement flexibles, mais ceci, apparemment, n'a pas toujours été un facteur positif. L'introduction récente d'une nouvelle fonction de supervision - le Comité de rémunération du secteur public - témoigne d'un certain mécontentement quant au fonctionnement des arrangements actuels. Il ressort clairement des entretiens que les systèmes de rémunération n'ont pas été adaptés aux besoins opérationnels spécifiques autant que le gouvernement l'aurait souhaité et que l'administration s'est trouvée confrontée à des problèmes de cohérence.

En conclusion, un Bureau de l'État employeur fort, capable de définir les paramètres de négociation des rémunérations paraît être une base importante pour la décentralisation de la détermination des rémunérations.

\section{2. $\quad$ Accords en matière de gestion financière}

Cette section traite la question des arrangements budgétaires généraux et la façon dont ceux-ci constituent des cadres de référence et interagissent avec le processus de délégation de la détermination des rémunérations. Les accords de gestion financière sont essentiels au bon fonctionnement de tout système décentralisé de détermination des rémunérations.

$\mathrm{Au}$ sein de systèmes centralisés, l'administration centrale exerce un contrôle simultané sur les structures économiques comme sur la détermination des rémunérations et n'a aucune obligation à séparer ou formaliser ces deux processus. Tel n'est plus le cas en situation de décentralisation.

Ici, le problème de la relation principal-agent pose un problème particulier et, en fait, a joué un rôle important dans l'élaboration de cette théorie. On peut considérer que l'objectif premier du principal est d'obtenir des augmentations de salaire aussi élevées que nécessaire, et ce au centime près, alors que son objectif secondaire est de disposer de la flexibilité nécessaire pour prendre en compte les différences entre les augmentations de salaires souhaitées en fonction des divers secteurs, professions, lieux et personnes. Pour sa part, l'agent, c'est-à-dire l'entité locale habilitée, souhaite maximiser la base économique de son organisme, accroître le caractère attractif de ses emplois et éviter tout conflit avec ses employés et leurs syndicats. Ces questions seront abordées plus en détails à la section 3.4.

Il est donc nécessaire de séparer clairement le processus budgétaire du processus de détermination des rémunérations et éviter ainsi tout risque de les entremêler. L'agent préférera négocier une plus grosse enveloppe budgétaire que de mener des négociations agressives au niveau local. Comme le signalait un négociateur expérimenté, il prendrait alors le parti de ses employés et/ou de leurs syndicats contre l'autorité budgétaire plutôt que de représenter les intérêts du gouvernement lors des négociations.

La totalité des pays étudiés ont également procédé à la séparation effective des deux processus. Il existe cependant une différence entre le Danemark, la Finlande et les Pays-Bas, pays qui pratiquent la budgétisation descendante sur plusieurs années, et l'Australie qui recoure à la budgétisation ascendante plus traditionnelle. Le Royaume-Uni occupe une position médiane, du fait de la portée du mandat du ministre responsable du Trésor (le Chancelier). La Nouvelle-Zélande a pratiqué auparavent la budgétisation ascendante mais elle a introduit récemment des éléments considérables de la budgétisation descendante dans son processus budgétaire.

Tant que l'administration centrale garde la maitrise de l'ensemble du processus, elle sera en mesure de gérer l'enveloppe budgétaire de chaque sous-entité, successivement et en fonction de ses propres mérites, et ce du fait qu'aucune décision n'est prise tant que le processus n'a pas totalement abouti. Toute détermination décentralisée des rémunérations accroît les coûts de transaction ainsi que les risques 
inhérents à la méthode ; d'ailleurs, la plupart des autorités budgétaires considèrent qu'il est plus rationnel de traiter avec toutes les entités habilitées de façon simultanée et uniforme. Cela permet aux orientations politiques du gouvernement de se concentrer sur un nombre limité de sous-entités. Il existe deux exceptions : le Royaume-Uni, où son long processus de soumission («remit system ») influe également sur l'enveloppe disponible pour les augmentations de salaire et les Pays-Bas, où il y a de l'interaction entre le processus budgétaires et celui de la détermination des rémunérations avec les secteurs « ministériels ».

Afin de déterminer cette enveloppe, l'Australie, le Danemark, la Finlande et les Pays-Bas prennent explicitement en compte l'évolution des salaires au sein du secteur public, ce qui n'a rien de surprenant. En effet, les conditions et les rémunérations proposées aux fonctionnaires par les administrations publiques doivent être assez attractives pour pouvoir recruter les employés dont elles ont besoin. Les salaires peuvent être inférieurs à ceux du secteur privé, étant compensés par d'autres avantages; cependant les augmentations ne peuvent pas lui être systématiquement inférieures, sous risque de miner le pacte social entre l'État et ses agents et de réduire ainsi l'attraction qu'exerce le statut de fonctionnaire.

Chacun des pays étudiés dispose de sa propre méthode pour ce faire. Dans le cadre de cette étude, nous avons recherché des traces de modèles de référence formels qui établiraient un lien entre l'évolution des salaires au sein du secteur privé, le calcul de budgets des entités habilitées et la détermination de plafonds de coûts salariaux. L'unique modèle de référence officiel que nous ayons rencontré est celui de la Suède, bien que le modèle australien lui soit relativement semblable. Ceci ne nous permet cependant pas d'exclure qu'il puisse exister ailleurs d'autres modèles officieux ou règles empiriques, faisant partie des « secrets du métier » des services budgétaires, et donc inconnues du public.

\section{Étude de cas $\mathrm{n}^{\circ} 4$ : Le modèle de référence suédois}

Les administrations suédoises disposent d'un budget administratif unique sans aucun plafond de dépenses particulier permettant de limiter les coûts salariaux. Le point de départ de toute délibération politique sur les budgets des administrations ou agences est l'ajustement du budget de l'exercice précédent, basé sur des indices distincts pour les rémunérations, les charges locatives et autres frais administratifs.

Les deux agences gouvernementales (Statistiques Suède et l'Agence suédoise pour les employeurs du secteur public) établissent un indice annuel des augmentations de salaire au sein de l'industrie manufacturière privée. La moyenne du taux d'évolution de la productivité du secteur des services privé sur les 10 dernières années est ensuite retranchée de l'indice. Le résultat obtenu est appliqué à la totalité des budgets des agences, sauf lorsque la convention collective centrale prévoit des augmentations supplémentaires pour certaines activités ou professions. Dans ce cas, le budget des agences concernées se voit ajusté.

Cependant, les délibérations politiques peuvent déboucher sur des augmentations ou des réductions des budgets par rapport à l'ajustement normalisé.

La Nouvelle-Zélande compte plutôt la capacité des entités habilitées à accroître suffisamment leur productivité pour pouvoir financer les augmentations de salaire. Celles n'étant pas en mesure de le faire doivent présenter et défendre leur dossier de demande de fonds supplémentaires, dossier précisant, entre autres, leurs salaires relatifs et les conséquences potentielles sur le recrutement et la conservation du personnel.

Chaque pays détermine l'enveloppe budgétaire selon des modalités différentes. L'autorité budgétaire $^{41}$ est partout un acteur essentiel, mais dans les pays disposant d'une convention collective centrale, le bureau de l'État employeur joue également un rôle capital. Les ministères sectoriels sont bien évidemment toujours impliqués dans la détermination de l'enveloppe budgétaire. Un important facteur en ce qui concerne la stabilité du système est probablement que, durant le processus de détermination de l'enveloppe budgétaire destinée aux augmentations de salaire, il existe une interaction directe avec l'entité habilitée locale. Ceci semble dépendre du fait que l'ajustement portant sur le budget de l'exercice 
précédent soit déterminé par chacune des entités locales habilitées ou bien qu'il soit basé sur un ajustement normalisé.

Comme nous l'avons noté plus haut, le processus en Australie est similaire à celui de la Suède tel que décrit ci-dessus. La principale différence est que l'Australie semble procéder à une évaluation discrétionnaire du besoin d'un ajustement correspondant aux ajustements de salaires «normaux » sur le marché du travail. Certains salariés australiens voient leurs rémunérations définies en fonction de normes salariales négociées, qui peuvent affecter les évaluations précédentes.

Au Danemark, les budgets des entités habilitées font l'objet d'un ajustement lorsqu'il s'avère nécessaire pour satisfaire aux exigences d'une convention collective particulièrement coûteuse. Un autre élément propre au modèle danois est que la convention collective centrale permet de procéder à une correction rétroactive égale à $80 \%$ des différences enregistrées entre l'évolution des salaires du secteur privé et ceux du secteur public.

Tableau 2. Établissement de l'enveloppe budgétaire afférente aux augmentations de salaire

\begin{tabular}{|l|l|l|l|}
\hline Pays & $\begin{array}{c}\text { Acteur principal/ } \\
\text { autres acteurs }\end{array}$ & $\begin{array}{c}\text { Interaction entre } \\
\text { négociation des } \\
\text { rémunérations et } \\
\text { budget }\end{array}$ & $\begin{array}{l}\text { Principal élément moteur de } \\
\text { l'enveloppe }\end{array}$ \\
\hline Australie & Bureau du budget & $\begin{array}{l}\text { Basé sur un } \\
\text { ajustement normalisé, } \\
\text { aucune interaction } \\
\text { directe }\end{array}$ & $\begin{array}{l}\text { Résultat du processus } \\
\text { budgétaire }\end{array}$ \\
\hline Danemark & $\begin{array}{l}\text { Bureau du budget } \\
\text { et Bureau de l'État } \\
\text { employeur }\end{array}$ & $\begin{array}{l}\text { Basé sur un } \\
\text { ajustement normalisé, } \\
\text { aucune interaction } \\
\text { directe }\end{array}$ & $\begin{array}{l}\text { Résultat de la convention } \\
\text { collective plus correction } \\
\text { rétroactive pour les } \\
\text { différences par rapport au } \\
\text { secteur privé }\end{array}$ \\
\hline Finlande & $\begin{array}{l}\text { Bureau du budget } \\
\text { et Bureau de l'État } \\
\text { employeur }\end{array}$ & $\begin{array}{l}\text { Basé sur un } \\
\text { ajustement normalisé, } \\
\text { aucune interaction } \\
\text { directe }\end{array}$ & $\begin{array}{l}\text { Accord général sur les } \\
\text { revenus }\end{array}$ \\
\hline Nouvelle-Zélande & Bureau du budget & $\begin{array}{l}\text { Basé sur un } \\
\text { ajustement normalisé, } \\
\text { aucune interaction } \\
\text { directe }\end{array}$ & $\begin{array}{l}\text { Résultat du processus } \\
\text { budgétaire }\end{array}$ \\
\hline Pays-Bas & $\begin{array}{l}\text { Bureau du budget } \\
\text { et ministère de } \\
\text { I'Intérieur }\end{array}$ & $\begin{array}{l}\text { Basé sur un } \\
\text { ajustement normalisé, } \\
\text { avec interaction } \\
\text { directe }\end{array}$ & $\begin{array}{l}\text { Résultat du processus } \\
\text { budgétaire }\end{array}$ \\
\hline Royaume-Uni & Bureau du budget & $\begin{array}{l}\text { Ajustement } \\
\text { discrétionnaire et } \\
\text { interaction directe }\end{array}$ & $\begin{array}{l}\text { Résultat du processus de } \\
\text { soumission (« remit system ») }\end{array}$ \\
\hline
\end{tabular}

Deux des pays étudiés ne présentent pas de séparation claire entre le processus budgétaire et celui de la détermination des rémunérations. Les ministères sectoriels des Pays-Bas participent tous deux au processus budgétaire et sont responsables de la détermination des rémunérations. Il semble qu'ils n'aient pas toujours activement recherché de solutions au sein de leurs propres budgets mais qu'ils tendent plutôt à solliciter des fonds supplémentaires, fonds qui leur ont parfois été octroyés. Au Royaume-Uni, il semble que, dans le cadre de leur processus de soumission («remit system»), les entités habilitées négocient avec le Trésor. 
En Finlande, l'Accord général sur les revenus joue un rôle prépondérant et s'applique à une vaste majorité d'entreprises nationales et de salariés tout en permettant de fixer l'agenda politique et social sur plusieurs années. Les facteurs pouvant l'expliquer remontent probablement à la situation de la Finlande à la fin de la Seconde Guerre Mondiale, à l'origine d'une culture profondément enracinée de cohésion et de collaboration nationales. Les budgets des agences sont généralement conçus pour intégrer l'inflation prévue ainsi que les augmentations de salaire précisées dans l'accord sur les revenus. La convention collective centrale couvrant le secteur de l'État n'est donc plus qu'un simple cadre secondaire venant en complément de l'accord sur les revenus.

\section{Étude de cas $\mathrm{n}^{\circ} 5$ : Le pacte social en Finlande}

Le premier Accord général sur les revenus (Inkomstpolitisk uppgörelse) fut négocié en 1968. II s'agit d'un ensemble d'accords officiels trilatéraux ${ }^{42}$ pouvant couvrir une vaste palette de questions d'ordre économique et politique, tels que les salaires, l'impôt, les retraites, les indemnités de chômage et les frais de logement. Par le biais de ces accords, le gouvernement, les syndicats et les employeurs s'efforcent de s'entendre sur ce que seraient, pour l'économie nationale, les meilleurs choix en matière de croissance économique et de salaires réels. II est ensuite mise en œuvre par le biais des conventions collectives centrales et des accords des secteurs secondaires.

Ils ne sont cependant pas prescrits par la loi. Si les organisations nationales des employeurs et celles de leurs salariés ne s'entendent pas, aucun accord exhaustif ne sera signé. Dans un tel cas, des négociations inconditionnelles concernant des rémunérations sont menées par chaque fédération de syndicats, sans que l'État n'y participe.

Le gouvernement finnois considère que l'accord de 2005-2007 a permis de stabiliser le marché du travail et de dynamiser la consommation et l'emploi au niveau national.

Une enquête conduite au mois de mai 2004 montre qu'une majorité qualifiée d'employés finnois préféraient un tel accord général à des négociations individuelles menées par les différentes fédérations syndicales. Au mois de juin 2006, le Congrès de l'organisation centrale des syndicats finlandais fit part de son soutien vigoureux à une telle coopération entre gouvernement et partenaires sociaux dans le domaine de la politique salariale.

Le problème de la relation principal-agent inhérent à toute délégation de la détermination des rémunérations faisait que les autorités budgétaires ${ }^{43}$ chargées d'exercer leur contrôle sur la totalité du processus éprouvaient certaines réserves quant à savoir si les entités habilitées respecteraient ou non les intérêts, voire même les instructions, de leur gouvernement. Un certain nombre d'inquiétudes sont apparues, comme par exemple celle de voir les entités habilitées se montrer trop généreuses ou encore que les agences entrent en concurrence entre elles et surenchérissent afin d'attirer les meilleurs employés. Elles auront ainsi tendance à ne pas souhaiter déléguer leur autorité sans soit conserver un contrôle minimum, soit introduire certains mécanismes compensatoires.

Il arrive ainsi communément, du moins dans un premier temps, que l'administration centrale garde sa mainmise sur l'approbation des décisions et accords salariaux locaux. Elle pourra également, dans le cadre du budget de chaque sous-entité, maintenir ou introduire certains plafonds de dépenses limitant les coûts salariaux. Le Danemark recourt encore à cette pratique, mais uniquement en ce qui concerne les «agences bureaucratiques ». Sont exclues les agences au caractère plus fonctionnel pouvant disposer de revenus externes.

Il apparaît que le meilleur mécanisme compensatoire est un processus budgétaire parfaitement autonome de détermination des rémunérations, permettant de pratiquer un ajustement normalisé des budgets de l'ensemble des entités habilitées. Un régime budgétaire strict et la conviction que les frais salariaux doivent leur être intégrés permettent de réduire le risque qu'une entité habilitée se montre trop complaisante. De tels mécanismes n'empêcheront pas une entité locale d'attirer à elle un employé d'une autre agence en «l'achetant», mais elle ne pourra pas le faire systématiquement du fait qui lui faudra financer son offre selon un budget ajusté de façon uniforme. En conséquence, l'Australie a aboli toute restriction autre que le seul principe d'accessibilité. 
On doit également remarquer que les employeurs entrent en concurrence pour une main-d'œuvre parfois rare, parfois abondante. Un tel phénomène est fondamentalement positif, et ce, même s'il implique deux employeurs publics, du fait qu'il renforce l'efficience du marché du travail. Cela signifie également que les administrations publiques doivent déterminer leurs rémunérations de façon à ce que le service public soit suffisamment attractif par rapport aux autres possibilités s'offrant aux agents et aux chercheurs d'emploi.

Un ajustement normalisé des budgets des entités habilitées ne va cependant pas sans poser problème.

Sur le marché, la rémunération relative des différents savoir-faire n'est pas quelque chose de statique ; le versement d'une compensation normalisée pour les augmentations de salaire désavantagerait certaines entités par rapport à d'autres. Plus problématique encore, le fait que les gains de productivité potentiels varient selon les activités. Les agences qui peuvent automatiser et simplifier leurs processus ont plus de chance d'accroître leur potentiel de productivité que celles qui ont affaire avec des gens. Le recours à une déduction de productivité uniforme signifierait en fait que certaines entités habilitées seraient exposées à des réductions budgétaires annuelles réelles alors que d'autres pourraient tirer parti de leurs gains de productivité pour procéder à des augmentations de salaire et pour accroître leurs coûts ${ }^{44}$.

Au fil du temps et au fur et à mesure que s'accumuleraient leurs effets, ces mécanismes en viendraient à entraîner certaines dans des situations intenables où elles se verraient incapables de verser des salaires corrects à leurs employés ou de réaliser les missions et/ ou d'obtenir les résultats que l'État attend d'elles. D'autres entités habilitées pourraient disposer d'importantes ressources économiques superflues et verser ainsi à leurs employés des salaires plus élevés que ceux que percevraient d'autres fonctionnaires occupant le même type de poste et ayant les mêmes compétences.

Les pays qui fondent leurs processus budgétaires sur des ajustements normalisés au sein des entités habilitées doivent ainsi évaluer de façon régulière leur effet sur la base de ressources économiques et sur les salaires relatifs de chacune d'elles. Une solution alternative pourrait être de regrouper les entités une fois accru leur potentiel de productivité puis de recourir à des ajustements normalisés distincts pour chaque groupe. Au cours de notre étude des six pays concernés, nous n'avons trouvé aucun élément explicite à ce sujet, bien qu'il s'agisse de toute évidence d'un aspect implicite de leur processus budgétaire.

\subsection{Gouvernance des salaires et autres formes de rémunération}

Cette section traite la question de la gouvernance des salaires des fonctionnaires de l'État et autres formes de rémunération; elle n'aborde pas la question des accords de gestion financière ${ }^{45}$. Elle considère :

- la mise en œuvre de politiques concernant les salaires et autres formes de rémunération s'appliquant à l'ensemble des services de l'État ;

- la conception et l'étendue de la décentralisation de l'autorité habilitée à déterminer les rémunérations et ;

- le soutien fourni aux directeurs responsables de la détermination des rémunérations au niveau local.

La décentralisation des salaires et d'autres formes de rémunération ne correspond quasiment jamais à un transfert total des compétences. Cela peut être le cas en ce qui concerne certaines d'entre elles, alors que d'autres peuvent simplement avoir été déléguées ou être restées centralisées ${ }^{46}$. Les gouvernements ayant procédé à un transfert de compétences pour la détermination des rémunérations (sous réserve 
d'accessibilité) ont également d'autres politiques et d'autres priorités qu'ils souhaitent que leur administration mette en œuvre et/ou respecte.

Un concept essentiel à cet égard est celui de cohérence (voir la section 3.3). Les instances gouvernementales ne souhaitent pas voir de trop grandes disparités d'emploi se développer au sein de leurs diverses administrations, et ce, en partie pour des raisons d'équité, mais également du fait qu'elles considèrent que celles-ci entravent la mobilité au sein des administrations publiques. Une autre raison encore est qu'une coordination nationale des activités syndicales impliquerait une même coordination chez l'employeur. Les pays ayant fait l'objet de cette étude traitent de différentes façons ce besoin de cohérence et de coordination de la part de l'employeur.

Tableau 3. Coordination centrale de la détermination des rémunérations

\begin{tabular}{|l|l|l|}
\hline Pays & Acteur central & Principaux moyens \\
\hline Australie & $\begin{array}{l}\text { Ministère du Travail et des Relations } \\
\text { professionnelles }\end{array}$ & $\begin{array}{l}\text { Paramètres de négociation } \\
\text { Suivi des conventions collectives } \\
\text { locales par l'administration centrale }\end{array}$ \\
\hline Danemark & Autorité de l'État employeur & Convention collective centrale \\
\hline Finlande & Bureau de l'État employeur & Convention collective centrale \\
\hline Pays-Bas & Ministère de l'Intérieur & Paramètres de négociation \\
\hline Nouvelle-Zélande & Commission des services de l'État & $\begin{array}{l}\text { Paramètres de négociation } \\
\text { Approbation des conventions } \\
\text { collectives locales par } \\
\text { l'administration centrale }\end{array}$ \\
\hline Royaume-Uni & $\begin{array}{l}\text { Présoramètres de négociation } \\
\text { Approbation des conventions } \\
\text { collectives locales par } \\
\text { l'administration centrale }\end{array}$ \\
\hline
\end{tabular}

Le Danemark et la Finlande disposent de systèmes de conventions collectives à deux niveaux. Cela permet à l'organisme de négociation central (qui, dans ces deux pays, fait partie du ministère des Finances) de choisir dans quelle mesure il inclura au sein de la convention centrale des conditions cohérentes s'appliquant à l'ensemble du gouvernement, et jusqu'à quel point il déléguera son pouvoir décisionnel aux entités habilitées pour décider de telle condition. Il peut également fixer certaines conditions normatives au sein de la convention centrale, conditions pouvant être modifiées ou remplacées par le biais d'une convention locale. Les entités locales habilitées sont liées par celle-ci et ne peuvent en appeler au niveau politique. Les choix de l'organisme de négociation central doivent cependant être approuvés par les syndicats.

L'Australie et la Nouvelle-Zélande ont des systèmes de négociation collective à un seul niveau. Dans ces pays, l'organisme de supervision central publie des paramètres de négociation que les entités habilitées doivent utiliser et mettre en application; il s'assure également qu'ils soient respectés. Ce travail de supervision concerne les questions structurelles et les formes de rémunération autres que les salaires. 


\section{Étude de cas $n^{\circ} 6$ : Les conventions collectives salariales centrales au Danemark}

Au Danemark, les négociations salariales au sein de l'administration centrale ne s'inscrivent pas dans les limites d'une enveloppe budgétaire fixe mais sont plutôt étroitement contrôlées par le ministère des Finances. Elles deviennent ainsi une composante d'un plus vaste dialogue social entre le gouvernement et les confédérations syndicales nationales. Des conventions distinctes sont signées avec les principales organisations syndicales de fonctionnaires, à savoir, l'Association des organisations des employés de l'Etat danois (Statsansettes Kartel), les syndicats appartenant à la Communauté de négociation des fonctionnaires et des employés municipaux (Stats-og Kommunalt Ansattes Forhandlingsfællesskab) et l'organisation des diplômés d'université, la Confédération danoise des associations professionnelles (Akademikernas Centralorganisation).

Un nouveau système de rémunération a été introduit en 1997 et s'applique désormais aux deux tiers des fonctionnaires de l'administration centrale. Une grande partie des augmentations de salaires personnelles est déjà allouée par la convention centrale et, jusqu'ici, le rôle des conventions locales était minime, se limitant presque uniquement aux éléments de rémunération liés à la performance.

Quatre-vingts pour cent de la différence entre les augmentations au sein du secteur privé et celles au sein du secteur de l'année précédente sont ajoutés ou soustraits des augmentations convenues en vertu de la convention centrale. Ce lien entre l'évolution des salaires dans les deux secteurs a facilité les négociations salariales centrales en réduisant un élément d'incertitude affectant les syndicats.

Les statistiques centralisées au sein de la base de données ISOLA permettent d'établir des comparaisons entre les salaires proposés pour des tâches similaires au sein de différents ministères/agences et sont à disposition des syndicats comme des entités locales habilitées.

Le Royaume-Uni dispose d'un système similaire mais ses arrangements de supervision des négociations décentralisées sont bien plus complexes. La majorité des ministères et agences britanniques ont exprimé leur inquiétude quant au fonctionnement du système dit «de soumission » (« remit system») ou du moins vis-à-vis de certains de ses aspects, considérés comme trop bureaucratiques. Ainsi, dans le cas des agences d'État, les offres salariales sous soumises à plusieurs niveaux d'examen avant approbation finale, y compris par leur ministère de tutelle et le Trésor. De plus, les ministères et les agences contestent la contribution d'un tel système à l'efficience du processus de détermination des rémunérations, particulièrement lors de négociations internes portant sur moins de $1 \%$ de la masse salariale.

\section{Étude de cas $\mathrm{n}^{\circ} 7$ : Le système britannique de soumission de propositions (« remit systems »)}

Un système de soumission de proposition est un processus par lequel une autorité centrale surveille ou approuve des offres ou des politiques salariales locales avant leur mise en œuvre.

II peut être conçu de nombreuses façons différentes et peut aller de systèmes centralisés imposant l'approbation de l'administration centrale de toutes les composantes d'une offre salariale locale, jusqu'à des systèmes purement consultatifs où l'entité habilitée peut choisir les éléments qu'elle souhaite soumettre à approbation.

Là où la détermination des rémunérations est décentralisée, un tel système serait plutôt sélectif que déterminant, mais aurait plus qu'une simple valeur de conseil. L'administration centrale ne surveillerait que les seuls éléments perçus comme revêtant une importance particulière pour la mise en œuvre des politiques de l'État ou la cohérence de l'ensemble du système de rémunération. L'entité habilitée aurait la possibilité d'écarter ses conseils mais devrait dans ce cas motiver sa décision objectivement et professionnellement.

Dans les pays ayant un système de négociation à deux niveaux, les conventions collectives remplissent un grand nombre des fonctions du système de soumission. Il est cependant possible que certains éléments qui lui sont propres soient intégrés à leurs conventions collectives centrales.

Les systèmes de soumission offrent à l'employeur central un outil flexible lui permettant de surveiller les processus décentralisés de détermination des rémunérations et de promouvoir le niveau de cohérence souhaité au sein des systèmes de détermination des rémunérations et des autres conditions d'emploi, particulièrement lorsqu'ils sont associés à des paramètres de négociation mis à jour chaque année. Ils 
permettent d'appliquer un critère de subsidiarité lorsqu'il s'agit de déterminer le juste équilibre entre cohérence et adaptation au niveau local. Il est possible de gérer leur portée par le biais des paramètres de négociation. Ces derniers permettent également d'élargir graduellement le champ d'application de la décentralisation au moyen d'une résolution progressive des questions qu'ils traitent.

Nous n'avons pas procédé à une analyse détaillée des conventions collectives centrales et des paramètres de négociation officiels au sein des pays étudiés mais trois éléments se distinguent.

Généralement, les pensions et autres formes de prestations de retraite sont toujours gérées au niveau central. Ceci peut notamment s'expliquer du fait que de nombreux systèmes de retraite sont encore fondés sur des prestations précises et/ou des systèmes par répartition et, qu'à ce titre, il s'agit d'engagements à long terme, ou bien encore du fait que les systèmes de retraite uniformes renforcent la cohérence tout en encourageant la mobilité interne. Une transition vers un système qui serait fonction des contributions ${ }^{47}$ permettrait cependant d'obtenir les mêmes résultats, tout en permettant une convergence des systèmes publics et privés. Le choix entre consommer aujourd'hui ou bien demain, après la retraite, deviendrait plus évident et il serait alors possible de décentraliser les décisions portant sur les contributions.

Plusieurs pays ont conservé pour leurs postes des systèmes de grades uniformes, même après avoir décentralisé la détermination des rémunérations. Ceux-ci jouent le rôle de systèmes de classification et permettent de surveiller l'évolution des salaires et d'établir des statistiques sur les salaires moyens pour chaque type de poste ainsi que sur les niveaux de salaires relatifs au sein de chaque entité habilitée.

Tous ces pays ont encouragé leurs agences à inclure dans leurs systèmes de rémunération une part liée à la performance. Néanmoins, celle-ci ne semble représenter aujourd'hui qu'une petite partie de l'enveloppe salariale totale. Généralement, la performance est évaluée par le supérieur hiérarchique direct et les employés peuvent en référer à l'échelon supérieur au cas où la décision ne les satisferait pas. On a souvent pu observer que les superviseurs hésitent à établir des évaluations négatives; il existe de toute évidence un risque de dérive en ce domaine et il doit être pris en compte ${ }^{48}$.

Le manque de transparence peut également poser problème. Au Royaume-Uni, par exemple, les composantes de salaire liées à la performance semblent être largement acceptées et soutenues par la plupart des ministères et agences, mais leur mise en œuvre semble rencontrer un moindre succès. Il semblerait que la majorité des employés du secteur public ne comprend pas bien le fonctionnement du système et qu'ils estiment que son véritable objectif est de réduire leur rémunération totale. De nombreux commentaires soulignent également le manque de transparence de ces mécanismes.

La totalité des pays traitent aujourd'hui encore au niveau central les questions de rémunération et autres conditions d'emploi s'appliquant aux hauts responsables. Ceci est tout à fait compréhensible étant donné que les dirigeants des entités habilitées appartiennent à ce même groupe.

La détermination des rémunérations est une activité exigeante dont la plupart des responsables opérationnels n'avaient aucune expérience avant qu'elle ne soit décentralisée. Il ressort de l'étude menée dans plusieurs pays que la période de transition allant depuis l'introduction de tels systèmes au plein développement de leur potentiel a souvent tendance à se prolonger outre mesure du fait d'un manque de formation et de soutien adéquats. Souvent, l'administration centrale semble avoir davantage cherché à maintenir son pouvoir de contrôle plutôt qu'à promouvoir des systèmes et structures salariaux adaptés aux besoins opérationnels de chaque entité habilitée.

Les pays disposant d'une convention collective centrale ont tendance à établir des statistiques salariales précises à l'intention de l'administration centrale en se basant sur un système commun de grades ou de classification. Celles-ci permettent aux négociateurs centraux et locaux de comparer les salaires de 
fonctionnaires occupant des postes similaires. Les pays disposant d'un système de négociation collective à un seul niveau ont tendance à utiliser des analyses des salaires plus superficielles, souvent menées par des consultants externes.

De plus, les systèmes permettant de surveiller l'utilisation et les résultats des processus décentralisés de détermination des rémunérations paraissent souvent peu développés. Les auditeurs parlementaires danois ont par exemple examiné la mise en œuvre du nouveau système de rémunération en vigueur dans le pays. Leur rapport souligne l'absence d'outils adéquats et de procédures systématiques de suivi et de documentation des résultats des négociations salariales au niveau local ainsi que le manque de retour d'informations du niveau local vers le niveau central. Ils font également remarquer que de tels outils doivent rester simples, clairs et opérationnels et qu'ils doivent permettre d'établir des comparaisons entre les données issues des divers organismes.

De plus, la question de la délégation des responsabilités n'est pas toujours correctement prise en compte lors de l'évaluation de la performance des responsables opérationnels. Ceci pourrait être le signe d'une certaine asymétrie des résultats, c'est-à-dire que les avantages d'avoir procédé à des réformes salariales appropriées ne suffisent pas à contrebalancer les inconvénients de l'apparition de conflits internes du fait d'une opposition à leur égard. Si tel était le cas, cela ne ferait que contribuer au manque d'adaptation constaté dans nombre de situations spécifiques au sein des pays objets de cette étude.

\subsection{Gouvernance et autres questions relevant des ressources humaines ${ }^{49}$}

Cette section traite la question de la gouvernance par l'administration centrale de la gestion pratique des ressources humaines au sein des sous-entités; elle n'aborde pas la question des salaires et autres formes de rémunération. L'accent portera sur l'interaction entre, d'une part, l'entité centrale responsable des questions afférentes aux ressources humaines au sein de l'administration centrale et, de l'autre, ses autres composantes. Le Tableau 4 dresse la liste des organisations étudiées, précisant lesquelles sont également responsables des questions de rémunération.

Tableau 4. Gouvernance et autres questions relevant des ressources humaines

\begin{tabular}{|l|l|l|}
\hline Pays & Acteur & $\begin{array}{l}\text { Relation par rapport aux } \\
\text { questions de rémunération }\end{array}$ \\
\hline Australie & $\begin{array}{l}\text { Commission australienne des } \\
\text { services publics }\end{array}$ & Aucune \\
\hline Danemark & Autorité de l'État employeur & Intégration \\
\hline Finlande & Bureau de l'État employeur & Intégration \\
\hline Nouvelle-Zélande & $\begin{array}{l}\text { Commission des services de } \\
\text { l'État }\end{array}$ & Intégration \\
\hline Pays-Bas & Ministère de l'Intérieur & Intégration \\
\hline Royaume-Uni & $\begin{array}{l}\text { Bureau du Conseil des ministres } \\
\text { et Commissaire à la fonction } \\
\text { publique }\end{array}$ & Aucune \\
\hline
\end{tabular}

La discussion sur la cohérence dans la section précédente est significative pour la discussion de cette section. Il existe un nombre de domaines où l'administration centrale souhaite influencer le comportement des responsables opérationnels dans le domaine de la gestion des ressources humaines, soit afin d'obtenir une meilleure cohérence soit afin d'avancer leur objectifs politiques. Parmi eux figurent la réduction des arrêts maladies, la promotion de la diversité ethnique et de l'égalité des sexes. Ce rapport n'aborde pas ces questions, mais il s'avère que certains aspects de l'égalité des sexes en termes de rémunération doivent être adressés pour l'ensemble du gouvernement. La Finlande présente le seul exemple, où la convention collective actuelle pour le secteur de l'État comprend une réserve spécifique pour les augmentations de salaire supplémentaires pour les femmes à bas salaire. 
L'objectif premier des hauts responsables et/ou le perfectionnement des cadres supérieurs est d'améliorer les capacités et les compétences des dirigeants, particulièrement dans le domaine de la gestion des performances. Cependant, l'impression générale que l'on retire des entretiens est que le suivi et l'évaluation systématiques des compétences et des performances des dirigeants sont rarement pratiqués. La seule exception est la Commission des services de l'État néo-zélandaise puisque c'est son commissaire luimême qui choisit et nomme les hauts responsables des autres administrations centrales.

La documentation sur les valeurs du service public n'est pas répandu en dehors des sites des pays anglophones mais ceci ne pourrait n'être que l'expression d'une différence de culture administrative plutôt que d'une plus grande importance accordée au sujet. Ces trois pays ont adopté des codes formels de déontologie. La Commission australienne des services publics se distingue particulièrement, avec sa doctrine de gestion basée sur les valeurs («value-based management»), et du fait de ses nombreuses activités. Parmi celles-ci, la publication d'un exposé sur les valeurs du service public australien, d'un Code de déontologie ainsi que la nomination d'un Commissaire spécial à la protection du système de mérite.

\section{Étude de cas $\mathrm{n}^{\circ} 8$ : Gestion de la parité hommes-femmes}

Les marchés du travail des pays membres de l'OCDE se distinguent par deux différents types d'inégalité hommesfemmes. La plupart des contre-mesures visent la discrimination manifeste à l'embauche et en ce qui concerne les rémunérations et les avancements.

Cependant, il existe au sein de ces marchés des professions et des segments à prédominance soit masculine soit féminine. De plus, les rémunérations de marché ont tendance a être bien plus faibles pour ces dernières. Ceci ne peut s'expliquer par des facteurs objectifs et rationnels; il s'agit bien plutôt de la résultante de causes historiques et culturelles ainsi que d'une forme de discrimination structurelle.

II est difficile de la contrer par le biais d'une détermination décentralisée des rémunérations avec ajustements normalisés des budgets des entités habilitées. Un responsable opérationnel qui s'y essayerait se rendrait rapidement compte qu'il lui faudrait financer de telles augmentations en réduisant celles des autres employés. Du fait de verser des salaires supérieurs à ceux du marché à certains employés et des salaires inférieurs à d'autres, il se retrouverait vite dans une situation vulnérable.

Ainsi ce type de discrimination structurelle ne pourra-t-il être contré que par l'administration centrale. Celle-ci peut cibler les professions et/ou les secteurs pertinents, leur affecter des fonds supplémentaires, tout en s'assurant que ceux-ci seront utilisés de façon correcte au moyen de clauses dans les conventions collectives centrales ou les paramètres de négociation officiels.

Ces questions de relations professionnelles et de conventions collectives occupent une très grande place sur les sites Internet des autorités centrales du Danemark et de Finlande, ce qui s'explique du fait du système de négociation à deux niveaux en vigueur dans ces pays. En outre, ce système accroît d'autant la nécessité que l'administration centrale communique des informations et des consignes claires aux entités habilitées de niveau secondaire. Il semble cependant que ceci se fasse au détriment d'autres questions de ressources humaines non liées aux salaires. On peut établir ici une comparaison avec la Commission des services de l'État de Nouvelle-Zélande. Celle-ci ne signe aucun accord ou convention mais se contente de surveiller et de conseiller les entités de négociation locales. Elle propose également un nombre relativement important de consignes, de conseils et de services dans les autres domaines de la GRH.

\subsection{Le processus de détermination des rémunérations}

Cette section est consacrée à la façon dont les responsables opérationnels gèrent la détermination des rémunérations. Nous avons mené un certain nombre d'entretiens avec deux représentants d'entités habilitées, issus de chacun des pays étudiés ${ }^{50}$. Ils n'ont pas été choisis de façon aléatoire mais proposés par certains contacts dans ces pays, contacts qui les considéraient comme des exemples intéressants. Il est donc possible qu'ils ne soient pas représentatifs de la moyenne des entités habilitées. 
Ces entretiens ont permis de dégager un certain nombre de thèmes communs pertinents en mesure de mieux nous faire comprendre les défis et problèmes propres à la détermination décentralisée des rémunérations. En voici quelques-uns :

- l'augmentation inhérente des coûts de transaction qu'ils entraînent et la nécessité de créer une valeur ajoutée qui lui corresponde ;

- la mesure dans laquelle les systèmes par grades, les échelons et échelles de salaire et les systèmes d'avancement automatique ou semi-automatique doivent être remplacés par des conventions adaptées ;

- la conception et l'utilisation d'éléments liés à la performance au sein des systèmes de rémunération ;

- le recours à des consultations avec des pairs et à des analyses comparatives sur les rémunérations par rapport à celles d'autres secteurs et employeurs ;

- la participation des syndicats au processus décentralisé de détermination des rémunérations ;

- le rôle de l'employé lui-même dans un tel processus.

En Australie, la politique du gouvernement est que les directeurs d'agences établissent des contrats de travail individuels (accords professionnels australiens - «AWA») au bénéfice de tous leurs employés. Cette individualisation entraîne cependant une hausse des coûts de transaction et l'on a donc pu en déduire que les agences n'y recourent que lorsqu'il existe un véritable besoin opérationnel, comme par exemple pour les cadres supérieurs et les agents spécialisés. Cependant, de tels contrats peuvent également introduire une part de flexibilité du fait que les agences n'ont plus à consulter le ministère du Travail et des Relations professionnelles avant de signer un contrat individualisé. Il leur est donc ainsi plus facile de satisfaire à un besoin spécifique par ce biais plutôt qu'en procédant à une modification de la convention collective. Quoi qu'il en soit, le directeur de l'agence est en dernier lieu responsable de s'assurer que le contrat AWA respecte les paramètres stratégiques promulgués par le gouvernement australien.

Il semble qu'en Australie les conventions collectives soient essentiellement utilisées sur des lieux de travail à faible taux de syndicalisation où n'existe pas de négociateur syndical représentatif.

Dans tous les pays étudiés, la principale raison d'être d'une décentralisation du processus de rémunération est la nécessité de permettre aux responsables opérationnels d'adapter leur système de rémunération à leurs propres besoins opérationnels; il est donc nécessaire d'y inclure davantage de différenciation. Ce résultat n'a pas été pleinement réalisé, la plupart des entités habilitées préférant la voie de la facilité, c'est-à-dire de conserver l'ancienne structure de rémunération. L'on ne peut cependant pas exclure la possibilité que l'adaptation et la différenciation ne se développent au fur et à mesure que se renforceront l'expérience et le savoir-faire des responsables opérationnels.

La Nouvelle-Zélande offre un bon exemple de décentralisation complète et cohérente. Il n'existe pas dans ce pays de système ou de pratique de rémunération commun ou imposé par l'administration centrale ; les différents services publics doivent ainsi planifier leurs rémunérations dans le cadre de leur propre planification stratégique d'ensemble. Il en résulte une vaste palette d'accords de rémunération ${ }^{51}$. Certaines entités peuvent appliquer à leurs employés un seul et unique système, tandis que d'autres préfèrent recourir à différents types d'accords (en termes de critères d'avancement, de grilles de salaires et de l'utilisation d'études de marché et d'autres données), en fonction des différents postes ou familles de postes. Cependant, dans tous les cas, les systèmes de rémunérations s'appliquent à l'ensemble des employés 
pertinents, et ce qu'il existe ou non de conventions collectives. Ceci s'explique du fait qu'il est plus difficile et plus coûteux de gérer et d'appliquer différents systèmes de rémunération à des employés effectuant le même type de travail et que cela risquerait également de créer de fâcheuses inégalités.

Le seul exemple d'un système d'évaluation formel des nouveaux accords salariaux décentralisés provient du Danemark. Les auditeurs parlementaires danois ont examiné le nouveau système de rémunération en vigueur dans le pays. Leur évaluation est globalement positive et ils prennent note du fait que tous les organismes examinés ont adopté des politiques salariales locales. Dans le même temps, cependant, ils ont regretté que les critères d'augmentation de salaire ne soient pas suffisamment liés aux objectifs de l'entité habilitée. Bien au contraire, ceux-ci sont essentiellement fondés sur les qualifications professionnelles et personnelles ainsi que sur les fonctions. Ils ont également regretté qu'aucun des organismes examinés ne fût en mesure de démontrer que son nouveau système de rémunération avait eu le moindre effet sur leur productivité ni sur la qualité de ses activités.

Rien de surprenant en cela, car il faudra du temps aux responsables opérationnels pour développer les compétences nécessaires permettant d'en tirer le meilleur parti. Du fait du caractère très consensuel du système social danois, il est nécessaire de donner aux syndicats locaux le temps nécessaire pour s'y adapter.

Il ressort la même impression des entretiens conduits en Finlande où l'introduction progressive du nouveau système pour les employés de l'État a pris une bonne quinzaine d'années. Cette lenteur s'explique de plusieurs façons. Premièrement, la dépression économique du début des années 1990. De plus, il a fallu l'introduire dans les limites de l'enveloppe budgétaire existante. Les ministères et les agences manquaient peut être de préparation et ce n'est qu'il y a trois ans que fut lancé un programme de formation sur la détermination des rémunérations. Il semble également que les syndicats n'aient pas été suffisamment préparés.

L'exemple du secteur universitaire finnois illustre très bien les problèmes rencontrés lors de l'introduction d'un système décentralisé de détermination des rémunérations. Un groupe d'universités (représentant $25 \%$ de la fonction publique) fut parmi les pionniers et s'attela de façon ambitieuse à définir un nouveau système de rémunération, et ce, dès 1995. Cette première tentative aboutit à un échec. La barre avait été fixée trop haut et le système devint rapidement trop complexe à gérer. De plus, on ne peut parvenir à aucun consensus quant à savoir comment gérer l'opposition des syndicats. Le ministère de l'Éducation et le Bureau de l'État employeur élaborèrent conjointement un système commun et simplifié. Les syndicats le validèrent au début de l'année 2006. Il est fondé sur l'existence de systèmes distincts d'évaluation et de grades pour le personnel académique et les autres salariés. Les évaluations de compétences et de performance sont établies d'un commun accord par l'employé et son superviseur ou bien transmises au supérieur hiérarchique immédiat. Puis, elles sont agrégées au niveau des différentes universités et enfin comparées et ajustées afin d'éviter toute dérive.

Ce qui s'est passé aux Pays-Bas est tout aussi riche en enseignements. Les 13 «employeurs sectoriels » bénéficient désormais d'une plus grande liberté quant à l'affectation de leurs ressources au sein de leurs budgets et à la possibilité de différencier les conditions générales de leurs contrats de travail. À l'origine, il n'existait qu'un seul système de grades de rémunération pour tous les ministères. Cela est encore très souvent le cas car, au début, les employeurs ministériels ne firent que copier l'ancien système. Depuis, cependant, un petit nombre de modifications lui a été apporté.

Aux Pays-Bas, la décentralisation de la détermination des rémunérations ne concerne que le niveau sectoriel $^{52}$. Au sein de l'administration centrale, les responsables de moindre niveau hiérarchique n'ont pas la capacité de différencier les rémunérations, hors quelques rares éléments mineurs. Les employeurs sectoriels ont maintes fois proposé l'introduction de systèmes de rémunération liés à la performance mais 
n'ont jamais pu parvenir à s'entendre avec les syndicats sur leur conception. L'obligation d'accord interdit aux employeurs de prendre toute décision unilatérale et ceux-ci se sont jusqu'ici abstenus de subordonner les augmentations de salaire à un accord portant sur des une part de rémunération liée à la performance. Il existe cependant un certain nombre de systèmes de ce type, par exemple au niveau des secteurs provinciaux.

Le Royaume-Uni offre un exemple parlant des problèmes de cohérence. L'ancien système consistant en un petit nombre d'accords très centralisés s'est vu remplacé par un autre selon lequel les ministères et les agences détermineraient eux-mêmes les rémunérations. Le fait que ces organismes n'aient pas tous les mêmes capacités financières pour satisfaire à leurs besoins salariaux entraîne une certaine divergence et une moindre cohérence salariale entre eux. Une étude menée par le gouvernement en 1996-98 révèle que l'écart moyen entre les salaires au sein des ministères ne progresse que peu, ce qui semble être le signe d'une divergence négligeable. Nous disposons de certaines données plus récentes indiquant que celle-ci est peut-être actuellement bien plus importante pour des ministères, des agences ou des professions précises.

Pour des raisons historiques, il existe sur le marché du travail de la plupart des pays développés des différences de salaire totalement injustifiées entre les professions à prédominance féminine et celles à prédominance masculine. Les affectations budgétaires comme les conventions collectives centrales sont normalement établies de façon normalisée et le fait de procéder à de moindres augmentations de salaires à l'égard de certains groupes afin d'accroître ceux des femmes exerçant des professions mal rémunérées ne ferait qu'entraîner de nouveaux déséquilibres et exacerber le ressentiment de certains. Le seul exemple de mesure centralisée corrigeant les déséquilibres que nous avons observé est en Finlande où on trouve une réserve spécifique pour les augmentations de salaire supplémentaires pour les femmes à bas salaire.

\section{Étude de cas $n^{\circ} 9$ : Garanties contre les dérives des systèmes décentralisés de détermination des rémunérations}

Un système de rémunération n'est pas une simple question de finalités, mais également de valeurs et de l'introduction d'une nouvelle culture. Sur un plan abstrait, il permet de définir la relation entre employeur et employé. Un système de grades de rémunération local ne pourra s'appliquer durablement que s'il est fondé sur des principes largement acceptés et si l'employeur se montre crédible quant à son intention de les respecter.

Les systèmes décentralisés de détermination des rémunérations comportent plusieurs dangers, tels que le favoritisme, l'arbitraire voire même des comportements ouvertement discriminatoires. De tels travers porteraient tort à la crédibilité des valeurs du service public, à l'environnement professionnel même et, en dernier lieu, au système de rémunération tout entier. Ils pourraient résulter en des problèmes d'aliénation, de mécontentement, de manque de motivation et en des difficultés accrues de recrutement et de conservation du personnel.

Les systèmes de rémunération doivent donc être conçus de façon à fournir des garanties contre de telles dérives. Ils devraient inclure des mécanismes de traitement des réclamations crédibles, tels que des procédures de revue interne des décisions salariales ou la soumission des décisions salariales contestées devant des commissions d'appel indépendantes. Les syndicats sont également souvent autorisés à porter à l'attention des instances de supervision les plaintes et les éléments de preuve. Et finalement, les responsables opérationnels peuvent être formés et aidés pour prendre des décisions salariales plus équitables et appropriées. Certaines formations spéciales sur la parité hommesfemmes et la diversité ethnique pourraient également être envisagées.

Les relations et l'implication syndicales sont extrêmement puissantes au Danemark et en Finlande, du fait de leurs forts taux de syndicalisation et de leurs systèmes de conventions collectives à deux niveaux.

Parmi les autres pays, la Nouvelle-Zélande offre l'exemple d'une politique volontariste visant à une implication constructive des syndicats. Ses fondements sont l'accord de «Partenariat pour la qualité » que le gouvernement a signé en 2000 avec le plus important syndicat du service public (l'Association du service public), accord ultérieurement reconduit. Une des façons d'assurer la participation des syndicats est de créer un groupe de travail conjoint en mesure d'examiner la gestion des rémunérations ou de la 
performance pendant toute la durée d'une convention collective. De nombreux ministères disposant de conventions collectives ont parfois l'obligation (en vertu de dispositions explicites au sein de la convention elle-même) d'impliquer ou de consulter les syndicats pertinents lors de l'analyse de marché et du processus d'ajustement des salaires annuels. Toute modification des rémunérations qui s'ensuivrait s'appliquerait à l'ensemble des employés du ministère et non au seul personnel syndiqué couvert par la convention collective.

Cette implication des syndicats en Nouvelle-Zélande est facilitée du fait que les organismes d'État considèrent, en accord avec le principal syndicat du secteur public (PSA), que les systèmes de rémunération doivent être équitables, transparents, mis en application de façon cohérente, peu coûteux, simples à comprendre et à gérer, capables d'attirer et de retenir des agents de qualité et qu'ils doivent se conformer aux paramètres de négociations fixés par le gouvernement. Quoi qu'il en soit, en ce domaine, les avis divergent. Les organismes d'État ne sont pour leur part pas favorables à un système de rémunération universel, bien qu'ils adhèrent à certains principes généralement appliqués, alors que les syndicats souhaitent une plus grande normalisation au sein des différents services publics.

Au Royaume-Uni, les relations avec les syndicats ont été moins harmonieuses. Les principales organisations de fonctionnaires (regroupées au sein de la CSSU) n'ont pas accepté la décision prise en 1994 concernant la délégation de la détermination des rémunérations ; en outre, ils n'ont jamais approuvé le démantèlement du système de négociation centrale ni la nouvelle orientation en la matière. Cependant, ils semblent maintenant conscients du fait que les ministères et les agences ne souhaitent absolument pas revenir à l'ancien système centralisé et que les responsables opérationnels se sont rendu compte des avantages que présente le système de délégation. Actuellement, les syndicats se montrent favorables à une approche nationale globale des questions des rémunérations et des conditions y afférentes.

\subsection{Résultats}

Nous ne disposons que de peu de données concrètes quant aux résultats des systèmes décentralisés de détermination des rémunérations. La plupart des évaluations sont issues des commentaires émis par les personnes interrogées. Lorsqu'elles étaient corroborées par d'autres analyses similaires de personnes différentes, par de la documentation ou par des analyses de leurs conditions et conséquences, nous les avons considérées comme crédibles. Les résultats en termes de niveaux de rémunération ou les caractéristiques précises des systèmes mis en place n'ont pas été examinés, cette analyse se limitant aux perspectives de gouvernance et de processus.

La principale raison d'être d'une telle décentralisation est de permettre aux responsables opérationnels d'adapter les arrangements du domaine de la gestion des ressources humaines aux besoins stratégiques de leur organisation. Un des points essentiels sera donc de savoir dans quelle mesure les entités habilitées ont su tirer parti de cette nouvelle capacité d'adaptation des structures salariales de leur organisation à ses besoins stratégiques. De nombreux éléments laissent à penser qu'une telle évolution est en cours dans tous les pays étudiés.

Quoi qu'il en soit, il s'agit sans aucun doute d'un processus très lent; il faudra sans doute bien plus de temps que ce que prévoyaient les plus ardents défenseurs de la décentralisation pour que la totalité des résultats escomptés ne se matérialisent. La Finlande a mis en œuvre son nouveau système de rémunération il y a environ 15 ans et le Danemark il y a environ 10 ans, mais aucun de ces deux systèmes n'est encore parvenu à maturité. Il semble que cette lenteur s'explique par le fait qu'il s'agit ici d'un processus d'apprentissage. Afin de pouvoir en tirer pleinement avantage, les responsables opérationnels comme les représentants des employés doivent acquérir des compétences et de l'expérience en ce domaine ainsi qu'en ce qui concerne l'analyse des besoins stratégiques de leur organisation. Un renforcement insuffisant des capacités avant son introduction ou une méfiance vis-à-vis du sérieux des intentions de l'administration 
centrale feront que les entités habilitées feront preuve d'une prudence excessive, préférant alors préserver des structures similaires à celles des anciens systèmes centralisés.

Le corollaire logique est qu'un soutien adéquat de l'administration centrale est essentiel pour que les résultats escomptés se réalisent. Ce soutien peut prendre la forme d'une sélection et de la formation des cadres dirigeants, de la diffusion de manuels et d'autres types de recommandations, ainsi que d'outils statistiques en mesure d'aider les responsables opérationnels à évaluer leurs propres structures de rémunération et à les comparer avec celles d'autres entités habilitées. Certaines données semblent indiquer qu'un manque de soutien retardera la matérialisation des résultats souhaités, qu'il contribue à des réactions très négatives et à une remise en cause globale de la rationalité de la réforme en question.

Une question intéressante est de savoir dans quelle mesure celle-ci a abouti à une individualisation des rémunérations. Ces deux concepts ne sont pas identiques, bien que la décentralisation soit probablement une condition préalable du second. Il existe également un élément d'individualisation dans l'intérêt universel manifesté à l'égard des éléments de rémunération liés à la performance. D'ailleurs, l'Australie comme la Nouvelle-Zélande ont tous deux mis en œuvre des accords de rémunération individualisés en tant que partie intégrante de leurs réformes.

On peut certes soutenir que le potentiel de l'individualisation a souvent été surestimé. Il sous-tend des coûts de transaction supérieurs à ceux des conventions collectives et normes uniformes et l'on peut donc penser qu'un responsable opérationnel rationnel continuera d'utiliser des contrats et des conditions de travail normalisés et des structures de rémunération collectives, à moins qu'une valeur ajoutée notable ne découle de l'individualisation. On peut raisonnablement considérer que les compétences et les performances auront tendance à se conformer à la courbe de distribution normale et que, en dehors de l'administration centrale, les coûts de transaction de toute différenciation seront élevés; ainsi, une ambition réaliste serait-elle de procéder à une différenciation pour $10-15 \%$ des tranches supérieures et inférieures.

Une autre question fondamentale est de savoir si les structures économiques mises en place ont véritablement permis de garantir que les évolutions de salaire globales ont contribué à maintenir la stabilité des finances publiques et à préserver le caractère attractif de la fonction publique. Rien ne permet de penser que ceci n'est pas le cas dans les pays étudiés. En même temps, le fait d'aménager dès le départ et de manière normalisée les budgets des entités chargées de la négociation présente des avantages spécifiques. En effet, ceci réduit les coûts de transaction, améliore leur capacité à planifier leurs opérations sur plusieurs années et permet aux administrations publiques de concentrer leurs délibérations politiques sur les organisations pour lesquelles des ajustements supplémentaires semblent nécessaires d'un point de vue politique ou opérationnel.

Une des dernières questions essentielles est de savoir si les accords décentralisés de détermination des rémunérations sont compatibles avec le maintien à travers toute l'administration publique d'une cohérence suffisante des rémunérations et autres conditions de travail. Plusieurs pays semblent avoir noté que les différences de structures et de niveaux de rémunération sont venues compliquer les fusions des différentes entités habilitées. Il semble cependant que ces problèmes aient finalement pu être réglés par la plupart des pays, probablement du fait des ajustements normalisés apportés aux entités habilitées. Le Royaume-Uni fait figure d'exception : dans ce pays, la mise en application de la budgétisation ascendante et le processus de soumission entité par entité semble être à l'origine de différences de capacité financière imprévues ainsi que d'écarts de rémunération aussi importants qu'injustifiés entre personnes disposant de mêmes compétences et occupant des postes similaires. 


\section{Deux modèles de gouvernance}

Les deux modèles de gouvernance que nous avons identifiés - le système de soumission de propositions et le système de convention collective - sont essentiellement des cadres généraux et flexibles. Ils se basent sur un nombre limité d'éléments structurels, à l'intérieur desquels on retrouve un éventail d'options de conception différentes, disponibles pour les administrations publiques. Les deux modèles permettent une mise en œuvre flexible, dans le temps ainsi qu'à travers l'éventail des entités du gouvernement central.

Un élément commun des deux modèles est que le niveau politique ne s'applique qu'à la politique générale et à l'adoption des cadres. Celui-ci ne s'applique ni aux négociations des rémunérations ni à la détermination même de ce dernières. Ces fonctions relève de la responsabilité de la fonction publique, soit au niveau central soit au niveau local. La Nouvelle-Zélande est, cependant, le seul pays où il existe un pare-feu entre le niveau politique et la négociation salariale. Dans les trois autres pays où il existe une politique de «non intervention » au niveau politique, il y a, néanmoins, des attentes précises.

\subsection{Le système de soumission de propositions}

Ce modèle se base sur un seul niveau de négociation. Une collection commune de paramètres de négociation et le processus de soumission de propositions garantissent la cohérence à travers l'administration centrale. La négociation et la détermination salariales ont été décentralisées ou transférées à des organisations infranationales, qui doivent soumettre leurs accords salariaux préliminaires à une autre organisation pour évaluation et approbation avant signature.

Les paramètres de négociation portent des éléments et des principes communs, ainsi que des initiatives politiques. En Australie, ils sont déterminés par le gouvernement et en Nouvelle-Zélande par une agence centrale de personnel, la Commission des services de l'État (SSC).

En Australie, les accords salariaux doivent être approuvés par le ministre responsable. Les directeurs des organisations infranationales doivent soumettre leurs accords préliminaires au ministère de l'Emploi et des Relations professionnelles (DEWR) pour l'évaluation de leur compatibilité avec les paramètres de négociation. L'avis du DEWR s'agit d'un simple conseil, mais le directeur doit en informer le ministre au moment qu'il demande l'approbation de l'accord salarial.

En Nouvelle-Zélande, la compétence pour la négociation et la détermination des rémunérations a été transférée à la SSC et ensuite déléguée aux directeurs des organisations infranationales. Ceux-ci doivent soumettre leurs accords préliminaires au SSC pour l'évaluation de leur compatibilité avec les paramètres de négociation. L'avis du SSC s'agit simplement d'un conseil, donné dans le cadre du contrôle du SSC vis à vis des nominations des directeurs.

Les paramètres actuels de négociation en Australie et en Nouvelle-Zélande étant relativement limités dans leurs envergures permettent un éventail important de liberté managériale. Les paramètres de négociation peuvent, en théorie, être très détaillés, laissant peu de questions à négocier pendant la procédure de négociation. Cette versatilité pourrait être utile pour l'introduction d'une négociation et d'une détermination décentralisées des rémunérations, par une augmentation progressive de l'influence managériale.

À la base du plus grand nombre de discussions entre les directeurs et le DEWR est l'obligation d'« accords simples, basés sur des principes » qui figure dans les paramètres australiens de négociation. Il apparaît que les entités de négociation salariale ont rencontré lors de la transition des arrangements actuels très complexes vers des arrangements d'un processus de négociation unique. 
Les paramètres de négociation australiens étant relativement courts, un guide plus détaillé comprenant les lignes directrices ${ }^{53}$ est disponible en supplément. En Nouvelle-Zélande, les lignes directrices font parties des paramètres de négociation, résultant en un document plus conséquent. Les paramètres de négociation néo-zélandais comprennent une référence à l'accord «Partenariat pour la qualité » que l'administration a signé avec le plus grand syndicat du secteur public (l'Association du service public). Cet accord se concentre sur l'établissement des relations coopératives et ouvertes et reflète la politique du gouvernement concernant les relations souhaitées entre l'administration publique et les syndicats.

\section{Les paramètres de négociation australiens ${ }^{54}$}

1. Les accords doivent s'inscrire dans les politiques du gouvernement des relations de travail, y compris : i) conformité avec la Loi sur les relations de travail; ii) relations directes entre les employeurs et les employés ; iii) la liberté syndicale ; iv) des accords simples, basés sur des principes ; v) la disponibilité des AWAs à tout le personnel ; et vi) la responsabilité de résoudre les conflits incombe à l'employeur et aux employés (y compris les mouvements sociaux).

2. Les améliorations de rémunération et des conditions de travail doivent être liées aux améliorations de la productivité et de la performance de l'organisation. Sauf cas exceptionnel, les augmentations salariales doivent s'appliquer dans le futur.

3. Les améliorations de rémunération et des conditions de travail doivent être financées par le budget de l'agence.

4. La reconversion obligatoire, la réduction et retranchement des provisions, avec tout changement n'augmentant pas les arrangements actuels en matière de licenciement, doivent figurer dans les accords. Un ministre sectoriel peut, en consultation avec le ministre adjoint au Premier ministre pour le service public, approuver des incitations financières à part afin de résoudre les changements organisationnels majeures. Le coût de telles incitations doit être nul pour l'agence dans le contexte d'un changement organisationnel majeure.

5. Les accords doivent faciliter la mobilité au sein de l'APS en : i) maintenant les structures compatibles avec les Classification Rules, avec les augmentations de salaire basées sur la performance ; et ii) gardant la portabilité des droits de congés payés dus.

6. Les accords doivent inclure des politiques d'absence et des pratiques d'emploi qui autorise le départ des réservistes soit pour l'entraînement en temps de paix soit pour déploiement.

Comme on peut l'observer dans les paramètres de négociation, le système de «soumission de propositions » en Australie et en Nouvelle-Zélande ne se limitent pas simplement à la mise en œuvre des critères formels ou à une évaluation «reçue ou pas ». Il assure un dialogue entre les deux tiers. L'entité habilitée doit montrer que la convention collective préliminaire est juste. Ceci lie le processus de soumission de propositions aux mécanismes généraux de comptabilité et à l'évaluation du directeur à l'entité habilitée.

Les paramètres de négociation en Australie et en Nouvelle-Zélande ne couvrent ni les coûts réels ni les niveaux des rémunérations résultant des négociations. Ils font tous les deux référence au «principe de accessibilité ». Les paramètres australiens de négociation spécifient que les améliorations de rémunération et des conditions de travail doivent être financées par le budget de l'agence alors que les paramètres de négociation néo-zélandaise déclarent qu'en fixant les niveaux salariaux, les départements doivent prendre en compte ... leur capacité de payer selon les montants convenus. En conséquence, la négociation salariale au niveau local ne doit pas dépasser l'enveloppe budgétaire de l'entité habilitée, qui a été alloué auparavant par un processus distinct.

Aucun de ces deux pays a un plafond spécifique pour la masse salariale. Les entités habilités peuvent utiliser des revenues extra budgétaires, de l'épargne et tout autre type de dépense pour financer une augmentation de la masse salariale, soit par l'augmentation du nombre de personnel soit par l'augmentation du salaire moyen. 
Les accords en vigueur au Royaume-Uni sont similaires à ceux qui existent en Australie et en Nouvelle-Zélande, bien que plus complexes et moins transparents. Leur principal défaut étant l'absence de séparation entre le processus d'élaboration du budget et celui de la négociation des rémunérations. Le Royaume-Uni n'a pas mise en œuvre un transfert de compétences total utilisant un «principe de accessibilité ». Le système de soumission de propositions inclut le coût réel de l'accord et a une influence sur l'enveloppe budgétaire de l'entité habilitée. En même temps, la rémunération d'un grand nombre d'employés du secteur public est déterminée par les sentences arbitrales et non par un accord. Les problèmes de cohérence que nous avons relevé au Royaume-Uni peuvent être dû à ce manque d'approche systématique.

\section{Les paramètres de négociation néo-zélandais ${ }^{55}$}

La politique générale du gouvernement en matière de rémunérations est :

Les systèmes de rémunération doivent contribuer à réaliser des résultats et maintenir/améliorer la performance des extrants en : i) développant et maintenant la capacité organisationnelle afin de réaliser les résultats définis dans leur statements of intent; ii) pourvoyant les incitations et les opportunités pour que les employés développent les compétences nécessaires, et/ou d'améliorer la performance.

1. Le gouvernement doit payer une rémunération juste (pour les employés) mais pas extravagantes (pour être juste au regard des contribuables).

2. Les systèmes de rémunération doivent être justes et transparents, liés à un système d'ajustement de salaires transparent et juste, qui reflète l'acquisition de compétences (par l'expérience ou les formations), et/ou une meilleure performance.

3. Les principes de rémunération doivent être convenus avec tous les employés et tous les syndicats.

4. Généralement, le gouvernement attend une négociation du salaire minimum et sauf cas exceptionnel, celui-ci figurera dans la convention collective.

5. Le gouvernement n'est pas en faveur des systèmes de rémunération qui permettent des augmentations de salaire basé sur l'ancienneté. En général, toute augmentation au-delà du salaire minimum doit être méritée.

Le niveau de rémunération doit être défini en prenant compte de :

6. La demande du marché pour les compétences, l'expérience et les responsabilités ;

7. des problèmes de recrutement et de maintien ;

8. capacité de payer dans les limites approuvées ;

9. comparaisons avec d'autres groupes du même ministère :

10. toute politique visant à réaliser les résultats élargis pour les employés en général ou pour un groupe spécifique d'employés, par exemple des politiques et processus en matière de rémunérations et d'équité.

D’autres facteurs spécifiques au ministère :

Les accords doivent contenir des provisions détaillant le résultat en cas d'une restructuration ou d'un licenciement, y compris une clause pour " chômage technique ». La clause de "chômage technique " doit préciser que le personnel auquel a été offert des postes dans une autre agence (les termes et conditions d'emploi restant les mêmes) n'aura pas droit à une indemnité de licenciement en cas de refus de l'employé ;

L'approbation du SSC est obligatoire avant toute proposition visant à assouplir les conditions actuelles d'arrêt maladie par l'introduction d'un arrêt maladie sans limite de durée ; 
La consultation avec le SSC est obligatoire avant de développer des propositions significatives :

11. Qui amélioreraient considérablement des primes annuelles, parentales ou autres ;

12. Qui amélioreraient considérablement des prestations ou allocations du «State Sector Retirement Savings Scheme » ou qui changeraient les arrangements d'autres systèmes de cotisations de retraite ;

13. En termes de primes ou des différences de salaires pour les employés d'une région spécifique ;

14. Des initiatives en termes de rémunération et équité.

\subsection{Système de convention collective}

Ce modèle se base sur un système de conventions collectives à deux niveaux. Dans un premier temps, une convention collective centrale traitant tous les employés de l'administration centrale est négocié avec les syndicats. Cette convention centrale est ensuite mise en œuvre par des négociations à un niveau infranational. La cohérence de l'ensemble de l'administration centrale est assurée par les clauses de la convention centrale.

Un des avantages de ce modèle est que les paramètres de négociation du niveau infranational (correspondant à des paramètres de négociation du système de soumission de propositions) ont été approuvés par les syndicats au niveau central. Ils doivent également gouverner le comportement des représentants des syndicats au niveau infranational. Cela signifie que le gouvernement ne peut définir des paramètres unilatéraux.

Le Danemark et la Finlande ont créé des Bureaux de l'État employeur, des agences au sein du ministère des Finances. Ces bureaux, sous tutelles, mais gérés indépendamment, représente le gouvernement dans la négociation centrale. Nous imaginons qu'il existe, en interne, des paramètres de négociation, mais ceux-ci ne sont pas rendus public. Les conventions collectives finales doivent être approuvées par le gouvernement, généralement il s'agit d'une simple formalité.

Au Danemark, la convention collective est liée au processus budgétaire. Les budgets pour les entités infranationales sont décidés avant que la négociation des rémunérations commence, mais ceux-ci peuvent être augmentés si la convention collective centrale est plus élevée que prévue. En Finlande, les processus budgétaire et de négociation sont devancés par un accord compréhensif au niveau national déterminant le montant des augmentations de salaire.

La Suède a pris le devant, en créant un Bureau de l'État employeur comme une agence indépendante. La négociation et la détermination salariales ont été transférées aux agences, qui nomment le conseil de direction, qui à son tour nomme le haut responsable. La convention collective centrale ne fait pas l'objet d'une approbation du gouvernement, hormis pour les clauses relevant des retraites. La Suède a mise en œuvre le même « principe de accessibilité » que nous avons observé en Australie et en Nouvelle-Zélande.

La convention collective peut, en théorie, être très limitée, laissant une grande liberté managériale, ou bien être très détaillée, laissant très peu de marge de manœuvre dans les négociations infranationales. Il s'agit là de la même versatilité que l'on trouve dans les paramètres de négociation du système de soumission de propositions. Ce modèle peut donc être utilisé pour l'introduction d'une négociation et d'une détermination décentralisées des rémunérations, par une augmentation progressive de l'influence managériale.

La plupart des augmentations annuelles de salaire au Danemark correspondent à des augmentations générales, convenues dans la convention collective centrale, et seule une part mineure résulte d'accords infranationaux. La part locale est plus importante en Finlande, mais la plupart des augmentations de salaire restent toujours des augmentations générales convenues dans la convention collective centrale. Encore une 
fois, la Suède a pris le devant en définissant des garanties minimums individuelles et collectives dans la convention collective centrale, laissant la détermination aux négociations infranationales.

La convention collective centrale gouverne des situations de désaccord entre les entités infranationaux. Au Danemark, aucune décision locale d'augmenter les salaires n'est admise sauf en cas d'accord entre les entités infranationales. En Finlande, s'il n'y a pas d'accord local avant dans un certain délai, la réserve pour distribution locale est partagée en parts égales entre tous les employés. Une troisième option consiste en la médiation de tous les partenaires de la convention collective centrale et s'il s'agit, de régler les différences avec les entités infranationaux.

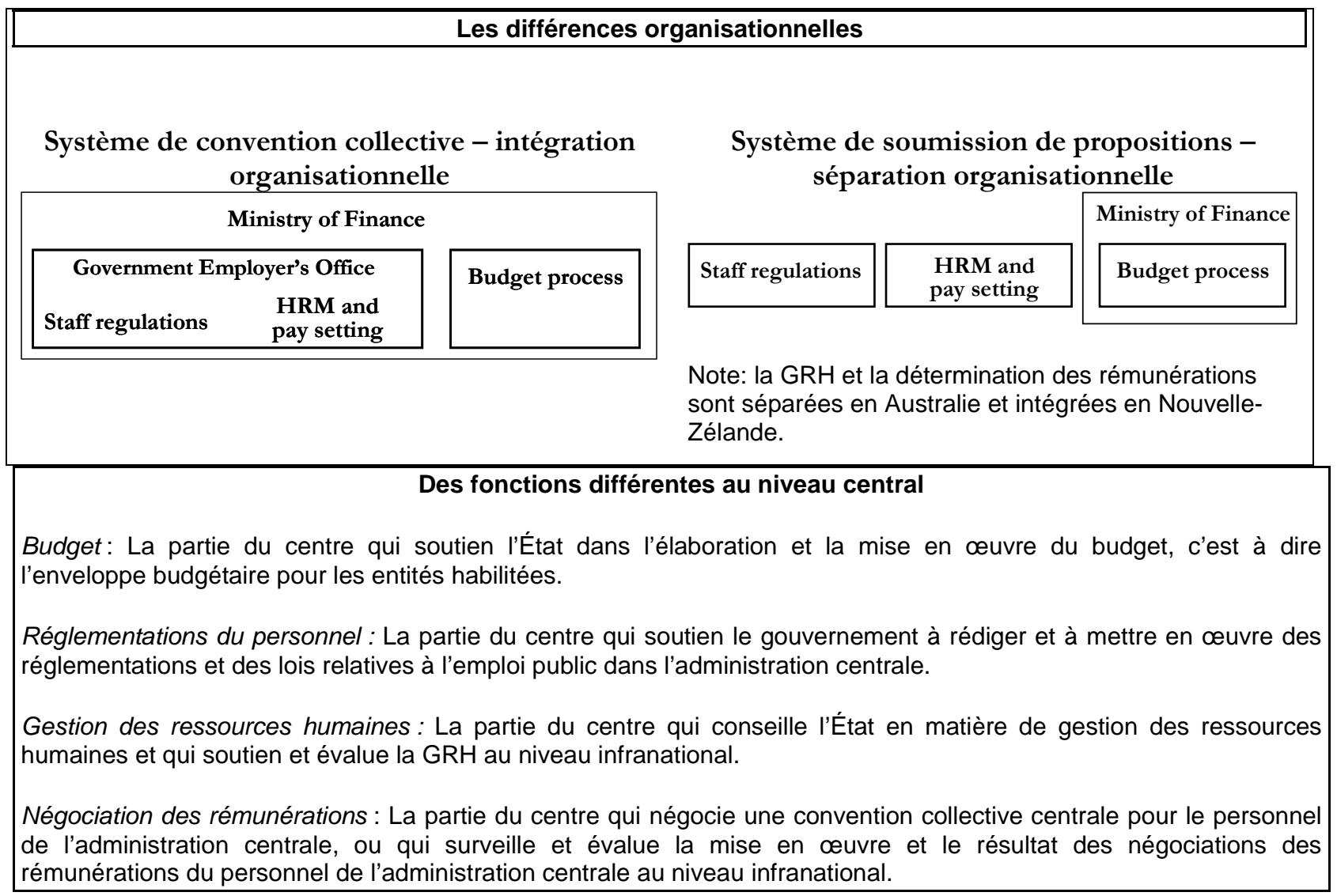

\section{Conclusions}

Les six pays examinés ne constituent nullement un échantillon aléatoire. Ils ont été choisis en raison de leur expérience de la détermination décentralisée des rémunérations et de l'intérêt qu'ils portent à cette question. Ils ont mis en place une vaste palette d'arrangements, de pratiques et d'expériences et constituent donc une base solide pour effectuer des comparaisons et tirer des conclusions provisoires. Cependant, il convient de souligner que celles-ci sont émises sous réserve. Il ne s'agit pas ici d'une étude compréhensive et les observations qu'elle contient se fondent sur un ensemble limité de données sujettes à interprétation.

Il ressort de cette étude qu'il existe, parmi les six pays analysés, deux modèles en matière de négociation décentralisée de la rémunération : d'une part celui de l'Australie et de la Nouvelle-Zélande et, d'autre part, celui du Danemark et de la Finlande (voir le Tableau 5). En ce qui concerne le Royaume-Uni, les accords paraissent moins cohérents et sont encore en pleine évolution. 
Ces deux différents modèles semblent bien fonctionner pour les pays qui les utilisent, probablement car ils sont conformes aux spécificités de leur culture politique et administrative. Ils représentent deux voies de développement différentes: la voie anglo-saxonne, qui, notamment, privilégie les relations contractuelles individuelles et la voie nordique, qui met davantage l'accent sur la cohésion et l'action collective.

Il est donc impossible de proposer des recommandations générales : chaque pays doit trouver sa propre voie en se fondant sur sa situation actuelle. On peut toutefois tirer de cet examen certaines conclusions générales. Celles-ci peuvent être groupées selon cinq catégories.

Tableau 5. Arrangements concernant la détermination des rémunérations

\begin{tabular}{|l|l|l|l|}
\hline Pays & $\begin{array}{l}\text { Conventions } \\
\text { collectives }\end{array}$ & Enveloppe budgétaire & Orientations \\
\hline $\begin{array}{l}\text { Australie et Nouvelle- } \\
\text { Zélande }\end{array}$ & $\begin{array}{l}\text { Système à un seul } \\
\text { niveau, avec contrats } \\
\text { individuels }\end{array}$ & $\begin{array}{l}\text { Base d'ajustement sous- } \\
\text { jacente normalisé }\end{array}$ & $\begin{array}{l}\text { Double orientation: } \\
\text { rémunérations et gestion } \\
\text { globale des ressources } \\
\text { humaines }\end{array}$ \\
\hline $\begin{array}{l}\text { Danemark et } \\
\text { Finlande }\end{array}$ & $\begin{array}{l}\text { Système à deux } \\
\text { niveaux }\end{array}$ & $\begin{array}{l}\text { Base d'ajustement sous- } \\
\text { jacente normalisé }\end{array}$ & $\begin{array}{l}\text { Orientation essentielle : } \\
\text { rémunérations et autres } \\
\text { conditions }\end{array}$ \\
\hline Pays-Bas & Système à un niveau & $\begin{array}{l}\text { Évaluation des } \\
\text { ajustements au cas par } \\
\text { cas }\end{array}$ & $\begin{array}{l}\text { Orientation essentielle : } \\
\text { rémunérations et autres } \\
\text { conditions }\end{array}$ \\
\hline Royaume-Uni & Système à un niveau & $\begin{array}{l}\text { Évaluation des } \\
\text { ajustements au cas par } \\
\text { cas }\end{array}$ & $\begin{array}{l}\text { Double orientation: } \\
\text { rémunérations et gestion } \\
\text { globale des ressources } \\
\text { humaines }\end{array}$ \\
\hline
\end{tabular}

\subsection{Introduction ou extension du processus décentralisé de détermination des rémunérations}

Introduire une négociation décentralisée de la rémunération, ou étendre son champ application, implique un processus d'apprentissage. Afin de pouvoir en tirer pleinement avantage, les responsables opérationnels comme les représentants des employés doivent acquérir des compétences et de l'expérience en ce domaine ainsi qu'en ce qui concerne l'analyse des besoins stratégiques de leur organisation.

Une préparation adaptée augmentera substantiellement les chances que ces pratiques soient introduites ou étendues avec succès. Le corollaire logique est qu'un soutien adéquat de l'administration centrale est essentiel pour que les résultats escomptés se matérialisent. Il existe des signes selon lesquels un manque de préparation et de soutien retardera la matérialisation des résultats souhaités, qu'il peut même contribuer à des réactions très négatives et à une remise en cause globale de la rationalité de la réforme en question.

\subsection{Garantir la cohérence}

La principale raison d'être de la décentralisation est de permettre aux responsables opérationnels d'adapter les arrangements du domaine de ressources humaines aux besoins stratégiques de leur organisation. Cela aboutira à une différenciation entre les divers arrangements dans l'ensemble de l'administration centrale, ce qui est en contradiction avec la notion de cohérence. La principale conclusion est donc que les gouvernements doivent adopter une position claire quant à savoir si tel ou tel élément de gestion des ressources humaines : 
- doit être uniforme à travers l'ensemble de l'administration centrale ;

- peut varier en fonction de l'entité concernée, mais ce, uniquement selon des limites explicites ; ou

- $\quad$ peut varier en toute liberté au travers l'ensemble de l'administration.

Le premier groupe d'éléments devrait continuer à être déterminé au niveau central, même si d'autres décisions portant sur d'autres éléments de la gestion des ressources humaines sont décentralisées. Cela devrait se faire soit au moyen de lois ou de réglementations soit par le biais de conventions collectives.

Le second groupe d'éléments peut être délégué aux responsables opérationnels, tout en étant toujours régi par le centre, soit par le moyen de paramètres de négociation et le contrôle par l'administration centrale de leur conformité par rapport aux accords locaux, soit par le bais d'une structure juridique claire ou de conventions collectives centrales.

Le troisième groupe peut faire l'objet d'un transfert de compétences au bénéfice des responsables opérationnels, le rôle de l'administration centrale se limitant alors à en surveiller l'évolution et à tenir les responsables opérationnels rétroactivement comptables des résultats et du caractère adéquat et approprié des accords signés. Le fait que ces éléments aient fait l'objet d'un transfert de pouvoir n'empêche cependant pas l'administration centrale de publier des documents d'orientation sur la qualité souhaitée et sur les caractéristiques de tels éléments.

\subsection{Gouvernance décentralisée de la détermination des rémunérations}

Pour une décentralisation efficace de la détermination des rémunérations, il apparaît essentiel de disposer d'accords appropriés en matière de gestion financière. Il est fondamental que ceux-ci séparent effectivement les affectations budgétaires de la négociation salariale, afin que la négociation décentralisée des rémunérations s'inscrive dans des limites d'accessibilité qui soient à la fois fixes et crédibles. Il est également évident que les pays qui appliquent un ajustement initial normalisé des budgets des entités habilitées ont pu ainsi créer des environnements de détermination des rémunérations plus stables et plus pertinents que ceux des pays qui en décident au cas par cas, en fonction de l'entité concernée. Ce premier modèle permet également de réduire les coûts de transaction et de mettre en évidence les situations où des ajustements supplémentaires seraient justifiables.

Il existe deux différents types de structure de gouvernance décentralisée. Les pays ayant des systèmes de conventions collectives à un seul niveau disposent d'un organisme central qui publie les paramètres de négociation et vérifie que les conventions collectives signées par les sous-entités s'y conforment. Ceux ayant des systèmes de conventions collectives à deux niveaux disposent également d'un organisme central mais celui-ci négocie et signe les conventions collectives centrales qui définissent une structure économique et juridique permettant de mener des négociations secondaires à des niveaux inférieurs.

Le peu d'éléments dont nous disposons ne nous permet pas de tirer de conclusions quant à laquelle de ces deux structures est la meilleure. La caractéristique essentielle semble probablement plutôt être son adaptabilité au contexte national. Cependant, un dénominateur commun est l'existence d'un organisme central distinct et compétent professionnellement capable de régir et de surveiller le comportement des entités habilitées. 


\subsection{Mise en auvre de la détermination décentralisée des rémunérations}

Un contrôle et une évaluation effectifs de l'adéquation des décisions des responsables opérationnels des entités habilitées sont essentiels au bon déroulement de la décentralisation, en particulier à long terme. Il est essentiel que les responsables opérationnels soient tenus comptables, à la fois en ce qui concerne leurs décisions et pour les résultats auxquels ils sont parvenus.

Les pays disposant d'un système de détermination des rémunérations décentralisé doivent également investir en vue de constituer un corps de cadres publics disposant des compétences adaptées aux spécificités de l'administration publique. Les implications de telles mesures sortent du cadre de cette étude, mais il semble clair que les conditions préalables sont de limiter la durée des mandats et d'accorder une plus grande importance aux compétences générales de management plutôt qu'à une expertise spécifique dans tel ou tel domaine.

Il sera possible d'accroître les chances d'une issue positive dans le domaine de la détermination décentralisée des rémunérations si l'organisme central fournit un soutien adéquat et approprié au processus. Celui-ci pourra prendre la forme de manuels, de livrets, de formations, de réseaux de consultation avec des pairs et d'outils statistiques permettant aux entités habilitées de comparer leur système et structure de rémunération avec celles d'autres entités au sein de l'administration centrale et également par rapport à l'évolution de la rémunération de marché pour des compétences et tâches comparables.

\subsection{Résultats escomptés}

La détermination décentralisée des rémunérations peut de toute évidence avoir des effets positifs sur les résultats et performance des administrations en question. Cela dépendra, cependant, du fait que le pays ait ou non institué des accords adéquats en termes de gestion financière et de gouvernance.

Il ne faut toutefois pas s'attendre à ce que l'introduction de ces pratiques produise des résultats immédiats. Pour que leurs avantages puissent pleinement se matérialiser, les responsables opérationnels comme les représentants des employés doivent acquérir des compétences suffisantes ainsi que de l'expérience en ce domaine. Le corollaire de cette proposition est qu'une introduction progressive est probablement préférable à un changement profond et radical à un moment précis. Il s'ensuit que la mise en œuvre de telles réformes devrait probablement s'étaler sur des décennies plutôt que sur quelques années.

Et, dernier point, il ne serait pas rationnel de passer à un système de rémunération et de conditions totalement différenciées et individualisées. Les contrats et conditions normalisés constituent une méthode bien établie de réduction des coûts de transaction. Un employeur rationnel ne fera recours aux contrats individualisés que lorsque cela est économiquement justifié et qu'il pourra y gagner en valeur ajoutée. 


\section{ANNEXE I \\ GROUPE CONSULTATIF}

Stephen D. BACH, King's College, Royaume-Uni

Peter BOLDT, Organisation centrale des syndicats finlandais, Finlande

Ard van BRIEMEN, ministère des Finances, Pays-Bas

Peter van der GAAST, ministère de l'Intérieur et des relations au sein du Royaume, Pays-Bas

Gerard MINNEE, le Trésor, Nouvelle-Zélande ${ }^{56}$

Ed PRIESTER, ministère de l'Intérieur et des relations au sein du Royaume, Pays-Bas

Lynne TACY, Commission de la fonction publique, Australie

Peter TERGEIST, Département de l'emploi, du travail et des affaires sociales, OCDE

Marten de VRIES, ministère de l'Intérieur et des relations au sein du Royaume, Pays-Bas

\section{$\underline{\text { Équipe de projet }}$}

Jennifer ALLAIN, Direction de la gouvernance publique et du développement territorial, OCDE Nick MANNING, Direction de la gouvernance publique et du développement territorial, OCDE Chris MOLL, consultant, Pays-Bas

Knut REXED, consultant principal, Suède 


\section{ANNEXE II \\ LISTE DES PERSONNES INTERROGÉES POUR LE PROJET}

Les personnes interrogées sont classées dans l'ordre suivant :

a. Organe de gestion des ressources humaines (GRH) et/ou employeur (niveau central)

b. Fonction budgétaire centrale

c. Entités habilitées à déterminer les rémunérations

d. Syndicats représentant les employés de l'État
AUSTRALIE
a. Tulip CHAUDBURY, ministère de l'Emploi et des Relations professionnelles
b. John IGNATIUS, ministère des Finances et de l'Administration
c. David DIMENT, Bureau des impôts australien
Keith FAIRBROTHER, ministère de l'Environnement et du Patrimoine
d. Alastair WATERS, Syndicat des collectivités et du secteur public (CPSU)

\section{DANEMARK}

a. Søren Rotvig ERICHSEN, Anne Kirstine DAMSAGER et Marianne HANSEN, Autorité de l'État employeur

b. $\quad$ Mogens PEDERSEN, ministère des Finances

c. Erik CHRISTIANSEN et Susanne HANSEN, Autorité danoise de la concurrence Doris DETHLEFSEN et Kristoffer ALMDAHL, Laboratoire national de Ris $\varnothing$

e. Helle JENSEN, Association des organisations des employés de l'État danois (STK)

Gitte T. HENRIKSEN, Confédération danoise des associations professionnelles (AC)

\section{FINLANDE}

a. Teuvo METSÄPELTO, Bureau de l'État employeur

Veikko LIUKSIA, Bureau de l'État employeur

Seija PETROW, Bureau de l'État employeur

b. Hannu MÄKINEN, département du Budget, ministère des Finances

c. Tiina ERÄNKÖ, département de la Police, ministère de l'Intérieur

Jouni KEKÄLE, Université de Joensuu

d. Harri SIRÉN, Fédération des salariés

\section{PAYS-BAS}

a. Kees MAAS, ministère de l'Intérieur

b. Meindert SMALLENBROEK, ministère des Finances

c. $\quad$ Ed PRIESTER, ministère de l'Intérieur

Ina SJERPS, Association des communes des Pays-Bas (VNG)

Jan VERINGA, ministère de l'Éducation

d. Xander DEN UIJL, ABVAKABO FNV 


\section{NOUVELLE-ZÉLANDE}

a. Rosemary HANNAH-PARR et Janine HARVEY, Commission des services de l'État

b. Gerard MINNEE, Trésor de Nouvelle-Zélande

c. Anne Marie TAGGERT, Département de la jeunesse, de l'enfance et de la famille Cheryl CROOKS et Fiona CAMERON, Agence de développement économique de la NouvelleZélande

d. Richard WAGSTAFF, Association du service public

\section{ROYAUME-UNI}

a. Christopher S. JOHNSON, Division des politiques et pratiques d'emploi, Bureau du Conseil des ministres John WHITTAKER, Division des politiques et pratiques d'emploi, Bureau du Conseil des ministres

b. Farha BHATT, Division des politiques et pratiques d'emploi, Bureau du Conseil des ming

c. Angus GRAY, ministère du Travail et des Retraites

Neil MACINTOSH, ministère de l'Environnement, de l'Alimentation et des Affaires rurales

d. $\quad$ Geoff LEWTAS, Syndicat des services publics et commerciaux (PCSU) 


\section{RÉFÉRENCES}

\section{Documents d'ordre général}

Amicus (2005), Amicus Guide to Bargaining Pay Systems, téléchargé depuis www.amicustheunion.org.

Association des organisations des employés de l'État danois (2006), Social Dialogue in the State Labour Market in the European Union. Téléchargé depuis www.stk.dk.

Bender, K.A. et R.F. Elliott (2003), Decentralised Pay Setting. A Study of the Outcomes of Collective Bargaining Reform in the Civil Service in Australia, Sweden and the UK, Ashgate Publishing.

CESifo (2004), Wage Setting Institutions, rapport DICE 4/2004.

Demmke, C. (2005), Ethics in the Civil Services of the Member States of the EU, communication présentee lors d'une conférence du Groupe européen d'administration publique (GEAP) consacrée à l'éthique, à l'intégrité et à la gouvernance.

Eichengreen, B. et T. Iversen (1999), Institutions and Economic Performance: Evidence from the Labour Market, Oxford Review of Economic Policy, 15(4).

Fairbrother, P. and Yates, C. (Eds) (2004), Trade Unions in Renewal. Routledge.

Gaston, N (2000), Unions and the Decentralisation of Collective Bargaining in a Globalising World. The Institute of Social and Economic Research, Osaka University.

Fondation européenne pour l'amélioration des conditions de vie et de travail (2005), Attractive Workplace for All: A Contribution to the Lisbon Strategy at Company Level (project in progress), téléchargé depuis www.eiro.eurofound.ie.

Marsden, D. (2003), Perspectives on Performance Pay in Government Organisations. Paper for an OECD Expert Meeting. OECD.

Milgrom, P. et J. Roberts (1992 ; 1997), Économie, organisation et management, De Boeck, Bruxelles.

OCDE (1993), Flexibilité des rémunérations dans le secteur public, Études sur la gestion publique du PUMA, OCDE, Paris.

OCDE (1994a), La détermination des rémunérations et les systèmes de rémunération dans la fonction publique des pays de l'OCDE, Études hors série sur la gestion publique / 1994 - série n 2, Paris.

OCDE (1994b), Sources statistiques sur l'emploi dans le secteur public, OCDE, Paris.

OCDE (2003), Gérer la haute fonction publique, La réforme de la haute fonction publique dans les pays membres de l'OCDE. GOV/PUMA(2003)17. 
OCDE (2004), «Fixation des salaires : aspects institutionnels et résultats », Perspectives de l'Emploi de l'OCDE - Edition 2004, OCDE, Paris.

OECD (2006), La rémunération liée aux performances dans l'administration. OCDE : Paris.

OCDE (2005), Moderniser l'État, GOV/PGC/RD(2005)2.

Odhner, C.-E., K.-O. Faxén et R.Spånt (1988), Lönebildning i 90-talets samhällsekonomi (« La formation des salaires dans l'économie politique des années 1990 »), Rabén \& Sjögren.

Odhner, C.-E., K.-O. Faxén, et G. Edgren, (1973), Wage Formation and the Economy, Allen \& Unwin.

OIT (2002), Le dialogue social dans l'administration publique, programme « InFocus » sur le dialogue social, le droit du travail et l'administration du travail, document de travail $\mathrm{n}^{\circ} 11$, OIT.

Reiersen, J: (2001), Centralised Wage Bargaining: Theoretical Considerations and Some Norwegian Experiences, Vestfold College, Tönsberg.

Ruysseveldt, J. van, et J. Visser (1996), Industrial Relations in Europe, Sage Publications, Londres.

\section{Australie}

Loi sur le service public (147/1999). Document de synthèse préparé le $1^{\mathrm{er}}$ janvier 2005 et prenant en compte les amendements allant jusqu'à la Loi n 140 de 2003.

Award Review Taskforce (2006), Rationalisation of Wage and Classification Structures. Australian Government.

Australian Bureau of Statistics (2005), Employee Earnings and Hours, May 2004. ABS.

Bender, K.A. et R.F. Elliott (2003), « Australia », in Decentralised Pay Setting, Ashgate, Londres.

Commission australienne de la fonction publique [APSC] (2000), Public Service Classification Rules, APSC.

Commission australienne de la fonction publique [APSC] (2003), Embedding the APS Values, APSC.

Commission australienne de la fonction publique [APSC] (2003): The Australian Experience of Public Sector Reform, APSC.

Commission australienne de la fonction publique [APSC] /Office australien d'audit national (2003), Building Capability: A Framework for Managing Learning and Development in the APS, APSC/ANAO.

Commission australienne de la fonction publique [APSC](2004), Public Service Commissioner's Directions, modifications prises en compte jusqu'à l'amendement 2004(1), APSC.

Commission australienne de la fonction publique [APSC](2006), Public Service Classification Rules Amendment 2006(1), APSC.

Commission australienne de la fonction publique [APSC]/Commission consultative de gestion (2003), Organisational Renewal, APSC. 
Commission australienne de la fonction publique [APSC]/Commission consultative de gestion (2003), Performance Management in the Australian Public Service: A Strategic Framework, APSC.

Commission australienne de la fonction publique [APSC]/Office australien d'audit national (2005), Managing and Sustaining the APS Workforce, APSC.

Conseil de l'emploi (2006), The Australian Fair Pay and Conditions Standard, téléchargé depuis www.workplace.gov.au.

Ministère de l'Emploi et des Relations professionnelles [DEWR] (2006), Workplace Relations Policy Parameters for Agreement Making in the Australian Public Service, DEWR.

Ministère de l'Emploi et des Relations professionnelles [DEWR](2006), Supporting Guidance to the Workplace Relations Policy Parameters for Agreement Making in the APS, DEWR, Canberra.

Podger, A.S. (2003), Improving Civil Service Capability in Developed Countries, The Australian Experience, discours prononcé au cinquième forum mondial «Réinventer l'État », Mexico City, novembre 2003.

\section{Danemark}

Lov om tjenestemaend. («Loi sur les fonctionnaires »).

Andersen, S.K., J. Due et J.S. Madsen (1999), « Negotiating the Restructuring of Public Service Employment Relations », in Bach, S., L. Bordogna, G. Della Rocca et D. Winchester (dir. pub.), Public Service Employment Relations in Europe, Taylor \& Francis Ltd, Londres.

Association des organisations des employés de l'État danois (2006), The Cooperation and Collective Bargaining System within the Public Sector in Denmark, téléchargé depuis www.stk.dk.

Association des organisations des employés de l'État danois (2006),The Danish Arbitration System, téléchargé depuis www.stk.dk.

Autorité de gestion financière (1999), Lønstyring i praksis, («Pratique la fixation des rémunérations »), Autorité de gestion financière.

Autorité de l'État employeur (2001), Motivation in the Danish Central Government Sector, Autorité de l'État employeur.

Autorité de l'État employeur (2003), The State's Personnel and Management Policy 2003, Autorité de l'État employeur.

Autorité de l'État employeur (2003), The State's Personnel and Management Policy 2003. Plan of Action, Autorité de l'État employeur.

Autorité de l'État employeur (2006), Cirkulare om Arbejdstid for tjenestemand i staten («Circulaire sur les heures de travail dans la fonction publique »), téléchargé depuis www.perst.dk.

Autorité de l'État employeur (2006), Cirkulare om Justering af tjenestemandslønninger mv. fra 1. april 2005 («Circulaire sur les accords de rémunération dans la fonction publique »), téléchargé depuis www.perst.dk. 
Autorité de l'État employeur (2006), Lønsystem och lønformer, (« Systèmes et modalités de rémunération »), téléchargé depuis www.perst.dk.

Autorité de l'État employeur (2006), State Sector Personnel in Denmark 2005, Autorité de l'État employeur.

Comité du Parlement pour les comptes publics (2005), Beretning om nye lønsystemer (« Rapport sur les nouveaux systèmes de rémunération »), Parlement danois.

Jørgensen, C. (2005), New Agreement Concluded for Employees in the State Sector, téléchargé depuis www.eiro.eurofound.eu.int

Jørgensen, Carsten (2005), Questionnaire de l'Observatoire (OERI/EIRO) portant sur l'évolution des systèmes nationaux de négociation collective depuis 1990 - Danemark, téléchargé depuis www.eiro.eurofound.eu.int.

Kettl, D.F., C. Pollitt et J. H. Svara (2004), Towards a Danish Concept of Public Governance, Forum danois pour l'excellence des hauts dirigeants.

Local Government Denmark (2003): Kommunestyret i Danmark. («Les collectivités locales au Danemark »). Local Government Denmark.

Ministère des Finances (1998): Ledelse, udvikling og løn («Gestion, développement et rémunération »), ministère des Finances.

Ministère des Finances (2006), Budget Preparation in Denmark, téléchargé depuis www.fm.dk.

Ministère des Finances (2006), Local Government, téléchargé depuis www.fm.dk.

Ministère des Finances (2006), State Employer's Authority, téléchargé depuis www.fm.dk.

Ministère des Finances (2006), The Modernisation of the Public Sector, téléchargé depuis www.fm.dk.

Pederson, Dorthe (2000), Introducing New Public Management in Pay Determination, École de commerce de Copenhague.

\section{Finlande}

Loi sur les conventions collectives (1946/436) telle que modifiée par plusieurs lois, y compris la loi $2001 / 864$.

Loi sur les contrats d'emploi (2001/55, telle que modifiée jusqu'à loi 2005/456.

Lag om statens tjänstekollektivavtal (1970/664) («Loi sur les conventions collectives pour les fonctionnaires »), telle que modifiée jusqu'en septembre $2006^{57 .}$

Statstjänstemannalag (1994/750) («Loi sur les agents de l’État»), telle que modifiée jusqu'en septembre $2006 .{ }^{1}$

Bureau de l'État employeur (2005), Pocket Statistics on Personnel within the State Budget, ministère des Finances. 
EMIRE (2005), Finland. Incomes Policy, téléchargé depuis www.eurofound.europa.eu.

Kiviniemi, M. et T. Virtanen (2000): Finland: the Development of a Performance Culture and its Impact on Human Resources Flexibilities, David Farnham et Sylvia Horton (dir. pub.), Human Resources.

Ministère des Finances (2001), Government Decision in Principle on State Personnel Policy Line, ministère des Finances.

Ministère des Finances (2005), Values in the Daily Job - Civil Servant's Ethics, ministère des Finances.

Ministère des Finances (2006), Budgeting Arrangements in Finland, téléchargé depuis www.vm.fi.

Ministère des Finances (2006), Finland - State Employer Functions, téléchargé depuis www.vm.fi.

Ministère des Finances (2006), The Finnish Public Sector as Employer, ministère des Finances.

Organisation centrale des syndicats finlandais (SAK) (2004), Den inkomstpolitiska uppgörelsen 2005-2007 («Accord sur les revenus 1995-97 »), téléchargé depuis www.sak.fi. ${ }^{1}$

Sandberg, Siv (2003), Local Government in Finland, Institute for Comparative Nordic Politics and Administration, Université Åbo Akademi.

Sauramo, Pekka (2005), Questionnaire de l'Observatoire (OERI/EIRO) portant sur l'évolution des systèmes nationaux de négociation collective depuis 1990 - Finlande, téléchargé depuis www.eiro.eurofound.eu.int.

Service économique du ministère des Finances (2006), Country fiche on Pensions: Finland, ministère des Finances.

Tjänste- och arbetskollektivavtal om justering av anställningsvillkoren för statsanställda 14.12.2004 (Collective Agreement on Revised Employed Conditions for Civil Servants and Contract Employees).

\section{Pays-Bas}

.Wilke, M (1996), Zijn de arbeidsverhoudingen bij de overheid marktconform? « Les relations professionnelles sont-elles identiques dans les secteurs public et privé ?»), Tijdschrift voor Politieke Ekonomie 1996, 19(2), pp. 11-29.

Association des employeurs du secteur public [VSO] (2004), VSO in beweging, Jaarverslag 2003, («L'Association en mouvement, rapport annuel 2003), Association des employeurs du secteur public - VSO. Téléchargé depuis www.vsowerkgevers.nl

Bestebreur, T. et K. Klaassen (2003), New Public Budgeting in the Netherlands, communication pour la conférence annuelle de 2003 du GEAP.

Grünell, M. (2004), 2004 Annual Review for the Netherlands, téléchargé depuis www.eiro.eurofound.eu.int.

Grünell, M. (2005), Tripartite agreement generates considerable conflict, téléchargé depuis www.eiro.eurofound.eu.int. 
Kaar, R. van het (2004), Employers and Government Propose Industrial Relations Reforms, téléchargé depuis www.eiro.eurofound.eu.int.

Kaar, R. van het (2005), Questionnaire de l'Observatoire (OERI/EIRO) portant sur l'évolution des systèmes nationaux de négociation collective depuis 1990 - Pays-Bas, téléchargé depuis www.eiro.eurofound.eu.int

Kamerstukken (II), Vergaderjaar 2004-2005, 30 064, nr. 1. Oprichting Verbond sectorwerkgevers overhead (VSO), téléchargé depuis www.eerstekamer.nl.

Krogt, T. van der, E. Beersen et A. Kemper (2000), «The Netherlands: Towards Personnel Flexibilities », in Farnham, D. et S. Horton (dir. pub.), Human Resources Flexibilities in the Public Services, Macmillan Press, Hampshire.

Ministère de l'Intérieur et des Relations au sein du Royaume (2001), De arbeidsmarkt in de collectieve sector, Investeren in mensen en kwaliteit (« Le marché du travail du secteur public. Investir dans le personnel et dans la qualité »), téléchargé depuis www.minbzk.nl.

Ministère des finances (2006), Begrotingsprocess (« Le processus budgétaire »), téléchargé depuis www.minfin.nl.

Moll, C. (2001),Veranderende arbeidsverhoudingen bij de overheid, langs de weg van geleidelijkheid. («L'évolution des relations professionnelles dans le secteur public : étape après étape »). Sociaal Maandblad Arbeid 2001, pp. 566-573.

Moll, C., M. van der Meer et J. Visser, (2003): Public Sector Industrial Relations in the Netherlands: Framework, Principles, Players and Representativity, Amsterdam Institute For Advanced Labour Studies.

OCDE (2001), Le processus budgétaire et sa gestion aux Pays-Bas, PUMA/SBO(2001)6/Final.

Posseth, J. et F. Nispen (2006), Performance Budgeting in The Netherlands: From Policy Budget to Accounting for Policy, rapport pour le $2^{\mathrm{e}}$ Dialogue transatlantique sur la performance du secteur public.

Roo, A. de (2002), The Settlement of (Collective) Labour Disputes in the Netherlands, rapport national pour le projet de l'UE sur la conciliation, la médiation et l'arbitrage.

Sociaal-Economische Raad (2005), Advies inzake het benoemingsrecht voor de Sociaal-Economische Raad voor de zittingsperiode 1 april 2006 tot en met 31 maart 2008. («Avis concernant le droit de nommer le Conseil économique et social pour le mandat allant du $1^{\mathrm{er}}$ avril 2006 au 31 mars $\left.2008 »\right)$, téléchargé depuis www.ser.nl.

Tros, F. (2000), Decentralisering van arbeidsverhoudingen (« La décentralisation des relations professionnelles »), Université d'Utrecht.

\section{Nouvelle-Zélande}

Agence de développement économique de la Nouvelle-Zélande (2003), Draft Remuneration Policy, document interne de l'agence. 
Association du service public (2006), NZ Public Service: Pay Arrangements, document interne de l'Association.

Commission des services de l'État (2001), Review of the Centre, rapport rédigé par un groupe consultatif ministériel.

Commission des services de l'État (2005), Remuneration Pressures System - 2005/06 Phase 1 Overview Report, préparé avec l'Association du service public et le Trésor.

Commission des services de l'État (2003), Political Neutrality.The Relationship Between the Public Service and Ministers, Commission des services de l'État, fiche de données $n^{\circ} 3$, document téléchargé depuis www.ssc.gov.nz.

Commission des services de l'État (2004), Remuneration Guidelines, Commission des services de l'État.

Commission des services de l'État (2005), Human Resource Capability Survey of Public Service Departments, Commission des services de l'État.

Commission des services de l'État (2005), New Zealand Public Service Code of Conduct, Commission des services de l'État.

Commission des services de l'État (2005), Public Service Remuneration Systems: Principles and Practice, Commission des services de l'État.

Commission des services de l'État (2005), The Government's Bargaining Parameters, Commission des services de l'État.

Commission des services de l'État (2006), List of State Services and Wider State Sector Organisations, téléchargé depuis www.ssc.gov.nz.

Ministère des Finances (2006), Expenditure Review, Terms of Reference, document interne.

Schick, A. (1996), The Spirit of Reform: Managing the New Zealand State Sector in a Time of Change, rapport préparé pour la Commission des services de l'État et le Trésor.

Trésor (2005), Budget Process Guide for Departments and Ministerial Offices 2006, Trésor néo-zélandais.

\section{Royaume-Uni}

Arrowsmith, J. (2005), Questionnaire de l'Observatoire (OERI/EIRO) portant sur l'évolution des systèmes nationaux de négociation collective depuis 1990 - Royaume-Uni, téléchargé depuis www.eiro.eurofound.eu.int.

Bender, K.A. et R.F. Elliott (2003), (2003), « The United Kingdom», in Bender, K.A. et R.F. Elliott, Decentralised Pay Setting, Ashgate, Londres.

Bureau du Conseil des ministres (1999), New Review on Pay and Grading Delegation ('Baker-report'), Bureau du Conseil des ministres.

Bureau du Conseil des ministres (1999), Performance Management Civil Service Reform, A Report to the Meeting of Permanent Heads of Departments 30 September - 1 October 1999, Bureau du Conseil des ministres. 
Bureau du Conseil des ministres (1999), Modernising Government, livre blanc du Bureau du premier ministre, téléchargé depuis www.archive.cabinetoffice.gov.uk.

Bureau du Conseil des ministres (2000), Partnership Working in the Civil Service, Accord entre le PCS, l'IPMS, le FDA, le CCSU et le Bureau du Conseil des ministres.

Bureau du Conseil des ministres (2002), Better Government Services, Executive Agencies in the $21^{\text {st }}$ Century, Bureau du Conseil des ministres

Bureau du Conseil des ministres (2005), Classification of Public Bodies, Guidance For Departments, Bureau du Conseil des ministres.

Bureau du Conseil des ministres (2005), Transformational Government Enabled by Technology, Bureau du Conseil des ministres.

Bureau du Conseil des ministres (2006), Civil Service Code, Bureau du Conseil des ministres.

Bureau du Conseil des ministres (2006), Civil Service Management Code, inclut les modifications apportées jusqu'au mois de juillet 2006, Bureau du Conseil des ministres.

Bureau du Conseil des ministres (2006), Senior Civil Service, Performance Management and Reward Principles, Bureau du Conseil des ministres.

Chapman, R. A. (2005), The Proposed UK Civil Service Act: A Legal Framework for Enhancing Ethics and Integrity?, communication présentée lors de la conférence organisée par le Groupe européen d'administration publique sur l'éthique, l'intégrité et la gouvernance.

Duggett, M. (1997), The Evolution of the United Kingdom Civil Service 1848-1997, communication rédigée pour la conférence de l'International Institute of Administrative Sciences.

Gershon, P. (2004), Releasing Resources to the Front Line: Independent Review of Public Sector Efficiency, Trésor britannique.

Lyons, M. (2004), Well Placed to Deliver? - Shaping the Pattern of Government Service: Independent Review of Public Sector Relocation, Trésor britannique.

Makinson, J. (2000), Rewarding Performance in National Government Networks, Public Services Productivity Panel 2000.

Office for National Statistics (2006), Public Sector Employment 2006. ONS.

Trésor britannique (2005), Civil Service Pay Guidance 2005-06, Trésor britannique

Trésor britannique (2006), Fiscal policy in the UK, téléchargé depuis www.hm-treasury.gov.uk

Winchester, D. et S. Bach (1999), Britain: «The Transformation of Public Service Employment Relations », in Bach, Bordogna, Della Rocca et Winchester (dir. pub.), Public Service Employment Relations in Europe, Routledge. 
1. «Accessibilité » signifie que l'entité doit pouvoir financer les coûts y afférents dans les limites du budget actuel.

2. Le nom officiel du pays est le Commonwealth d'Australie.

3. L' «agence» (agency) est l'appellation juridique pertinente, mais, selon leur nature, ces organisations pourront être désignées par les termes agence, autorité, bureau, commission, société, institut ou service, entre autres.

4. Il existe également une police fédérale, placée sous l'autorité du gouvernement du Commonwealth d'Australie.

5. Australian Bureau of Statistics. Employee Earnings and Hours, May 2002 and May 2004.

6. Dans les documents en anglais, ces organisations sont parfois désignées par le terme « directorates ». La version originale de ce rapport utilise la traduction officielle du terme danois.

7. Anderson, Due et Madsen, p. $211-212$

8. Les dénominations nationales sont données en suédois dans ce document.

9. Ces accords sont négociés par les partenaires sociaux sur la base des promesses conditionnelles du gouvernement et sont donc dépendant de l'approbation du parlement.

10. L'augmentation générale en 2005 était $30.06 €$ par mois, mais pas moins de $1.9 \%$ du salaire. La réserve locale en 2005 était $0.6 \%$ du salaire global.

11. Tjänste- och arbetskollektivavtal om justering av anställningsvillkoren för statsanställda 14.12.2004.

12. Le ministère de la Coopération et du Développement est dirigé par un secrétaire d'État (staatssecretaris).

13. Ces conclusions sont toutefois désignées par le terme « conventions collectives ».

14. État, police, défense, pouvoir judiciaire, éducation, universités, enseignement professionnel supérieur, centres hospitaliers universitaires, instituts de recherche, formation pour adultes et formation professionnelle, provinces, autorité locale et commissions des eaux.

15. C'est-à-dire : provinces, communes et commissions des eaux.

16. Normalement, au début de chaque période électorale.

17. Les paramètres de négociation sont déterminés par le Cabinet et publié par le SSC.

18. Dans certains cas le rôle d'employeur est investi à des commissions.

19. Les activités concernées sont l'armée, la police, l'administration pénitentiaire, les professions de santé, l'enseignement, l'appareil judiciaire et la haute fonction publique.

20. 1864 - 1920. Professeur de droit commercial à Berlin, il a également enseigné l'économie politique à Fribourg et Heidelberg et la sociologie à Vienne.

21. Kiviniemi, M. och Virtanen, T. (2000).

22. Le Département de la jeunesse, de l'enfance et de la famille a fusionné avec le Ministère du développement social le 1er juillet 2006. 
23. Il est parfois difficile de trouver des postes ou fonctions équivalents dans le secteur marchand. De nombreux outils d'évaluation des rémunérations peuvent toutefois être utilisés.

24. Voir en Allemagne le principe d'Alimentationsprinzip (droit aux moyens de subsistance), qui occupe aujourd'hui encore une place centrale au sein du débat national.

25. Cette normalisation peut également s'expliquer par la volonté d'éviter que l'autorité conférée par les décisions discrétionnaires soit mal utilisée.

26. Ceci correspond au système suédois tel qu'il existait avant 1976. Ces éléments sont toutefois des caractéristiques récurrentes de systèmes aujourd'hui en vigueur dans d'autres pays européens.

27. Bender et Elliott (2003).

28. Bender et Elliott (2003), Eichengreen et Iversen (1999).

29. D’après K.A. Bender et R.F. Elliott (2003), Decentralised Pay Setting , p. 11 - 12.

30. D'après K.A. Bender et R.F. Elliott (2003), Decentralised Pay Setting , p. 13 - 14.

31. On parle ici des prestations de retraite. Ce problème pourra facilement être évité dans les pays possédant des régimes de pension ou d'autres systèmes à cotisations définies.

32. coherent adj. (origin Latin cohaerere) 1 (of an argument or theory) logical and consistent. $\mathbf{2}$ able to speak clearly and logically. (Oxford English Dictionary).

cohérent adj. (1524; lat. coharens, p. prés. de coharere «adhérer ensemble ») 1 Qui présente de la cohérence, de l'homogénéité. 2 Qui se compose de parties compatibles, liées et harmonisées entre elles (discours, pensée). 3 Dont le déphasage est constant au cours du temps. (Nouveau Petit Robert).

33. Ces effets fâcheux peuvent par exemple comprendre : rémunération excessive, perte de personnel compétent en raison de rémunérations insuffisantes, démoralisation du personnel due à une détermination subjective des rémunérations, entrave à la mobilité interne ou à la restructucturation organisationnelle.

34. Dans cette perspective, augmenter la rémunération des compétences rares semble améliorer l'efficience allocative et conduire à terme à une offre plus importante de ces compétences.

35. Cela comprend toutes formes de systèmes de retraite anticipée.

36. Cette section se fonde largement sur des informations tirées du site Internet www.wikipedia.com.

37. Voir la section 3.2 pour une définition des termes « délégation » et « transfert de compétences ».

38. Milgrom et Roberts (1992).

39. Fairbrother et Yates 2004.

40. Dans ces deux pays, les entités administratives de second niveau négocient séparément.

41. L'autorité budgétaire fait partie du ministère des Finances au Danemark, en Finlande et aux Pays-Bas, et du Trésor en Australie, en Nouvelle-Zélande et au Royaume-Uni.

42. Ces accords sont négociés par les partenaires sociaux sur la base des promesses conditionnelles du gouvernement. 
43. Cette partie traite uniquement des aspects de ce problème concernant directement le budget. Les autres points seront examinés dans la partie section 4.3 sur la gouvernance centrale de la détermination des rémunérations.

44. Cet effet se produirait même dans le cas d'un dividende de productivité égal à zéro.

45. Ces questions sont étudiées dans la partie 4.2 portant sur les accords de gestion financière.

46. Voir la partie 3.2 pour une définition des concepts de délégation et de transfert de compétences (parfois nommé « dévolution »).

47. Système de cotisations de retraite.

48. Voir OECD (2003a).

49. L'analyse de cette section est basée sur des informations tirées des sites internet.

50. Voir Annexe II pour la liste des personnes interrogées pour le projet.

51. L'éventail des besoins est détaillé par l'étude de cas $\mathrm{n}^{\circ} 1$.

52. Sous-secteur du secteur de l'enseignement.

53. Supporting Guidance: Workplace Relations Policy Parameters for Agreement Making in the Australian Public Service.

54. Ce texte s'agit d'une version révisée du document intitulé Workplace Relations Policy Parameters for Agreement Making in the Australian Public Service.

55. Ce texte s'agit d'un résumé du document intitulé The Government's Bargaining Parameters.

56. Gerard Minnee a remplacé Paul Carpinter, parti à la retraite, au Trésor de Nouvelle-Zélande.

57. Ce document est uniquement disponible en finnois et en suédois. 